\title{
FASHION 2.0: THE USES AND GRATIFICATIONS OF FASHION BLOGS
}

\author{
by \\ Sasha Johnson \\ Bachelor of Journalism, Carleton University, May 2011
}

A master's research paper

presented to Ryerson University

in partial fulfillment of the

requirements for the degree of

Master of Arts

in the Program of

Fashion

Toronto, Ontario, Canada, 2013

(C) Sasha Johnson 2013 


\section{AUTHOR'S DECLARATION FOR ELECTRONIC SUBMISSION OF A MRP}

I hereby declare that I am the sole author of this thesis or dissertation.

I authorize Ryerson University to lend this thesis or dissertation to other institutions or individuals for the purpose of scholarly research.

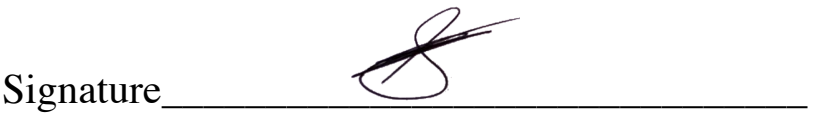

I further authorize Ryerson University to reproduce this thesis or dissertation by photocopying or by other means, in total or in part, at the request of other institutions or individuals for the purpose of scholarly research.

Signature

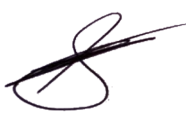




\section{Abstract \\ Fashion 2.0: The Uses and Gratifications of Fashion Blogs \\ Master of Arts in Fashion, 2013 \\ Sasha Johnson \\ Ryerson University}

There has been limited research in the field of fashion blogs. This study attempts to begin filling this void by examining fashion blogs from the user's perspective as they relate to other forms of fashion media. From the uses and gratifications perspective, this study employs a qualitative investigation to identify the motivational factors for fashion blog use. A two-step process, made up from an initial online questionnaire and in-depth interviews was used. The online questionnaire was answered by 247 women between the ages of 18 and 35 . Respondents for the second portion of the study, the in-depth interviews, were made up of 10 women who had previously participated in the questionnaire. Three new motivational factors were identified: habit, entrance, and retrieve/save content. Adhering to the belief that new media technologies supplement rather than succeed one another, these findings have been explained in relation to the use of fashion magazines. 


\section{Acknowledgements}

This master's research project would not have been possible without the abounding guidance and support of Professor Joseph Medaglia. As a supervisor, his encouraging and positive attitude was paramount to my success. I cannot thank him enough for his time, insight, and patience. I am also deeply grateful to the faculty at Ryerson University's School of Fashion for illuminating the fascinating and exciting area of fashion studies. Thank-you to everyone who participated in the online questionnaire and interview portion of this study. Your honesty and openness was greatly appreciated. To my family and friends, thank-you for your endless patience and support. This entire process would not have been possible without the emotional and financial support of my mother. I owe my greatest appreciation to her. Thanks, Mom! 


\section{Table of Contents}

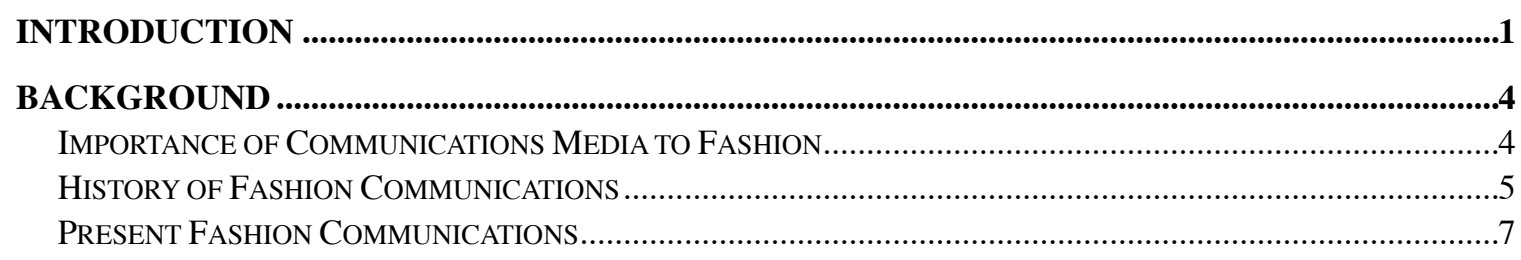

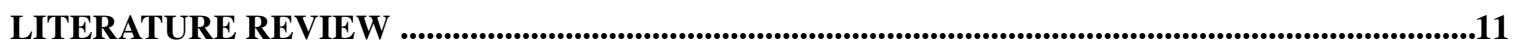

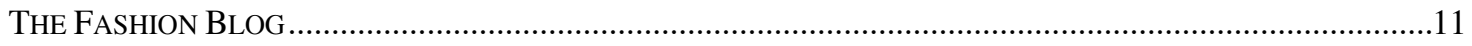

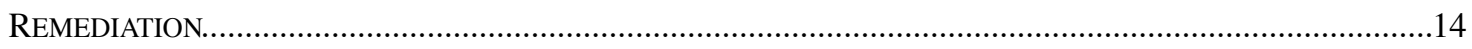

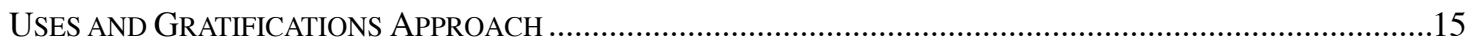

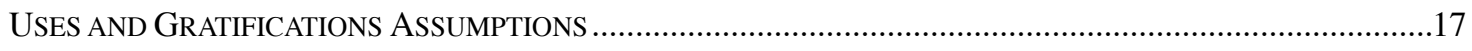

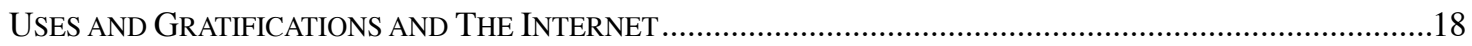

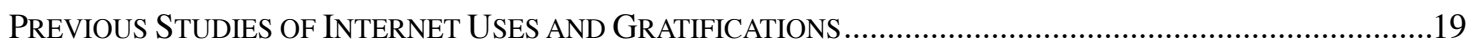

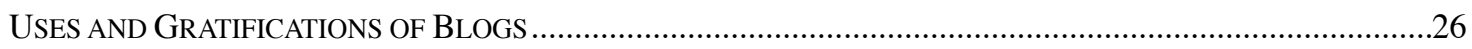

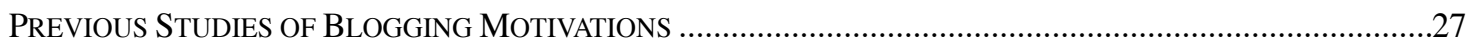

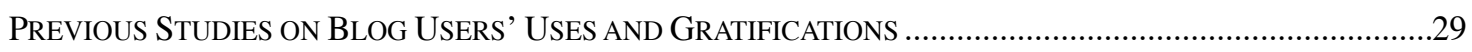

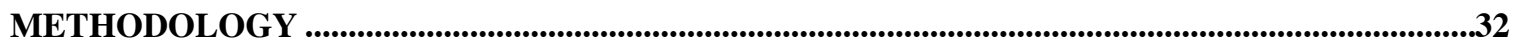

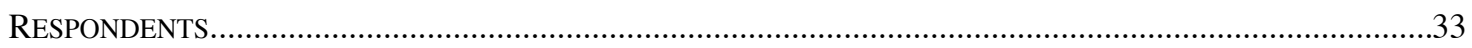

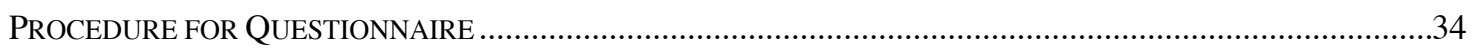

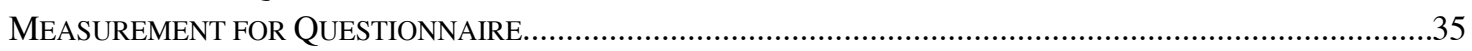

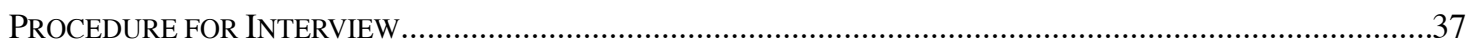

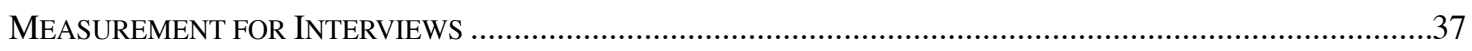

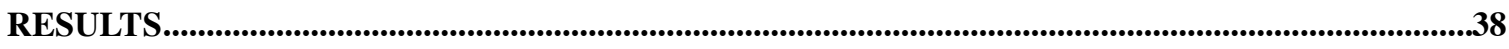

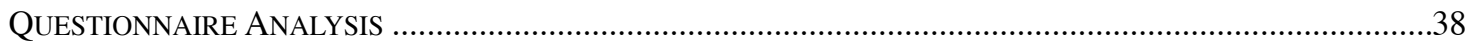

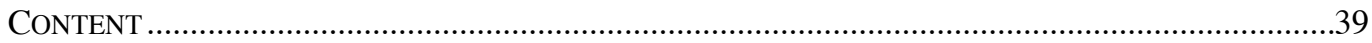

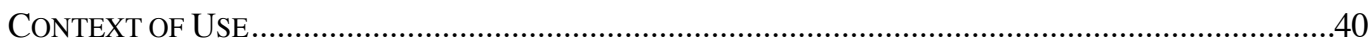

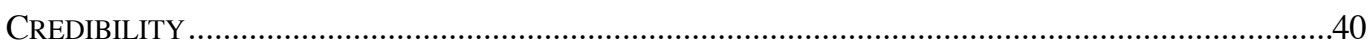

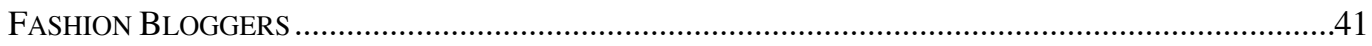

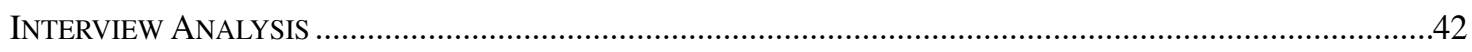

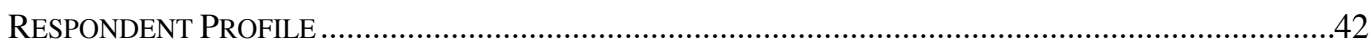

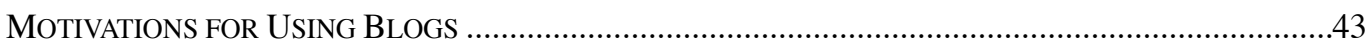

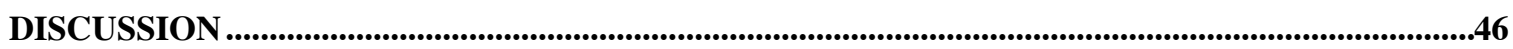

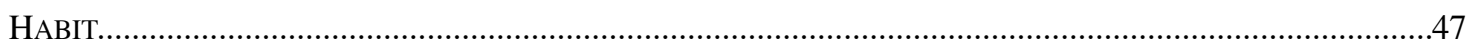

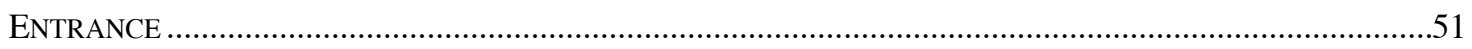

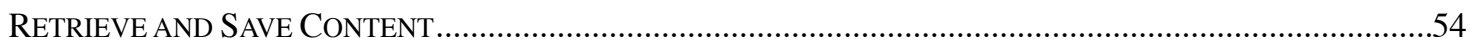

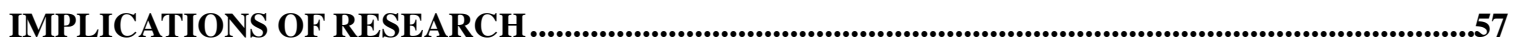

LIMITATIONS AND FURTHER RESEARCH ............................................................................................61

CONCLUSION .....................................................................................................................................................63

APPENDIX ........................................................................................................................................................................64

WORKS CITED.......................................................................................................................................................90 


\section{Introduction}

On February 10, 2013, respected and esteemed fashion critic Suzy Menkes penned an article for T Magazine entitled "The Circus of Fashion." The piece's tone is one of aggravation. Menkes, who has worked as the head fashion reporter and editor since 1988, reminisces with a frustrated longing for a simpler time in fashion communications' history. She blames fashion bloggers—a position that didn't exist when she began her traditional career as a fashion journalist - for the destruction of fashion media.

Since 1999, when the number of blogs (a then obscure term) numbered only 50 (Kaye, 2007, p. 128), the medium has come to amass a strong and substantial following. In 2008,184 million blogs existed (Rocamora, 2012, p. 92). The medium, which now incorporates both personal and corporate websites, relies on daily posts that appear in reverse chronological order. The first fashion blog was founded in 2003. In 2010, just a few short years later, the genre of fashion blogs included 2 million (Rocamora, 2012, p. 92).

As new media continue to evolve, the fashion media landscape has had to accommodate substantial shifting, which has perpetuated the tension between traditional fashion journalists and newcomers - the fashion bloggers. Much of this uncertainty has surfaced because there is not a clear understanding of how new fashion media supplements traditional fashion media. A better understanding of how fashion blogs are used by consumers in addition to traditional fashion magazines will have both theoretical and practical implications for fashion communications.

While some attention has been given to why individuals blog, very little academic research looks at why users read blogs. Only one previous study has used the uses and gratifications perspective to create a range of motivational categories and factors for blog use 
(Kaye, 2010). This current study attempted to find if there are any unique motivational factors that dictate fashion blog use specifically.

Fashion communications is somewhat of an enigma amongst the genre of cultural critique. It has been recognized that certain aspects, primarily the heavily entwined fashion industry and journalism, has made tastemakers out of designers, stylist, editors, and journalist alike. This traditionally exclusive industry does not replicate other forms of cultural communications.

This explorative study sought to identify the leading uses and gratifications of fashion blogs to determine how the medium is used in addition to traditional print fashion publications. Through a preliminary online questionnaire and in-depth interviews with women between 18 and 35 years of age, with a self-reported interested in fashion media, four uses and gratifications categories were identified; each category contains several motivational factors. The four categories are Accessibility and Convenience of Information Seeking, Blog Attributes, Specific Inquiry, and Escapism/Enjoyment (Appendix 3). Amongst these larger categories, three new motivational factors specific to the use of fashion blogs were found; the three motivational factors are habit, entrance, and retrieve/save content.

The first, habit, elucidates the daily use of fashion blogs by readers. Unlike fashion magazines, which were found to be used less frequently but for longer periods of time, fashion blogs were reported to be visited every day. The users only spend a couple of minutes on each blog and quickly gather as much information as possible in the shortest amount of time. The static aspect of the fashion magazine maintains that it is approached similarly to a book. However, fashion blogs are perpetually changing and evolving. Readers view them as an instant portal into the most current styles and trends. 
Another unique motivation factor to arise was entrance, which indicated the way that users are directed to new blog posts. Respondents stated that often they have not gone on their computer with the intention of visiting a fashion blog, but will be prompted to go on one via an update on a social media site or RSS feed. The action could indicate that users of fashion blogs are an inactive audience, who do not freely choose when and which blogs to visit. However, that act of clicking on a hyperlink signifies the choice to engage with the blog's content.

Readers also were found to actively remove content from blogs and store it on their own personal computers. This motivational factor has been identified as retrieve/save content. It was found that this behaviour was motivated by the desire to use the images on fashion blogs as personal inspiration for dressing. Removing the content from the context of the blog is a form of re-contextualizing and interactivity not previously identified by blog uses and gratifications studies. The interactive nature occurs not between the reader and the blogger or other users; instead, it takes place between the users and the content itself.

These uses and gratifications of fashion blogs help to illuminate the function and role that fashion blogs play in relation to traditional print magazines in the lives of fashion media consumers. By illuminating unique factors of fashion blog use, we gain a clearer understanding of how that use takes place alongside other fashion media consumption. Most saliently, it was found that fashion blogs satisfy the need for easily accessible fashion content on a daily basis; whereas, fashion magazines served to act as a form of relaxation and escapism. Both feature similar fashion content, but the media themselves are approached and treated differently by users. 


\section{Background}

\section{Importance of Communications Media to Fashion}

Those in the field of fashion studies have acknowledged the significant importance that discourse plays in the form of fashion journalism. It has been noted, in particular by Roland Barthes, that the way fashion is written and spoken about is innately influential to fashion objects. Barthes, in his seminal work, The Fashion System (1983), asserts that the value of fashion objects would not exist if not for fashion discourse. His methodical study is not specifically about fashion but rather about the language used to describe fashion. As Brian Moeran (2004) effectively declares, "it is indeed, the use of language that transforms clothing into fashion" (p. 35). Moeran analyzed the language used in Japanese fashion magazines in 2001, drawing out key descriptive words employed throughout the magazines to define and explain clothing. His study was one of the first to look at how fashion items are written about in magazines.

Agnés Rocamora (2012) has astutely noted that there is a substantial difference between the study of women/men's magazines (Winship, 1980; Hermes, 1995) and fashion magazines (Barthes, 1983; Moeran, 2004; Moeran, 2006; Rocamora, 2002; McRobbie, 1998). The difference being that the first reviews fashion, only in brevity, while the latter focuses solely on fashion images and 'written fashion' (Rocamora, 2012, p. 93).

In 2006, Moeran solidified the rarely studied production and consumption facets of fashion magazines by outlining two aspects: they act as both a cultural product and a commercial commodity (Moeran, 2006, p. 727). The symbiotic relationship between the fashion industry and fashion journalists has been further explored by Angela McRobbie (1998). In British Fashion Design, McRobbie draws attention to criticisms of fashion journalism. The large commercial 
influence on fashion journalism, she argues, has eroded the critical integrity and objectivity that remains in other areas of cultural media. Her opinion of fashion journalism becomes especially significant in light of the fashion industry's newest key players-fashion bloggers. By definition, journalism is meant to be objective; however, an imperative aspect of the blog is that it is subjective. Yet, fashion journalism, as McRobbie (1998) has discussed, can be recognized as a unique and dichotomous cultural critique, differing from art, film, music, and political journalism in that the fashion industry itself is tightly woven into a single piece of fabric. Fashion journalism is simply another piece of thread, along with stylists, designers, photographers, models, and all other tastemakers. Fashion journalism, McRobbie would argue, falls outside the generally expected standard of journalistic objectivity. Its subjective nature parallels that of blogs.

\section{History of Fashion Communications}

The first distribution of fashionable images was seen in the form of fashion plates (Steel, 2005). In late $15^{\text {th }}$ and early $16^{\text {th }}$ centuries, fashion plates began to function as portraits of styles. Improvements in communications (printing press) and travel led to an interest in the dress of other nations. At the time, fashionable dress was a marker of wealth and status, "to draw attention to the wearer, and to define his social position" (Nevinson, 1967, p. 68). The illustrations, originally woodcuts and engravings evolved into lithographs and eventually photographs (Nevinson, 1967). In the late 17th century, French styles captivated Europe. These fashions were recorded in Mercure Galant, which "deserves full credit for being the first modernstyle magazine" (Nevinson, 1967, p. 80). In 1678, the gazette contained fashion plates along with articles on fashion, news, poetry, and songs amongst other entertainment. After 1800, magazines grew in prominence and contained 'illustrated fashion articles' (Nevinson, 1967, p. 89). Again, 
technologies, such as steam-presses, enabled greater production and thus wider distribution. By the 1890s, photography techniques had developed and emerged in American magazines. Fashion photography would eventually become the aesthetic for the modern-day magazine; by the 1930s, they had replaced illustrations in American magazines. Fashion photography only grew in popularity throughout the 40s, 50s, 60s, and onwards (S H Steinberg \& John Trevitt, 2006). Antje Krause-Wahl (2009) has outlined the use of artists as models in fashion magazines from the 1940s to the 1970s, unintentionally highlighting the role of fashion photography to fashion magazines starting in the mid-20th century. Popular magazines, such as Vogue, worked with celebrated photographers whose work was featured in the magazines, not unlike the models in their images.

The 1950s saw a great shift in how North Americans received information. The advent of network broadcast television transformed media technologies. Previously, information had been disseminated singularly as either audio (radio) or visual (print) media. The television provided a platform for a more multi-sensory experience. In the wake of a transformation, radio, newspapers, magazines, and movies had to adjust and find a new place and role within the dissemination of information. As television was widely adopted, it became an essential outlet for fashion communications. The genre of fashion television provided viewers with content in a new way; models, designers, photographers and journalist were presented as television personalities. In 1967, the first television program dedicated to providing viewers with an insider's perspective of the exclusive fashion industry was produced. Videofashion News is still available in 2013. Elsa Klensch became the first television fashion journalist in 1980. Her segment, Style with Elsa Klensch ran on CNN until 2000. On the show's first episode, Klensch interviewed Liza Minnelli and Andy Warhol (Gay, 2001). Fashion Television gave rise to another renowned journalist, 
Jeanna Beker, whose series aired from 1985 to 2007. As the host of Fashion Television, Beker became an international fashion icon. Her program was broadcast in over one hundred countries. She brought styles and trends into the living rooms of the average viewers. The exclusive fashion industry was available to the mainstream with interviews of leading designers at high-profile runways shows, celebrity photographers captured at work, and profiles of idolized models solidifying a personality to match the beautiful faces.

At this time, fashion was disseminated to its audience with a strictly top-down approach. The traditional structure of magazines and television programing meant that viewers watched or read as the industries elite; editors, journalist, designers, and artistic directors dictated what was fashionable. Cyclically, trends and styles were decided and dispersed by the privileged influential few that sat at the top of the fashion food chain. This system differed significantly from the $14^{\text {th }}$ century, where fashionable dress was a signifier of wealth and status, when it worked to create a class structure. Being fashionable was restricted to a certain class (Rogers, 1995). In the $21^{\text {st }}$ century, the top-down propagation of fashion, by the organized means of broadcast television and print magazines, is meant to influence a far-reaching audience and have mass appeal. These avenues attempt to dictate what to wear and how to wear it to as large a population as possible.

\section{Present Fashion Communications}

The top-down model that, for the majority of the last century, dictated fashion trends by way of a unified industry was shattered with the advent of the Internet. In the 1990s, blogs first emerged, the name - a combination of web and log - is now, over two decades later, common vernacular. In about ten years, the number of reported blogs ballooned from 50 in 1999 to a whopping 184 million in 2008 (Rocamora, 2012, p. 92). The posts, often-daily updates, are arranged in reverse chronological order and can cover a variety of topics. This study is 
specifically interested in the genre initially appropriated by young women who wished to document their personal outfit choices. According to Rocamora (2012), the very first fashion blog came about in 2003 with the birth of nogoodforme (Rocamora, 2012).

Since then, the number of blogs that feature fashion content has amassed to 2 million, as of July 2010, according to blogger.com (Rocamora, 2012). This has come to include a host of both independent and corporate websites. The historically restricted fashion industry began to crumble in 2009, as fashion bloggers' clout continued to grow. In December of that year, The New York Times ran the article, "Bloggers Crash Fashion's Front Row." The image above the story showed fashion blogger Bryanboy sitting just a seat over from legendary Vogue editor-inchief Anna Wintour in the front row of a Milan runway show. The article highlights a growing tension between bloggers and those in traditional fashion journalism. The well-known fashion prodigy Tavi Gevinson, whose blog Style Rookie catapulted her into international stardom at the age of thirteen, was one of the first to be mentioned.

As a relatively new phenomenon in the crowded arena of journalists whose specialty it is to report the news of the catwalks, fashion bloggers have ascended from the nosebleed seats to the front row with such alacrity that a long-held social code among editors, one that prizes position and experience above outward displays of ambition or enjoyment, has practically been obliterated. (Wilson, 2009)

It was the same time that traditional magazines were making cutbacks. In 2009 it was reported by The New York Times that Condé Nast was being advised to cut about 25\% from their budget (Clifford, 2009). "Capping a painful year for print media, the decline in magazine advertising pages accelerated with each passing quarter of 2008." was the first line of a Wall Street Journal article (Ovide \& Adams, 2009).

Fashion bloggers steadily gained recognition. Jane Aldridge of Sea of Shoes, Leandra Medine of Man Repeller, Scott Shuman of The Sartorialist, and Susanna Lau of Style Bubble are 
just a few of the fashion bloggers who have created thriving careers out of their blogs and become modern day facets in the fashion industry. They have gained recognition by designers, editors, and companies who have used their brands (aka their blogs) in collaborations. They have collaborated on purses, one-off pieces and whole collections, like Leandra Medine's collection with PJK. One of the first to capitalize on the expanding attention blogs were receiving in 2008 was Marc Jacobs when he named a bag after blogger Bryanboy (Menkes, 2013). Ironically, some of the most successful blogs have now been published in print form as books, in the case of The Sartorialist, Facehunter, and What I Wore (Marwick, 2011), or as an annual magazine, in the case of Tavi Gevinson's Rookie (Moss, 2012).

As of 2011, The Independent Fashion Bloggers coalition (IFB.com) had over 3,000 members (Marwick, 2011). Theoretically, anyone with a computer and Internet access can create a fashion blog. This has led to the belief in 'the democratization of fashion,' A buzz term that has come to encompass the changing fashion media landscape by way of blogs and high street fast fashion stores. "The rise of the fashion blogosphere has resulted in the coming of prominence and the growing influence of individuals who had no institutional affiliation to the field of fashion when they started their blog" (Rocamora, 2012, p. 100). Allowing for a greater democratization of communications, the Internet's facilitation of user-generated content has promoted subjectivity within fashion writing.

However, the shifting fashion media landscape has brought with it tension between bloggers and traditional fashion journalists. Rocamora has noted Bridget Foley (2010) of WWD magazine's comment about the lack of knowledge of bloggers when she said, "I think we are starting to feel a little backlash towards the whole immediacy of things" (Rocamora, 2012, p. 
100). In the article "The Circus of Fashion" (2013), Suzy Menkes shames the fashion industry for becoming a whirlwind of 'street style.'

Adhering to the time-honored journalistic rule that reporters don't take gifts (read: bribes), I am stunned at the open way bloggers announce which designer has given them what. There is something ridiculous about the self-aggrandizement of some online arbiters who go against the mantra that I was taught in my earliest days as a fashion journalist: "It isn't good because you like it; you like it because it's good." Slim chance of that idea catching on among the fashion bloggers. (Menkes, 2013)

The controversial article (written by a traditional fashion journalist) has garnered

aggravated responses from bloggers. Medine of Man Repeller posted 'Blog is a Dirty Word' as a direct retort to Menkes' article. The growing tension between the two media is outside the scope of this study but does however highlight some aspects of the current fashion media landscape. 


\section{Literature Review}

\section{The Fashion Blog}

Only a handful of scholars have rigorously studied fashion blogs. Among the few is Agnés Rocamora, whose work is the most extensive. Rocamora's research is also the most relevant to this study, as she has written about fashion blogs as new media and, as a form of new media, the relationship between fashion blogs and traditional fashion journalism. In Hypertextuality and Remediation in the Fashion Media (2012), the author discusses the rise of the fashion blogosphere and the implications that fashion blogs have had on the 'mediation of fashion'. Rocamora highlights the ways that fashion blogs position themselves in regard to traditional fashion journalism. Rocamora (2012) outlines a key disparity within the presentation of fashion related information on a blog as opposed to a magazine - hypertextuality - when she says:

Where fashion magazines never refer to any other magazines - clearly implying their independence from the rest of print publications and a status as the on authoritative fashion source-linking "produces a network organization" (Landow, 1994, p. 24) whereby fashion blogs constantly relate to other blogs, be it through directly linking to them in a post or by including them in their blogroll, the list of blogs and the related links bloggers favour. (Rocamora, 2012, p. 96)

This linking or hypertextuality, she argues, is not a new concept. It does, however, work as a sort of citation system within the blogosphere (Rocamora, 2012). Compared to a print magazine, which is limited by its materiality, fashion blogs are "multilayered text whose many threads lead me towards a potentially unending flow of images, words and sounds" (Rocamora, 2012, p. 95). Another trait of fashion blogs, which has played on the traditional fashion industry, is time. Rocamora uses the previously twice-yearly designer collections, now pre-fall, resort, high summer, etc., as an example of the fragmentation perpetuated by immediacy. The 'culture of 
speed,' she posits, is maintained by the immediacy of fashion blogs. Newness, she says, is now a 'permanent present' and "in their constant, often daily, updating of sites with posts, fashion blogs feed into this tyranny of the new, constructing, more than any other media, fashion as transient, passing, already gone" (Rocamora, 2012, p. 97). The author also identifies that fashion blogs work to decenter fashion, in that; they promote untraditional tastemakers and uncommon fashion cities.

Eleanor Snare also looked at the fashion blogger practices and the social impact of fashion blogs in her 2011 dissertation. The paper examined the interplay between fashion bloggers and the fashion industry as well as social structures. Snare's study used empirical data from surveys of fashion bloggers.

In 2011, Rocamora specifically looked at personal fashion blogs, a subset of independent fashion blogs. From a gender studies perspective, Rocamora argues that personal fashion blogs can act as a 'space for identity construction' (Rocamora, 2011). Another paper that makes a connection between personal fashion blogs and identity is Minh-Ha T. Pham's 2012 article, "Blog Ambition: Fashion, Feelings, and the Political Economy of the Digital Raced Body." Pham traces opposing perspectives about the democratization of fashion as enabled by the Internet. The article uses Asian American fashion blogs to exemplify the discussion (Pham, 2012). In one example, Pham argues that the nostalgic posts on one woman's fashion blog reveals a history of Asian American designers, which is embedded within a history of labour and migration. This arguably neglected history, she contends, is 'rewritten' by the fashion blogger.

In a paper that presents a new theoretical definition for conspicuous consumption, Dr. Alice Marwick, explores how fashion bloggers have impacted different theories, mainly conspicuous consumption and information flow. She argues that online identity presentation is 
not sufficiently explained by current theories on conspicuous consumption. These interactions between fashion bloggers and aspects of the fashion industry, such as luxury goods or vintage fashions, embrace an accelerated fashion cycle and attempt to reposition 'top-down' fashion media.

Of the limited research that explores the emerging medium, no studies specifically examine fashion blogs from the user's perspective. This study will begin to fill this gap by considering how fashion blogs are used and interpreted in relation to traditional fashion journalism, by the users.

In a study exploring the phenomenological differences between reading women's magazines in print versus online, Brita Ytre-Arne found that “...readers strongly prefer magazines in print" (Ytre-Arne, 2011, p. 467). Ytre-Arne's findings have to do with the physical and aesthetic aspects of the magazine as an object. It should be noted that her study does not consider fashion blogs, but rather compares print fashion magazines to magazine's websites. Her study, more often than not, quotes women in their mid-thirties and older. It could be predicted that there is a generational gap, and thus differing perspectives of the Internet, between those who were introduced to the Internet later in life and a younger generation who became familiar with the Internet as a daily aspect of life at a very young age. When Ytre-Arne's study is considered independent of previously stated stats regarding the increase of blog use and blog development, it would appear that readers do not prefer to go online for fashion media; however, the popularity of fashion blogs indicates that there is a preference for fashion content being disseminated online. This study examines the motivations for use of fashion blogs, with the use of traditional fashion journalism in consideration. 


\section{Remediation}

This research will frame the uses and gratifications of fashion blogs within the context of 'remediation', whereby it is accepted that new media supplement rather than succeed traditional forms of dissemination. "New media may well transform established visions, but they never totally supersede old media, for a new medium always appropriates some of the characteristics of an older medium" (Rocamora, 2012, p. 101). As technologies emerge and are adapted into daily lives, they do not replace what has come before them; rather they begin to supplement one another. David Bolter and Richard Grusin (2000) define 'remediation' as a process by which new media refreshes old media and adopts certain aspects. "What is new about new media comes from the particular ways in which they refashion older media and the ways in which older media refashion themselves to answer the challenges of new media" (p. 15). In this sense television was a remediation of film and the Internet a remediation of print. Within fashion's current media landscape this process is visible. Both traditional fashion journalists and bloggers pay tribute to one another-bloggers feature editorials and images from their favourite magazines, while magazines capitalize on bloggers' popularity by having them influence their content as guest contributors. Some bloggers have based their entire careers on street style photography, a genre that, during its infancy paid tribute to the fashion industry's elite by photographing the highest and most respected fashion industry professionals. Rocamora (2012) also notes that the poses that personal and style bloggers use have been adapted from print magazines, thus another form of remediation. "The process of remediation makes us aware that all media are at one level a "play of signs"” (Bolter \& Grusin, 2000, p. 16). Adhering to this belief, this study examines how fashion media consumers use fashion blogs as a supplement to print magazines. Identifying the 
uses and gratifications of fashion blogs will illuminate how the current fashion media landscape as a whole currently satisfies users' needs.

\section{Uses and Gratifications Approach}

Since its dawn in the communications field, the uses and gratifications (U\&G) framework has been used to examine users relationships with a host of media and communications technologies. The perspective has been used to illuminate the effects of varying forms of communications media - from newspapers and radios to cell phones and social media. The focus of such examinations by scholars has predominantly been to gain insight into the interaction between the media and its audience. The perspective has given rise to a shift in communications research, from a focus on how communications media affect users to how users' needs affect media choice. In short, the U\&G approach posits that audience members actively choose and seek out media in order to gratify social and psychological needs.

It is generally accepted by $U \& G$ researchers that the uses and gratifications perspective was first developed in the 1940s for the study of radio program gratifications and other media such as the newspaper. The intention was to investigate audience members' motivations for engaging in media behaviours. At this time, the uses and gratifications approach was originating as an assessment of mass media from a functionalist perspective (Rubin, 1994; Ruggerio, 2000).

Early U\&G research focused on classifying audience responses into meaningful categories to better understand the gratifications associated with each media use. These studies signified a considerable shift in mass media research, which had previously focused solely on the media's intended effects and largely ignored user motivations. (Katz et al., 1974; Rubin, 1994;

Ruggerio, 2000). The uses and gratifications perspective has been classified by some scholars as a subset of media-effects research (Ruggerio, 2000). However, Rubin (1994) has defined a 
primary difference between the traditions based on contentions made by Windahl in 1981. Media effects researchers study mass communication from the communicator's end; whereas, the uses and gratification perspective begins by examining the audience member (Rubin, 1994). "It shifts the focus of inquiry from a mechanistic perspective's interest in direct effects of media on receivers to assessing how people use the media: 'that is, what purposes or functions the media serve for a body of active receivers' (Fisher, 1978, p. 159)" (Rubin, 1994).

During the 1950s and 1960s U\&G researchers took a social and psychological approach to the perspective (Ruggerio, 2000). Studies during this time largely focused on social and psychological attributes of individuals and how they related to media use (Ruggerio, 2000). In the 1970s, Katz et al. formally defined the U\&G perspective as a process by which,

The social and psychological origins of needs, which generate expectations of the mass media and other sources, which lead to differential patterns of media exposure (or engagement in other activities), resulting in other consequences, perhaps mostly unintended ones. (Katz et al., 1974, p. 20)

Interdisciplinary research in the fields of communications and psychology "produced abundant research on the ways human beings interact with the media" (Ruggiero, 2000, p. 6). Throughout the 1970s, a focus on cognitive motivations arose; it was also during this time that a distinction was made between gratifications sought (GS) and gratifications received or obtained (GO) (Ruggerio, 2000). Further, this was the time when criticism of the U\&G perspective began to be voiced. These criticism centered around five areas of concern: a) studies using this approach used compartmentalized typologies and there was not enough fusion between studies, b) that it was difficult to generalize beyond samples, c) central concepts were defined differently by individual scholars, d) the methodology's reliance on self-report data and, e) critics questioned whether audiences were active in their media choices (Rubin, 1994; Ruggerio, 2000; Elliot, 1974; Swanson, 1997). Scholars have since addressed these concerns. For example, 
Ruggerio (2000) has redefined the concept of an active audience as a choice that exists on a continuum. Others have addressed the criticisms by replicating found gratifications between medium channels; for example, Rubin (1994) contested many of the approach's criticisms through further research and through further delineating the perspective's assumptions.

\section{Uses and Gratifications Assumptions}

The U\&G approach makes the assumption that users actively choose to use media and interact greatly with communication media. The perspective assumes that there are many forms of media that compete for audience members' attention. Users are expected to choose and seek out the form of media (among competing channels) that best satisfies or gratifies their needs. Sought gratifications have been found to be, among many other things, a desire for information or for emotional connection. Other proposed areas of gratifications (motivations) for general media use are surveillance/information, escapism/entertainment, personal identity, and personal relationships/social integration.

Entertainment construct signifies the extent to which the user enjoys the media and how much fun it is considered to be. This construct's value lies in its ability to provide the user with escapism and hedonistic pleasure. Informativeness is the media's ability to provide the user with information that is resourceful and useful. Another potential construct (of which there are many) is irritation. This may deal with how easily the media can be navigated, used, and understood.

While the $U \& G$ approach faced criticism for being too focused on the individual that, it has been argued, is a passive participant, in recent years the model has been widely adopted as an acceptable and appropriate approach for studying new media and the Internet (Parker \& Plank, 2000). A contemporary perspective of the $U \& G$ model has been summarized by Alan Rubin (1994) as being based on five assumptions: 
1. Communication behaviour such as media use is typically goal-directed, purposive, and motivated.

2. People select and use communication sources and messages to satisfy felt needs or desires. Media use is a means to satisfy wants or interests such as seeking information to reduce uncertainty or to solve personal dilemmas.

3. Social and psychological factors mediate communication behaviour. Behaviour is a response to media only as filtered through one's social and psychological circumstances such as the potential for interpersonal interactions, social categories and personality.

4. Media compete with other forms of communication for selection, attention, and use. There are definite relationships between media and interpersonal communication for satisfying needs or wants.

5. People are usually more influential than media in media-person relationships.

\section{Uses and Gratifications and The Internet}

With every advancement in communication media, the U\&G approach has offered an appropriate research method for founding a base typology of motivational uses. The advent of the Internet has not been any different; thus, online media has prompted a resurgence in the uses and gratifications approach.

Today, audiences are faced with more media choices then ever before. Consequently, audience members must be even more selective in choosing a medium that satisfies their needs (Ruggiero, 2000). The U\&G notion of an active audience renders it a suitable perspective for this medium, as the Internet is inherently based on users' participation. Ruggiero (2000) has outlined other unique aspects of online communications that he recommends be considered when applying the $U \& G$ perspective to communication media in the $21^{\text {st }}$ century. These are, asynchronous or synchronous interactions (networks are available and can be accessed 24/7, new information is constantly available), interactivity, demassification, hypertextuality, and the ability to easily story, copy, and retrieve information.

A call to communications researchers emanated in the form of Morris and Ogan's 1996 seminal paper, “The Internet as Mass Medium," as they urged scholars to acknowledge the 
emerging mass media, which was the Internet. The uses and gratifications framework extends across both mass and interpersonal communication with an emphasis on audience activity and thus it was considered a natural model for studying the Internet (Morris \& Ogan, 1996). Rather than passively watching television and inertly focusing on content, the Internet requires uses to search for relevant content in order to satisfy their needs. Users click on links and use search engines in goal directed ways in order to fulfill sought gratifications (Johnson \& Kaye, 2004). In order for the web to act as a form of communication media, audience members (Internet users) must take some form of action.

Since the late 90s, several communications scholars have used the U\&G approach to study the Internet in general (Parker \& Plank, 2000; LaRose et al., 2001, Stafford \& Stafford, 2004; Stafford \& Gonier, 2004), specific websites and the Internet for commercial purposes (Eighmey \& McCord, 1998; Papacharissi, 2000), individual characteristics of users (Johnson \& Kaye, 2004; Papacharissi \& Rubin, 2000) and online social media websites (Flanagin, 2005; Quan-Hasse \& Young, 2010; Chen, 2011). Amongst these studies similar gratifications have been found and reported, but it must be recognized that there is not a verified and consistent measurement scale used in $U \& G$ research. Also, it should be noted that although the same motivational factors are reported to be found, these terms and definitions are crafted by each scholar on a study-to-study basis.

\section{Previous Studies of Internet Uses and Gratifications}

One of the initial studies to investigate the uses and gratifications of the Internet was Parker and Plank's exploratory analysis of 204 university students' responses to a questionnaire taken during the summer of 1997. The questionnaire consisted of statements determined through earlier uses and gratifications studies of other media forms in order to define gratifications gained 
from using online sources. Parker and Plank identified three factors obtained from online sources: companionship and social needs was found to be the strongest gratification, then surveillance/entertainment, and relaxation/escape (Parker \& Plank, 2000). The study also found that respondents had not "abandoned traditional forms of media for the Internet" (Parker \& Plank, 2000). In 1997, print media was favoured as the primary source for information.

Television was found to be the second most popular source for information and it was noted that the medium was used widely for news/weather, politics, and entertainment (Parker \& Plank, 2000). The authors used a fairly broad approach to studying the uses and gratification of online sources. Almost a decade later, the prevalence of the Internet has grown significantly; therefore, the finding that traditional media had not been abandoned for the Internet may no longer prove true. The study does however serve as an example of U\&G being applied to a new and evolving medium and identifies gratification factors that appear again throughout later research.

LaRose, Mastro, and Eastin took a social-cognitive approach to studying the uses and gratifications on the Internet in 2001. The authors posit that gratifications sought and gratifications obtained are quite similar to a social-cognitive theory called enactive learning. Primarily, "enactive learning describes how humans learn form experience" (LaRose, Mastro \& Eastin, 2001, p. 397). It is through this social-cognitive lens that they examine the uses and gratifications of the Internet. They found that outcome expectations and specific types of incentives found in their study were parallel to findings from Internet uses and gratifications studies. Activity outcomes (entertaining), pleasing sensory outcomes (pass time), novel sensory outcomes (information), and social outcomes (communication) were all positively related to Internet usage. 
Stafford and Stafford sought to enhance the uses and gratifications understanding of the Internet in 2004. Their study of AOL subscribers was accomplished through a two-step process, common to the uses and gratifications perspective. The initial open-ended questionnaire, created using word association probes was used to extract a list of uses and gratifications associated with Internet use. Stafford and Stafford found three main gratifications: internet process (resources, search engines, searching, surfing), internet content (education, information, knowledge, learning), and internet social (chatting, friends, interactions, people) (Stafford \& Stafford, 2004). The gratifications identified in this study act as 'umbrella gratifications' of the Internet, while many of the micro-gratifications identified are echoed by other studies. For example, social interactions (Ferguson \& Perse, 2000; Papacharissi \& Rubin, 2000; Parker \& Plank, 2000) and informative (Ferguson \& Perse, 2000).

In the same year, Stafford and Gonier published another study of AOL users. This study was presented in greater brevity than the Stafford and Stafford (2004) study; however, it does utilize the same data from the $915 \mathrm{AOL}$ users. In this analysis, four main factors are identified: searching, information, communication, and socialization. They also note that shopping is worth considering however it had a fairly low score. The results from this study, which was presented in a less academic fashion, expanded the Internet social category (Stafford \& Stafford, 2004) into two separate categorizes of communication and socialization (Stafford \& Gonier, 2004).

In an early study of the uses and gratifications of specific websites, Eighmey \& McCord (1998) examined the gratifications associated with five individual product websites. A small group of 31 participants browsed five selected websites in the summer of 1995 on a Net-scape browser. The websites included a telecommunications company, a manufacturer of candy, and a sportswear company. The study found eight uses and gratifications associated with online 
websites: entertainment, personal involvement, personal relevance, information involvement, clarity of purpose, controversy, credibility, continuing relationship, and purchase interest. The largest portion of variance was attributed to those uses and gratifications that had been identified in previous studies, such as entertainment value (Parker \& Plank, 2000), information (Stafford \& Stafford, 2000), and personal relevance. Some factors that had not been previously identified emerged relating to personal involvement and continuing relationship. The study's participants were most responsive to websites that were organized, spoke in a personal voice, and were entertaining (Eighmey \& McCord, 1998).

In 2004, Johnson and Kaye looked at a niche segment to determine if individual differences impacted the uses and gratifications of using alternative websites. They surveyed politically interested individuals in the weeks before the 2000 presidential election to gain insight into their motives for using the Web, bulletin boards/electronic mailing lists, and chat forums for political information. Johnson and Kaye compared whether political attitudes, personal characteristics, and Internet experience affected the motivational use of these different Internet components. They found that four factors differed in the respondents' use on the three Internet communications possibilities: political guidance, entertainment/social utility, convenience, and information seeking. This study uncovers that even within a niche segment, such as politically interested individuals, the motives associated with using different web based communication channels, in this case chat rooms, bulletin boards, and WWW, differ depending on the channel and person.

In another study that looked at individual differences in relation to motives for Internet use, Papacharissi and Rubin (2000) examined individuals who had both high and low willingness to communicate, in order to investigate if the Internet could function as an alternative to face-to- 
face communication. Five factors were identified in relation to Internet use: interpersonal utility, pass time, information seeking, convenience, and entertainment. The study found that individual psychological and social differences, such as the unwillingness to communicate, affected the rank of gratifications for online use. Papacharissi and Rubin (2000) established that the social and psychological differences of uses affect gratification motives of Internet use potentially offer a functional alternative to fact-to-face conversations for those who devalue oral communication.

In 2000, Ferguson and Perse acknowledged that online search engines had increasingly begun to reach more adults than popular television shows; they designed a study to investigate whether the Internet could function as an alternative to television viewing. By employing an online survey and media-use diary, Ferguson and Perse (2000) identified three major and two minor factors attributed to Internet use: entertainment, pass time, relaxation, social information, and information. The authors noted that the most striking finding from their research was the salience of entertainment as a motive for using the Internet. Entertainment is also the primary gratification of television audiences (Ferguson \& Perse, 2000). In light of their research question, the authors concluded that the Internet could replace television, if it continued to gratify entertainment needs, as well as other competing gratifications such as passing time, while remaining just as convenient as television viewing (Ferguson \& Perse, 2000). The Internet could therefore serve as an alternative to television based on the similarities of found uses and gratifications. Over the past decade the Internet has continued to evolve and potentially now functions as an alternative to many other channels of communication including print media. This research study will consider whether the found uses and gratifications of online fashion blogs is 
consistent with motivations for fashion magazines, thus identifying that the emerging fashion blog may act as an alternative to the historical fashion magazine.

In what could be considered an original study of the blog, Papacharissi's 2002 study observed the motives for authoring personal homepages. The study utilized an online questionnaire of web page authors and a content analysis of respondents' web sites. Internet, media, and interpersonal motives previously determined were adapted to create an index for measuring personal homepage use. Papacharissi (2002) found six factors for authoring a personal homepage: passing time, entertainment, information, self-expression, professional advancement, and communication with friends and family. The most salient motives from this sample were information and entertainment. Both of these factors have been identified in other studies of online uses and gratifications (Parker \& Plank, 2000; Eighmey \& McCord, 1998; Ferguson \& Perse, 2000, Papacharissi \& Rubin, 2000).

In a more recent study, Jung, Youn and McClung (2007) examined Korean individuals' motives for constructing personal homepages as well as interpersonal self-presentation strategies employed by the Cyworld website's authors. The study's authors refer to the Cyworld personal mini-homepages as being in a weblog format; this again signals that these studies were initial investigations into the examination of the motives for authoring a blog. The motives for hosting weblog format homepages were found to be for entertainment, self-expression, professional advancement, passing time, and communication with friends and family. Echoing the findings from Papacharissi (2002), entertainment was identified as one of the most salient motivational factors in hosting a personal homepage (Jung, Youn \& McClung, 2007).

As communication tools online continued to diversify over the past decade, research studies in the field of computer-mediated-communications has grown extensively. In 2005, 
Flanagin posited that scholars had largely ignored the expansive mass of online communication tools available and attempted to fill this void by examining the motivations for instant messaging (IM). Instant messaging was a popular online communication tool for some time and was widely used by the demographic of 12 to 17 year olds (Flanagin, 2005). A survey was administered to college students in 2004 to assess the needs fulfilled by instant messaging. The study found four factors: social entertainment, task accomplishment, social attention, and meet new people. IM was compared to other more traditional forms of communication to determine if this form of computer-mediated-communication could function as an alternative to face-to-face communication. The author noted that face-to-face communication was the most versatile and useful channel for satisfying individuals' information, communication, and social needs (Flanagin, 2005).

In recent years, rapid advancements in computer-mediated-communication technologies and platforms have emerged in the form of social networking sites. Social networking sites have quickly grown in popularity with the arrival of Facebook and Twitter, two of the most popular platforms worldwide (Quan-Hasse \& Young, 2010). As social media networks increased in popularity, instant messaging use decreased; however, Quan-Hasse and Young (2010) have pointed out that social media do not replace one another but instead are integrated into a repertoire of users' media communications. The integration of new media with older forms will be examined in this study; users may identify their use of fashion blogs and fashion magazines as an interchanging practice, with each medium satisfying a unique and distinctive set of needs.

In 2010, Quan-Hasse and Young studied the comparative uses and gratifications for Facebook with those for instant messaging to examine the extent of differences in users' needs fulfilled from different types of social media (Quan-Hasse \& Young, 2010). The study reveled six 
gratifications obtained from Facebook: pastime, affection, fashion, share problems, sociability, and social information. When compared to the gratifications obtained form instant messaging, the authors conclude that IM is geared towards maintaining and developing relationships whereas Facebook is used for information about social networks and social activities. The study reveals that individuals utilize numerous communication platforms because they garner different uses and gratifications from each media channel.

Twitter, one of the fastest growing social media sites, is a communication channel that allows users to post (tweet) 140-character message that can be viewed by anyone who chooses to follow the users' Twitter account (Chen, 2011). In 2011, Chen contended that Twitter users are actively gratifying a need to connect with other people. Through an online survey of Twitter users, Chen (2011) found that "spending a lot of time using Twitter over a series of months" (p. 760) was the largest factor associated with gratifying people's need to connect with others. This influence was greater than the amount of time per day or act of sending messages on Twitter. These findings, the author notes, confirm past findings that people who are active on social networks are likely to feel connected (Chen, 2011).

\section{Uses and Gratifications of Blogs}

Blogs, or weblogs as they were often referred to in the early stages of their development, as an emerging communication channel were first studied in the form of personal homepages (Papacharissi, 2002; Jung, Youn \& McClung, 2007). With the rapid advancements and increasing prevalence of the blog, the area of blog research has also begun to expand. 


\section{Previous Studies of Blogging Motivations}

In 2004, Nardi et al. used an ethnographic approach to investigating the motivations for creating and maintaining blogs. They interviewed a sample of 23 people who maintained a blog at the time of the study. The authors noted that even among their relatively small sample, content that the bloggers wrote about was extremely diverse. Utilizing qualitative in-depth interviews Nardi et al. (2004) found five motivations for blogging: documenting one's life, providing commentary and opinions, expressing deeply felt emotions, articulating ideas through writing, and forming and maintaining community forums. This study is one of the early examinations of blogging in its initial stages of emerging as a mainstream communication medium and the motivations found offer one of the first looks at blogging gratifications. The authors suggest that a relationship can be drawn between the content published on a blog and the motivations of the blogger. Aspects of the blog, such as appearance, frequency of posts, format, content, and style may signify the blogger's motivations for maintaining the website (Trammell et al., 2006).

William et al. (2005) used the 2004 presidential campaign as a way to examine blogging and hyperlinking. The authors noted that the blog structure allowed for more "in-depth, interlinked, and possible interactive form of electronic communication" (William et al., 2005, p. 178-179). They used content analyses of candidate websites and blogs during the 2004 presidential campaign in order to evaluate the hyperlinking strategies of presidential candidates. In terms of linking to other blogs and endorsements of interest groups, there was no difference found between candidates' websites and blogs. In fact, websites were found to be more likely to link to promotional material than candidates' blogs. In terms of content, the candidates' blog 
covered various topics with less depth than candidates' websites, which were found to cover fewer issues more in-depth (William et al., 2005). This study did not employ a uses and gratifications perspective however it does demonstrate some early research into the use of blogs for differing practices, in this case political campaigning. It also highlights the interactive feature of blogs. The study also compares the uses of blogs to other online websites.

In a study that examined the motivations of Polish bloggers, Trammell et al. (2006) employed a quantitative textual and visual analysis of content on Polish blogs. Motivations were assessed based on a coding structure derived from Papacharissi (2002) in order to gauge Polish bloggers' motivations. The six a priori categories were entertainment information, social interaction, self-expression, passing time, and professional advancement (Papacharissi, 2002). Through a content analysis of the front pages of 358 blogs the researchers determined that Polish bloggers were motivated by the following factors: self-expression, social interaction, entertainment, passing time, information, and professional advancement. Self-expression, an internal-level motivation, was determined to outweigh social interaction, an external motivation. The authors concluded that similarly to English bloggers, self-expression was the primary motivation for blogging; they also noted that a diary-like genre was highly popular, echoing findings from Papacharissi (2004) (Trammell et al., 2006).

Chung and Kim (2008) contended that cancer patients have significant reasons to use the Internet for support and information sharing. They used the uses and gratifications perspective to investigate blogging activity among cancer patients and their companions. The study interestingly used a sample of both blog readers and bloggers combined. Of the 113 survey respondents, $62 \%$ hosted their own blog. This study specifically targeted personal journal blogs as the blog's content dealt with cancer treatment. The authors found four factors influencing 
cancer patients' use of blogs: prevention and care, problem solving, emotion management, and information sharing (Chung \& Kim, 2008). The study found that cancer patients perceived blogging to be a beneficial activity in regards to their current condition; the most prominent factor reported was emotion management.

In 2010, Hollenbaugh built on the findings of Chung and Kim (2008). Hollenbaugh (2010) asserted that previous research on personal journal blogs (Chung \& Kim, 2008) was very specific to the bloggers' experiences with cancer. Hollenbaugh (2010) sought to research more general motives for hosting a personal journal blog. An online questionnaire was completed by 299 bloggers in 2008, the bloggers all maintained personal journal blogs (blog post content was related to the bloggers' life and 'internal self'). The motivational scale used was derived from previous studies. A list of 25 motivational items emerged, which were categorized into seven factors: helping/informing, pass time, exhibitionism, archiving/organizing, get feedback, and professionalism.

\section{Previous Studies on Blog Users' Uses and Gratifications}

Blogs have been studied primarily with a focus on blog content and what motivates people to create and maintain blogs. Few academic scholars have actually focused on blog readers, and little research has been done to gain insight into the uses and gratifications of blog audience members (Kaye, 2005).

In a leading study and one of the first to investigate what motivates people to read blogs, Kaye (2005) surveyed 3,747 Weblog readers. The survey was administered in the spring of 2003 in an attempt to understand how and why readers use blogs and what needs they gratify.

Statements derived form past uses and gratifications studies were used to comprise a selection of motivations to gauge blog readers' motivations. Six primary factors emerged out of the 28 
reasons analyzed. Those six factors were information seeking and media checking (individuals compare weblog accounts with traditional media), convenience (going to one site where pertinent information to relevant issues has been collected and posted by blogger), personal fulfillment (information to use in discussion and fulfill needs: entertainment, relaxation, excitement, involvement), political surveillance, social surveillance, and expression and affiliation (interacting with like-minded individuals) (Kaye, 2005). Kaye also found that among the demographic she surveyed, respondents tended to be highly educated, white men. Since this study, blogs have become ubiquitous and blogging has expanded into numerous genres, and therefore this original sample of blog users from 2003 may not be representative of blog users today. The study does nevertheless provide one of the first insights into the uses and gratifications of reading blogs.

In 2007, Kaye sought to develop a blog uses and gratifications gauge that was not based on adapting factors from previous media gratifications scales. She further developed this scale in 2010. The 2010 descriptive study was based on the earlier exploratory study of the uses and gratifications of blogs (Kaye, 2007) and acted as a follow-up to the earlier study (Kaye, 2007), which had identified 62 motivational factors for using blogs based on open-ended responses from 2,397 survey respondents in 2003. The follow-up analysis in 2010 was based on results from an online survey administered in 2007. "This descriptive study offers a first step in developing a blog uses and gratifications scale based on open-ended responses rather than on adapting items from other media use scales" (Kaye, 2010, p. 204). Using an exploratory qualitative approach allows for open-ended questions to identify unique factors that had not been previously identified by other media studies. A total of 56 motivational items were found, these items were then categorized into broader motivational factors. Nine categories emerged; the primary blog use 
motivation was identified as convenient information seeking. Blogs were found to be a convenient way to seek aggregated news; they offer links and up-to-date information on a variety of issues and topics. This factor is made up of 14 items, 11 of those 14 items were among the most salient responses of users' motivations for accessing blogs. The other eight overall categories that emerged were antitraditional media sentiment (blogs are independent of traditional media and may include information that traditional media omits, traditional media is viewed with suspicion), expression/affiliation (interact with like minded individuals and feel involved), guidance/opinion seeking (blogs support user's own opinions and offer validation), blog ambiance (attracted to a specific blogger, enjoy good writing, find blogs humorous), personal fulfillment (relaxing, pastime, fulfill emotional needs), political debate (information from specific political perspective), variety of opinion and specific inquiry (blogs are often centered around a particular issue or topic, blog readers look for information on niche subjects) (Kaye, 2010). This study offers the most thorough and comprehensive list to date of blog users motivations. 


\section{Methodology}

Uses and Gratifications research can be conducted either quantitatively, qualitatively or using a mixed-methods approach. Ruggiero (2000) has noted the importance of both approaches to the $U \& G$ perspective. The methodology most often utilized in $U \& G$ studies is quantitative in nature; the researcher compiles a list of previously found motivations and applies them to the medium under investigation (Parker \& Plank, 2000; Papacharissi \& Rubin, 2000; Flanagin, 2005; Quan-Hasse \& Young, 2010). Using predefined gratifications can pose a risk when examining a new and evolving medium, as this practice does not allow for original, unique, and formerly undefined gratifications to emerge. The second approach, which is less often used in $\mathrm{U} \& \mathrm{G}$ research, is a qualitative approach. This exploratory investigation better allows for spontaneous findings to occur (Nardi et al., 2004; Kaye, 2010). A medium - such as fashion blogs - which has had little or no U\&G examination because of its early stage of development as a medium, is better examined through an exploratory, qualitative approach. This study attempts to discover and classify the leading uses and gratifications of fashion blogs, without using a limiting gauge made up of previously found factors. Therefore, an initial exploratory questionnaire and subsequent in-depth interviews have been used to examine unique and unidentified motivations of fashion blog use.

The results from the online questionnaire informed the second portion of this study by identifying emerging patterns and themes within the broader motivations for using fashion blogs and fashion magazines from the users' perspectives. The online questionnaire also acted as a screening process for potential participants for the primary investigation portion of this study. Respondents to the questionnaire were given the opportunity to leave their name and email address if they wished to participate in the second part of the study, the in-depth interviews. 


\section{Respondents}

This study set out to examine the uses and gratifications of women's fashion magazines and fashion blog users. The sample studied, consisted of women, between the ages of 18 to 35 , who currently reside in Canada. In order to qualify, participants had to have a self-reported interested in fashion, fashion blogs, and fashion magazines.

The Consume Magazine Fact Book 2012, published by Magazines Canada, has found that home and gardening magazines and women's magazines have the highest average issue circulation in Canada, after general interest magazines. Further, this report identifies that the highest demographic of magazine readership in Canada is 12 to 34 year-olds, with $88 \%$ of those between the ages of 18 to 24 and $87 \%$ between 25 to 34 year-old indicating magazine use. Vogue's readership is $86 \%$ women, with an average age of 35 (Condé Nast Vogue media kit). Similarly, over $50 \%$ of ELLE magazine's readers are between the ages of 18 and 34 and $88 \%$ of this magazine's readership are women (Elle media kit).

Breaking Media, the company that owns the fashion blog Fashionista.com states that $75 \%$ of Fashionistas' readers are between the ages of 18 to 49 years old. The International Fashion Blogger's association, which was founded in 2007 by Jennine Tamm, has an extensive website and community of bloggers who are largely female and feature female fashion content. Understanding the motivations of fashion blog users means understanding the consumption behaviours of a largely female audience base.

By limiting the age range of participants to 18 to 35 years-old, the study is able to focus on an age group which makes up a vast majority of fashion media consumption. In addition, it allows for a target audience that is familiar with the internet and has used the internet on a daily basis for a great deal of their life. This familiarity with the Internet allows for an unbiased 
opinion of fashion blogs as compared to print magazines. The decision to solicit and recruit participants via the Internet (email, Twitter, and Facebook) was made to specifically target a sample population familiar and comfortable with the Internet. This study sought to investigate fashion blog users and therefore it was necessary to recruit participants who read both fashion magazines and fashion blogs. Since the focus use is on the Internet it is appropriate that the method used to recruit participants took place online. The target audience being interviewed for this study has an interest in fashion media and has a self-reported high use of fashion blogs. Therefore, the sample will be made up of women who already have an interest in fashion discourse and regularly use the Internet.

\section{Procedure for Questionnaire}

This study employed a two-step exploratory research design. The first step consisted of an online questionnaire (Appendix 1), which consisted of three distinct categorizes aimed at collecting a general understanding of users' motivations for using blogs as compared to print magazines. The Ryerson Research Ethics Board approved the study in two steps. An application was submitted first for the approval of the online questionnaire (Appendix 4), and after that portion of the study was complete, another application was submitted and approved for the second portion of the study, the in-depth interviews (Appendix 5).

The questionnaire was intended to identify users' basic opinions about reading fashion blogs and fashion magazines, as well as their beliefs about the two media's purpose, value, and credibility. This questionnaire was administered online. The survey host, Opinio, was accessed through Ryerson University. A link to the online questionnaire, hosted on opinio.com, was distributed via email and social media platforms (Twitter and Facebook); a description of the 
research study and requirements for potential eligibility accompanied the survey link. A waterfall approach was used in order to have the questionnaire distributed broadly; therefore, it is unknown exactly how many invitations with links to the online questionnaire were sent out via email and social media platforms. The first page to appear, after clicking on the link, was a consent form. During both portions of the study users were notified that they could quit at any time. Participants had to click on the 'agree' button in order to advance to the qualifying questions. The qualifying questions consisted of demographic information. In order to take part in the questionnaire, participants had to identify themselves as female, age 18 to 35 , and currently residing in a Canadian city. If a respondent did not meet these requirements then they were unable to proceed and participate in the research. The questionnaire was open from November 14, 2012 to December 12,2012. Of the 418 links that were opened, 274 online questionnaires were completed. The responses were analyzed by the Opinio software, which provided respondents' answers in percentages.

Of the total 274 questionnaire respondents, 64 provided contact information. A selection of ten potential participants was chosen based on reported demographic information and answers in the preliminary questionnaire. Those who reported high usage of fashion magazines and fashion blogs were selected as potential participants. They were recruited, via email, to participate in the second portion of this study.

\section{Measurement for Questionnaire}

The questionnaire was designed using both a 5-point likert scale, ranging from 1 (strongly disagree) to 5 (strongly agree), and a multiple-choice model, with the number of available answers ranging depending on the question. The 36 questions were divided into three 
sections aimed at illuminating general users' trends in three distinct areas (Appendix 1). The first area focused on fashion magazine use. A 'fashion magazine' is defined, for the purpose of this study, as a consumer magazine featuring primarily fashion and beauty content in print format, such as (but not limited to) Vogue, Elle, or Flare.

The second portion of the questionnaire focused on fashion blog use. For the purpose of this study fashion blogs have been defined as a website, frequently updated in reverse chronological order, and primarily featuring fashion related content. There are several different types of fashion blogs. Personal blogs, style blogs, and professional blogs could be an acceptable classification system for the endless number of web-based, fashion dialogues that may be accessed on a regular basis. The personal and style blog classifications would fall under individual blog, whereas the professional fashion blog could be considered a corporate blog. The categories of individual and corporate were recognized by Rocamora (2010) as an acceptable classification for fashion blogs. The personal blog is one in which the blogger uploads daily photos of the outfits they are wearing along with a description of their personal style choice and day-to-day life. Atlantic-pacific.blogspot.ca, bjonesstyle.com, and karlascloset.com are all appropriate examples of 'the personal fashion blog'. Style blogs are a collection of photos, inspirations, lookbooks, etc. that the blogger has sourced and chosen to include in their blog. An appropriate example of this type of blog may be manrepeller.com or becauseimaddicted.net. The professional fashion blog can be defined by a blogger who works for a recognizable company and is blogging for that company. For example, Fashionista.com has an editorial staff that updates the blog daily and is employed by Breaking Media. It is somewhat difficult to stringently classify fashion blogs as they are malleable, constantly evolving, and fluctuating in the type and amount of content they feature; however, this classification system acts as a decent guide. 
The third section of the online questionnaire compared and contrasted fashion blogs and fashion magazines. This section aimed at gaining a greater insight into users' opinions of the two media when considered simultaneously. This section of the questionnaire attempts to determine the differences in uses and gratifications of fashion blogs and print fashion magazines.

\section{Procedure for Interview}

The principal research for this study was conducted through in-depth interviews. The exploratory interviews were open-ended and structured around four primary research questions. The interviews lasted between 15 and 40 minutes per respondent. Respondents' answers to initial questions led to probing questions by the researcher. In order for respondents to feel comfortable and uninhibited, the interviews were loosely structured and allowed for conversational aspects to occur. The interviews were held at Ryerson University and audio recorded. Respondents were compensated for their time by being entered into a draw for a $\$ 100.00$ Holt Renfrew gift card.

\section{Measurement for Interviews}

The interviews were audio recorded, from these recordings the interviews were transcribed and analyzed. Patterns and themes that emerged through respondents' answers were grouped into categorizes and rated based on how many times the motivation was mentioned. The interviews were structured around the following research questions.

RQ 1: What are the Uses and Gratifications of fashion blogs?

RQ 2: Do fashion blog users report using fashion blogs as an alternative to other communication channels?

RQ 3: What are the most important parts of 'the fashion blog'?

RQ 4: What is the duration and frequency of fashion blog use? 


\section{Results}

\section{Questionnaire Analysis}

The online questionnaire went live on November 14, 2012 and closed on December 12, 2012. It was open to the public for nearly one month; during that time, 418 people opened the link to the questionnaire, and of the questionnaires opened, 274 were completed. The 61 that were opened and not completed are attributed to participants not meeting the qualifying questions. The qualifying questions were:

A. Age (participants were required to be between 18 to 35 years old).

B. Gender (participants were required to identify as female).

C. Country of residence (participants were required to, at the time the survey was completed, be residing in Canada).

D. The final qualifying question determined whether participants were familiar with both fashion blogs and fashion magazines. This question asked whether they had read a fashion blog and fashion magazine in the past year, if they had not, then they were unable to complete the survey.

Three quarters of the questionnaire respondents were between 18 and 23 years-old (75.57\%). The 36 questionnaire questions were split into three sections and dealt with fashion blog uses and beliefs, fashion magazine uses and beliefs, and a compare/contrast of the two media.

The questionnaire revealed that, on a daily basis, participants were more likely to read a fashion blog than a fashion magazine. The questionnaire found that participants did still read magazines; however, this did not take place as frequently as blog use. The findings support framing this study with the concept of remediation and the belief that new media technologies supplement rather than succeed traditional forms of media. In order to find out more about how 
fashion blogs are used in addition to magazines, this questionnaire prompted the in-depth interviews to investigate, specifically, the uses and gratifications of fashion blogs.

Participants were more likely to read a fashion blog than a fashion magazine when they had free time. Using a likert scale, $14 \%$ of participants agreed or strongly agreed that they read fashion magazines instead of taking part in other types of leisure activities. Comparatively, 28\%, double the amount of participants, agreed or strongly agreed that they would read a fashion blog instead of taking part in another type of leisure activity. This could potentially be attributed to the finding that over half the participants (64\%) either agreed or strongly agreed that they will visit a fashion blog when they have gone on the Internet to do something else.

\section{Content}

Both media were reported to be used 'to find out what is in style.' Fashion blogs scored slightly higher; $60 \%$ of participants agreed or strongly agreed that they look at fashion blogs and $55 \%$ agreed or strongly agreed that they look at fashion magazines to find out what is in style. Participants were able to agree/strongly agree to using both media, as this motivational factor was examined using a likert scale format. However, when answering a multiple choice question, $47 \%$ of respondents said that they were more likely to 'mimic' an outfit that they saw on a fashion blog, while only 19\% said they were most likely to 'mimic' an outfit from a fashion magazine. In terms of the content that is featured in each medium, 52\% of participants agreed or strongly agreed that fashion blogs feature original context. A slightly less proportion of participants, $41 \%$, said that magazines feature original content. When asked what was similar about fashion magazines and fashion blogs, $32 \%$ of respondents said nothing was similar, another $35 \%$ said that the photos were often similar, and only $22 \%$ said that they found the written articles to be similar. 


\section{Context of Use}

A large divergence in the use of the two media was reported in the contexts in which they are used. Almost three quarters, $72 \%$ of respondents said they are more likely to read a magazine while on a vacation than a regular week at home. Whereas, only $13.5 \%$ of respondents said that they are more likely to look at a fashion blog while on vacation than a regular week at home. It was also found that fashion magazines were very unlikely to be read in the morning. While 50\% of respondents stated that they would read a magazine in the evening, and $45 \%$ said they would read a magazine during the day, only 5\% indicated that their use would be in the morning.

\section{Credibility}

In terms of perceived credibility, $45 \%$ of respondents said they agree or strongly agree that fashion magazine writers are a more credible source than fashion bloggers, while $34 \%$ did not have an opinion (felt neutrally). There were, however, a more significant percentage of participants $(70 \%)$ who agreed/strongly agreed that editors and magazine writers have access to more exclusive products than bloggers do. When it comes to reading fashion related articles, almost $40 \%$ said they equally enjoy reading articles written by a fashion blogger or fashion journalist. Following this, $34 \%$ prefer to read an article written by a journalist and $21 \%$ prefer to read an article written by a blogger. Users' beliefs about the motive behind the creation of each medium were found to be quite different. Almost $82 \%$ of participants said that fashion magazines have profit drive motives, whereas only $13 \%$ of participants said that fashion bloggers have profit driven motives. Clearly, the respondents perceived the motive for creating each medium to be quite dissimilar. More then $85 \%$ of participants said that fashion magazines rely most heavily of advertisements and $60 \%$ said that magazines also rely more heavily on industry collaborations. 


\section{Fashion Bloggers}

Just over $70 \%$ of respondents strongly disagreed or disagreed with the statement, 'anyone can be a good fashion blogger.' A large portion of fashion blog users thus credits fashion bloggers with having some sort of skills, talents and commitment to their blogs. Respondents also agreed or strongly agreed (65\%) that bloggers have been accepted into the fashion industry, an industry that has traditionally been deemed ultra-exclusive. Further, $66 \%$ of participants agreed that bloggers help make the fashion industry more transparent and inclusive. Around half of the respondents (51\%) said that they usually click on links that the blogger has posted to other websites.

The findings from this questionnaire suggest that consumers of fashion media spend time using both fashion magazines and blogs, but on a daily basis, use fashion blogs much more frequently. They were twice as likely to read a fashion blog than a fashion magazine instead of partaking in another form a leisure activity. It was also found that users of both mediums reported that they were more likely to 'mimic' an outfit they saw in a fashion blog, suggesting that the content is more closely related to their own self-view. While participants did not agree with the statement 'anyone can be a good fashion blogger' they did indicate that they believe the motive for creating and maintaining a fashion blog is unlike a magazine. Eighty-two per cent of participants said that magazines have profit driven motives whereas only $13 \%$ of respondents said the same about fashion bloggers. Their opinions of the content creators are thus divergent. In a question that could infer that magazine use is linked to relaxation, $72 \%$ of respondents said they were most likely to read a fashion magazine while on holiday, whereas only $13.5 \%$ said the same thing about fashion blogs. 
On the surface it can be presumed that both fashion blogs and fashion magazines fulfill the same needs - to disseminate fashion related content. The reader flips from side to side through a magazine and similarly scrolls from top to bottom through a blog. The blogger curates content, much like an editor of a magazine would do, and they present that given content with a focused point of view. Yet, this questionnaire clearly established that users approach each medium with distinctive expectations, specific sought gratifications and dissimilar beliefs about the medium. This led the researcher to further investigate the uses and gratifications of the fashion blog specifically. The second portion of this study, the in-depth interviews, attempts to establish a primary set of uses and gratifications of fashion blogs. As the newer and less studied of the two mediums, it is imperative that a useful understanding of how users approach fashion blogs be established, in order to illuminate how both media are used simultaneously and for what separate needs they gratify.

\section{Interview Analysis}

\section{Respondent Profile}

All interviews were conducted with women who had previously participated in the online questionnaire. The women all currently reside in Toronto or the GTA and are between the ages of 19 to 31 years-old. (Of the ten participants one was 19, one was 20,2 were 21, 3 were 23 , one was 28 , and two were 31 ) The participants are highly educated, with many reporting to be in university and graduate programs. In order to qualify, they had to self-identify as having an interest in fashion; however, they do not work in the fashion industry. They were invited to participate in the interview portion of this study based on their report of their own fashion blog use. All participants indicated that they had moderate to high fashion media consumption. 


\section{Motivations for Using Blogs}

The most highly reported reasons for using fashion blogs were found to be 'for information about a specific interest (fashion and style), 'because blogs are more personal', 'because it is part of my daily routine', 'to look at fashion images', 'because I am directed to updates' and 'for inspiration on how to dress'. The weakest reported motivations for using fashion blogs were found to be 'for information for my own blog', 'to make fun of others', 'to feel efficient' and 'because of environmental reasons'. All 24 motivations identified are listed in Appendix 2.

The 24 motivational factors that were identified during the in-depth interviews have been categorized into four factor categories for fashion blog use. These are F1. Accessibility and Convenience of Information Seeking, F2. Blog Attributes, F3. Personal Gain, F4. Escapism and Enjoyment (Appendix 3).

\section{Accessibility and Convenience of Information Seeking}

Fashion blogs provide users with a breadth of information on a specific area of interest, which is easily found and retrieved. For many of the subjects interviewed, viewing fashion blogs was part of their daily routine. Their use was reported to be very quick, a fast skim of the 'top' or newly added posts (aka. information). Over half of the participants acknowledged that they would visit a fashion blog because they were prompted to, either by an update on a social media site, a daily email, or because a RSS feed (like Google Reader) had indicated an update. Users are notified about updates throughout their daily computing activities, which speeds up the immediacy and increases the convenience with which they can obtain information. Seven of the ten participants 
interviewed noted the frequency with which blogs are updated and/or the overt accessibility of content as leading motivations for use.

\section{Blog Attributes}

Users recognized specific qualities of the fashion blog; seven of the ten respondents stated that fashion blogs are 'more' personal than other forms of fashion media. They feel a greater connection with the blogger and identify the stylistic content on fashion blogs as being attainable. A large portion of participants reported that they use the fashion blog as a way to retrieve and store inspirational content. These users remove content from the blog's context and save/store the (almost always) images on their own computers. As an online source, fashion blog users recognize the ability to extract useful content for their own personal use. It was also frequently mentioned that the blog content was free and thus they did not have to spend any money for the information they desired. Fashion blogs possess distinctive properties that users are aware of and appreciate.

\section{Specific Inquiry}

The fashion blogs provide users with specific information that is deemed useful to their daily lives. It was common for interview subject to mention looking at blogs' content when they were having trouble deciding what to wear or struggling with their own wardrobes. The fashion blogs provide outfit inspirations and allow users to approach their own closets with a new perspective. Users also expressed validation when they saw a style they were interested in or wore themselves being reflected on the fashion blogs. Many users also mention viewing fashion blogs for instructional D.I.Ys. These qualities of the fashion blog attribute to users' personal fulfillment.

\section{Escapism / Enjoyment}


Many users stated that they often use fashion blogs to view images. They described the fashion images as beautiful and enjoyable to look at. Some respondents identified their use of fashion blogs as a way to balance depressing/upsetting news stories. It was common for respondents to state that they enjoyed looking at fashion blogs and the images. Users look at fashion blogs to battle boredom. They also use fashion blogs while watching television, in order to feel as though they are completing more than one task at a time, or in other words to feel efficient. 


\section{Discussion}

RQ 1: What are the Uses and Gratifications of fashion blogs?

This exploratory study set out to identify the uses and gratifications of fashion blogs without using any previously determined gauge. The in-depth interviews allowed for unique factors that had not formerly been determined for blog use to emerge. Twenty-four motivational factors were identified in this study. These motivational factors have been organized into four main categories. The larger categories, which are made up by a range of found motivations, are Accessibility and Convenience of Information Seeking, Blog Attributes, Specific Inquiry, and Escapism/Enjoyment (in order of strength). This first category is the same one that was determined by Kaye (2010) for the use of blogs (not specifically fashion blogs, but rather, blog use in general). This category explains that the primary motivation for using blogs is because they are convenient for information seeking. Kaye (2010) found 14 specific motivational factors that made up this category. This study found that six strong factors make up this category for fashion blog users. Two of the factors identified in this study, habit (because it is part of my daily routine) and entrance (because updates are directed to me), were not identified in Kaye's (2010) list of factors. These unique motivations may thus be distinct to users of fashion blogs and have only emerged through this study, which specifically examines the uses and gratifications of fashion blog users. The other three categories identified in this study (Blog Attributes, Specific Inquiry, and Escapism(Enjoyment), while not necessarily named alike, were also identified in some respect in Kaye's work (2010). In some cases, similar motivations were found, but they were uniquely described and explained by participants in relation to the content of fashion blogs.

For example, the second most salient category identified in Kaye's study (2010) was 'antitraditional media sentiment,' which was made up of factors such as, 'to expose traditional 
media for bias, to avoid conservative media bias, and to expose traditional media when they make mistakes,' these are just the first three factors of 9 in this category. These factors did not arise in the open-interviews with fashion blog users. However, motivations like, 'because blogs are more personal and feature content that is more attainable than fashion magazines' did surface. These motivations for fashion blogs use also serve as alternatives to traditional media but specifically to traditional fashion media, which carries its own specific qualities.

One other unique motivational factor that was not identified by Kaye (2010) is the ability to retrieve/save content. The three unique factors that were found in this study, habit, entrance, and retrieve/save content, were among the most salient reported motivations for fashion blog use. They work to explain the remediation of the current fashion media landscape. The users' actions illuminate the notion that new media, in this case 'the fashion blog,' does not supersede older media, such a print magazines. Rather, it acts as a supplementation, gratifying needs that print magazines cannot, while simultaneously emphasizing the characteristics specific to print magazines.

RQ 2: Do fashion blog users report using fashion blogs as an alternative to other communication channels?

RQ 4: What is the duration and frequency of fashion blog use?

(Both of these research questions are answered by the discussion of the following found motivational factor)

\section{Habit}

Almost every participant identified her fashion blog use as a daily practice. Often the use was reported to be short in duration. Blogs are often updated daily, so users will only be 
checking the blog in order to view the latest post. The daily skimming of fashion blogs could take place either in the morning, as participant 7 has stated, or in the evening, or between classes, depending on the respondent's personal schedule. What was uniform in responses was that fashion blogs were used quite frequently for short amounts of time.

Participant 3: "I spend about ten to twenty minutes [on a blog], it's a short amount of time because I check it everyday so there isn't too much new on a day-to-day basis." Participant 7: "I check [blogs] at least once a day. It's part of my morning ritual of Interneting before getting to serious work."

Participant 5: "It's part of my morning routine. I get up, check the weather, look at the news, and check my fashion blogs..."

The immediacy of blogs was highly valued in respect to the daily, rapid use. One participant noted that the quick, convenient access to information complimented her fast-paced life.

Participant 1: "I like that they are sort of part of our culture of convenience-I like that I can you know feed my fashion curiosity within one minute if I want to...It's nice to get a fix everyday."

This motivational aspect resonates with what Rocamora (2012) has explained about the influence of the blogosphere on time. Where fashion was once dictated by seasons "and the monthly publications of glossies, now fashion has accelerated, fragmented into a series of moments that have shattered its orderly pace" (Rocamora, 2012, p. 97). Bloggers' daily updates document the 'newest' in fashion, on a schedule that is no longer dictated by seasons, months, or even days, but hours. This 'culture of speed' is perpetuated and satisfied by blog use, which upholds the 'tyranny of the new' all the while crafting an addiction for the latest nugget of information. The fashion 'fix' as this participant has described it, is one that, like many drugs, fades fast. Within 24 hours, users will be back, skimming new blog posts. The blogosphere immortalizes fashion as transient. 
One respondent even noted that she is deterred from looking at a blog if there is a long article. She would rather not take the time to read the entire post and worries that there may be valuable information, but if it is not presented in bite sized, straightforward, quick updates, she will not read it.

Participant 8: "If it's a really long article I won't necessarily finish it all so...they could have some really good information but it sometimes distracts people from reading it all."

Fashion blogs are used to absorb the most amount of fashion content in the shortest amount of time. This was reaffirmed by other participants who credited the accessibility of fashion blogs and ability to quickly receive a small amount of information at anytime as an important aspect of the medium.

Participant 10: "I like that you can see trends instantly as they're happening online...if someone posts a look today, I can imitate it tomorrow."

Participant 6: "I like having it at my fingertips all the time because I can look at them [fashion blogs] on my phone or on my computer."

Magazines were reported to be reserved for occasions when a greater length of time could be devoted to reading them. Magazines would be read in either print form or downloaded to an iPad; the digital aspect did not affect treatment. It was more often just a personal preference to viewing either in digital form or traditional print. Participant 5 and 7, who both said they read fashion blogs "about once a day," also said that they still prefer to read magazines in a print format.

Participant 5: "It's [print magazines] so much more tactile, it's got all the tactile feels to it and it's more relaxing. A lot of people have said that being online you're in more of a work perspective and when you have the print you're more relaxed-you can take it in the tub or on the couch with you."

Participant 7: "I guess they [print magazines] carry a different kind of relaxation, because I work so much on my computer, it's so hard for me to enjoy and relax using my computer so my habits change a lot when I pick up a print copy and I'll have a glass of tea or wine." 
For these participants, it was important to be able to remove themselves from a digital screen in order to fully relax. Their comments echo the findings of Brita Ytre-Arne, who argued “...readers strongly prefer magazines in print” (Ytre-Arne, 2011,p. 467). What this study has found is that even if users do prefer reading magazines in print, they still consume fashion blogs on a daily basis. Each medium satisfies two very different needs; blogs are used for an immediate, quick, and convenient way to access fashion content on a daily basis, whereas magazines are consumed for pleasure, to escape, and relax. For some, being in print is significant in order for relaxation. However, not all respondents in this study acknowledged that type of phenomenological importance. One respondent, who said that she gave up reading print magazines a couple of years ago after 'becoming more aware of the environment,' said that she felt bad throwing magazines away.

Participant 4: "There is this website called PDFgiant.com and it's all print magazines but they're in PDF form so you can put them on your iPad. I do read magazines but I read them in a different format and I get them for free-but I only really do that when I actually have time to read."

This respondent said that the only time she reads magazines is when she has enough free time to spend with it and enjoy reading it. This was the common notion towards magazines, regardless of the format, they were used for relaxation. Many respondents also noted that the price of magazines deterred them from using them more frequently.

Participant 6: "I have subscriptions to magazines but they were gifts. I can't afford it on my own and when it comes a time when nobody has given me those as gifts I can't afford to keep buying magazines because it's expensive."

Other respondents echoed this notion, saying that they would purchase a magazine as a 'special treat'; one said that she only buys a magazine once a year, the coveted September issue. Reading the magazine in digital form did not mean that it did not carry the same type of leisure and entertainment. There was always an association with fashion magazines as being a form of 
relaxation. This finding is supported by the initial questionnaire, which found that almost three quarters, $72 \%$, of respondents said they are more likely to read a magazine while on a vacation than during a regular week at home. The magazine is read on vacation for enjoyment, to relax, and take time away from daily routines. The questionnaire also found that only $13.5 \%$ of respondents said that they are more likely to look at a fashion blog while on vacation than a regular week at home, significantly less than what was reported for magazine use while on holiday. This medium is only used when the reader has a significantly longer amount of time to spend with it. It was reported that magazines are often consumed in whole, in one or two sittings. There is a definitive beginning and end; it is a static entity, whereas blogs continue to be updated in small amounts on a daily basis. The consumption of fashion blogs thus takes on a daily, ritualized form. There is no clear end to the fashion blog, it continues to speed up the fashion cycle with every new post and users consequently consume fashion on a non-stop basis, expecting the fleeting trends to change and evolve with every passing day. Fashion blogs were not reported by respondents to be used in this same way as magazines. Rather, they provide convenient, fast, and accessible access to fashion content. Fashion blogs were considered by users as a quick informational update, whereas magazines were reported to be used only a few times a year and for much longer periods of time.

\section{Entrance}

Another unique motivational factor found for the use of fashion blogs is the way the blogs are entered. Like daily use, almost all respondents mentioned this factor and it falls into the leading category, convenience and accessibility of information. The users are prompted to visit the fashion blog because of updates via other forms of social media. For example, it was reported 
that a user might be looking at Twitter or Facebook and a link advertising a new blog post will appear on their feed. They will then click on the link from the social media website and be redirected to the blog post.

Participant 3: "If they [bloggers] have some feeds on Facebook, if it's interesting then I will click on it from Facebook and link to the blog. So usually the blogs have other entrances, they have Facebook and Twitter, and I will check every time when they come up on my wall."

Participant 8: "I will visit them [blogs] often cause they're just in my reader. I like to look at the odd things that will pop up on my Facebook wall."

This particular form of hyperlinking has not yet been identified in the scholarly literature on fashion blogs. While Rocamora (2012) does identify hypertextuality as the primary difference between magazines and blogs, she refers primarily to the hypertextuality within and between blogs. As she refers to it as, 'a form of citation' where the proverbial rabbit hole of information is endless, clicking on one link may bring you to another page of information and so on (Rocamora, 2012). What has been identified in this study is the motivational factor for accessing a fashion blog. This factor, which has been labeled entrance, is reliant on a how a blog post is brought to the user's attention and thus the reason they visit the fashion blog. In this sense, the linking takes place through social media or, as will be discussed below, through RSS feed readers and news aggregators. This factor is responsible for explaining continued use and perhaps even illuminates, to some extent, why fashion blogs are visited so frequently. The finding from the questionnaire, that over half the participants (64\%) either agreed or strongly agreed that they will visit a fashion blog when they have gone on the Internet to do something else, supports this factor.

The users have already identified a blog that interested them and so they decide to 'follow' that blog via a social media platform. Participants in this study mentioned Twitter and 
Facebook as being places where links initially get their attention. When a notification appears on social media, with a link to the blog, users are prompted to visit and read the blog.

Another variation of entrance was found to be through RSS feed readers. RSS feed readers are applications that can be used to organize and search through websites' updates. A popular example is Google Reader, an application created in 2005. The platform works by users 'subscribing' to websites; one way of doing this is entering the site's URL and then the reader will notify when an update has been made to that particular website. Items can be organized in many different ways and labeled.

Participant 4: "I put everything [blogs] onto my Google reader so I have like 70 different blogs and they kind of all mash together... and I try to sort of pay attention to which blogs I like more and then which ever ones I like less then I'll get rid of those. I'm just trying to constantly curate it so it's stuff that I'm always interest in."

Another form of this practice, albeit less productive, is receiving updates by email, as one participant noted.

Participant 1: “They email me their updates so that's why I go everyday because it'll come into my inbox."

The users have already 'followed' the blog, either on social media or by adding the blog's URL to a RSS feed. In a way, we may consider this 'subscribing' to a particular blog similar to a subscription to a magazine. These alternative ways of entering the fashion blog, means that the users don't actively think about visiting the blog, rather they do other things online and when a notification pops up, they visit the blog. Another participant mention Pinterest as a way that she enters blogs.

Participant 10: "I often spend most of my time looking at photos so I prefer to use Pinterest which redirects me to specific posts on the blogs." 
The particular act of 'pinning' in which a user can click on an image on a website and save that image to their own personal account overlaps into another unique motivational factor of fashion blog use found in this study, which is retrieving and saving content.

RQ 3: What are the most important parts of 'the fashion blog'?

\section{Retrieve and Save Content}

The digital aspect of blogs facilitates a saving and organizing of information and content that other forms of media do not. Thus, the motivational factor of retrieving/saving content emerged in this study. This unique factor was not found in the uses and gratifications studies of blogs in general (Kaye, 2010). This is likely because of the unique aspect of fashion blogs, which is that they are made up largely of images. Many of the participants said that they primarily visit fashion blogs to look at images.

Participant 4: "The primary reason I use [fashion blogs] is to look at photos...I don't really read what they write. I don't really read about why they were inspired to wear a tiger hat with a snake skin shirt-like I just don't care why."

Participant 5: "Her photos are always really nice, so that's what I'm primarily going for-for the photography element."

Participant 7: "To look at things that are pretty and make me feel like the world might be okay."

Participant 8: "It's a more visual way of understanding."

In this way, fashion blogs differ greatly from other cultural blogs that contain more written content. For example, the street style blog, The Sartorialist was mentioned by over half of the participants as one of their favourite fashion blogs. The Sartorialist features little to no written content. It is made up solely of the street style images of unknown fashionable pedestrians, which Scott Schuman, the blogger, takes on the streets of cities around the world. The fact the people photographed are 'average' and unknown is what many of the participants said drew them to this particular blog. In a multiple choice question in the preliminary questionnaire, $47 \%$ of 
respondents said that they were more likely to 'mimic' an outfit that they saw on a fashion blog, while only $19 \%$ said they were most likely to mimic an outfit from a fashion magazine. Through the in-depth interviews it became clear that users identified more closely with images on fashion blogs and often used these images for personal style inspiration.

The motivational factor that emerged in the interviews was the ability to remove the images from the blogs and store them on their personal hard drive or in a personal virtual folder. This act is distinct to the highly visual quality of fashion blogs. The factor has not been recognized by any of the other research on fashion blogs. Many users explained that they like to revisit the images for inspirations, either for inspiration on how to dress or for other areas of their life, like artistic endeavors. Those that mentioned using the photos as inspiration for approaching their own wardrobe, such as participant 7 , also indicated that they valued that the people being photographed were 'regular' and that their styles were 'accessible' and 'things I could see myself wearing,' Many of these participants explained that they save images and store them on their own personal desktop for future reference.

Participant 4: “Also what I do too is I'll save images and file them...so I'll save images and that's what's really nice about doing anything online is that you can just drag and drop right away."

Participant 7: "I have a file on my computer that if I see an image that I really like-like on The Sartorialist-I'll click and drag it and I have this one file that if I'm having a hard time deciding what to wear I'll go to it and I'll mimic certain things."

This obtained gratification, to retrieve/save images, was described (by participant 4) as the ability to 'drag and drop' - a quality of the Mac operating system in which an image can be dragged into a folder and it will be saved there. In this process the users remove the images from the context of the blog. The images are appropriated to the users' own 'inspiration folder'. This same process is undergone on the social media site Pinterest. Participants reveled that they 'pin' and therefore save an image that they like to their own Pinterest boards (or folders). 
Participant 1: "I'll pin things on fashion blogs and that is something I obviously can't and won't do with print. With magazines I'm just seeing things and trying to remember them, I'm never going through the magazine and cutting things out. So, ya I like to do the pinning thing."

Participant 10: "Sometimes I pin something interesting I've found."

By doing this, users can easily return to and look at a specific image they have seen. This motivational act is interesting because it means that the visuals are removed from their original context. One participant even acknowledged (when talking about blogs that feature runway looks) that prefer to view fashion images stripped of any contextual references.

Participant 4: "Often with magazines it's like put into a situation where you're sort of persuaded to feel a certain way about a product... [on fashion blogs] not only do you get to see it right away...but it's not put with other items, it's not overly styled in any way or put on backgrounds, it's just raw, it's just the look."

The ability to remove the image from the context of the blog permits users to impose their own perspective on the fashion image. Arranging images into folders, one participant stated, "I probably have about 30 different folders," means that the users make their own judgments about the content by rearranging and re-contextualizing the blogs based on their personal opinions. The fashion images, thus, continue to evolve even after they have been posted online. 


\section{Implications of Research}

The tension between fashion journalist's of traditional print publications and bloggers would suggest that both media are competing for the sole attention of users. Yet, each medium creates a different product and satisfies different user needs. This study has found that fashion blogs are consumed as a matter of convenience and accessibility. They are part of the "culture of immediacy' in a society addicted to instant information; the fashion blog fills this void for those searching for constantly updated fashion media. The fashion magazine is a static entity; this study found that its primary purpose is to satisfy the need for relaxation. It is used to unwind, slow down, and be entertained. Whether in digital or hard copy, the magazine services the same sought gratifications. They are produced and published slower, they maintain rigorous editing, offer a more thoughtful perspective, and users appreciate these qualities. However, these aspects do not support the type of daily update of information that can be shared on a blog. Thus, both media gratify different needs for the user. Publishers of traditional magazines can use these findings when approaching their own content. The readers interviewed in this survey noted that they do not buy a print publication very often, most said they will only do so a couple of times a year and treat it as a coffee table book. In a radical approach, magazines could slow down their cycle of publication, to combat the speed at which information is disseminated online. Longer, more-in-depth researched stories and packages could be offered in a quarterly magazine. Some newer publications, such as Bullet media already follow this cycle. They have a quarterly print publication and then offer all their other content online through daily posts. Readers of Bullet can therefore gratify the needs offered by both media.

The expected daily posting of new fashion content on a blog perpetuates the speeding up of the fashion cycle. This study found that users value the accessibility of rapid and constant 
updates, which subsequently encourages bloggers to continue producing content according to this expeditious cycle. This found motivation resonates with the contention made by Rocamora (2012) when she asserts that, "in the field of fashion newness was once restricted to a twiceyearly event, it is now a permanent present, a situation the Internet has fed off and sustained" (Rocamora, 2010, p. 97). This transient aspect of the fashion blog does contrast with fashion magazines as indicated by Rocamora (2012), which maintains the practical implication of producing, less frequently, a whole and complete object. For bloggers, this may mean that the starting place, which once may have been print, is increasingly online. It is much more affordable and accessible for interested parties to begin a media venture online. As noted previously, with the international success of a blog comes the potential to produce in print, a lasting and more valued static object. This publication would thus be treated by the users similarly to a magazine, as found in this study, which means reserved for a time when substantial attention can be focused on the content. This study also identified that fashion blog use is highly associated with visual imagery. The importance of visuals to the success of a fashion blog is an extremely significant aspect. It should also be noted that those visuals can expectedly be removed from the context of the blog and re-purposed by the users. The motivation factor retrieve/store content should illuminate to bloggers that their users do not interact with the given content simply as it appears on the blog, but rather manipulate those images and store them for their own personal use. It could be necessary for a blogger to watermark their original images in order to preserve credit for the creative property. This act is somewhat contrary to the hypertextuality of the blogosphere as identified by Rocamora (2012). While the Internet supports and promotes the interconnectivity of websites and information, the removal of the content form the Internet altogether removes it form the 'citation' system fostered by hypertextuality. The 
content is stored on individuals' computers and may even be reused and uploaded again to the Internet without referencing the original source.

This study also identified that users of fashion blogs appreciate shorter posts. They value the ability to quickly read the new information; fashion blogs are associated with fast, speedy access to up-to-date information. In order to better satisfy this need or sought gratification, bloggers can mindfully provide written content with a specific approach. As stated previously, more in-depth articles may be reserved for a more highly curated publication that is produced with a distinct beginning and end, whether it is available in PDF version to be read on a tablet or in traditional print. As it was found that many fashion blog users access new posts via social media channels, a highly active social media presence can be attributed to fashion blog success. Once a reader is introduced to a fashion blog, their continued use, as this study found, could be accredited to that site's ability to advertise new blog posts. These advertisement links are viewed and clicked on through social media websites. A significant presence on Instagram, such as one held by The Coveteur, caters to the important highly visual aspect and social media presence imperative to the success of a fashion blog.

Other responses to the increasing rapid cycle of the fashion industry, perpetuated by the way fashion blogs are used, could be a rebellion by the garment producers. Instead of adhering to the progressively hurried fashion cycle, by producing, for example, pre-fall or resort collections, designers could return to a twice-yearly collection cycle. This is a very simplistic solution to a changing industry that has been impacted only in part by new fashion media and therefore this implication is only suggested as a starting point to a discussion and not necessarily meant to be interpreted too unequivocally. 
The title of this study, Fashion 2:0, denotes the interactive nature of the fashion blog. The term 2.0, which is largely associated with Tim O'Reilly, signifies the development of webpages that facilitate participation by the user, for example, by way of interconnectivity. It was found in this study, that users interact with the blog in a way that has previously been unexplained. Instead of commenting on a post, users interact with the content by retrieving and saving the images they find most inspiring. They interact directly with the content by re-contextualizing the fashion images in their own folders and work. The ability to easily remove and digitally organize/store the most pertinent information and images is a highly valued aspect of fashion blogs and an interactive quality that should be further investigated. 


\section{Limitations and Further Research}

While in-depth interviews were necessary for this investigation stage of uncovering previously undefined motivational factors, now that a list of motivational factors and categories for fashion blogs has been established, a quantitative uses and gratifications survey could be administered using the categories found in this study as a gauge. Given that this research engaged an exploratory qualitative approach, the findings must be confirmed by way of a quantitative survey. A study of this nature could use the motivational factors that emerged in this

study along with others for general blog use and to create a comprehensive list of confirmed uses and gratifications with a scale of strength. A further quantitative study of this kind could directly compare fashion blogs with fashion magazines, again to verify more rigidly the findings of this study.

This suggested quantitative survey should use a larger sample than investigated in this study. The sample in this study was limited to women aged 18 to 35 and living in Canada. It may be useful to include men who have an interest in fashion and read fashion blogs, as well as users in other countries. Including both men and women will allow for researchers to determine whether there are any gender differences in regards to motivations for fashion blog use. The use of fashion blogs as compared to fashion magazines by males is a particularly interesting area of further research. Fashion magazines with primarily male content are much less prevalent than those that are offered to their female counterparts. It could be hypothesized that many males with an interest in fashion content rely much more heavily on fashion blogs than females. Further research could investigate whether a significant gender difference exists for fashion blog use. Online fashion content has recently merged with e-commerce sites. This fusing of editorial and 
e-commerce, for example leading high-end fashion e-tailor's Net-a-Porter's online magazine The Edit, is an emerging area of fashion communications media that deserves great attention. 


\section{Conclusion}

The use of fashion blogs does not exist independently of any other form of fashion media. Adhering to the remediation perspective, its uses are determined and shaped by other media and act to simultaneously shape those other media. Fashion communications are continually evolving and with each new development, the fashion industry is forced to assess and reinvent how it functions. As it is asserted in this paper, new forms of fashion media will not replace or succeed traditional modes of fashion communications; they will however create a shift, where the uses of each medium are directly related to the other.

In the present study, the researcher has taken the first step at examining fashion blogs

from a user's perspective. This approach can continue to shed light on the shifting feild of fashion media; however, in order to fully examine the contemporary fashion media landscape as it evolves, a better understanding of the content producers as well as consumers must be further developed. 


\section{Appendix}

\section{Appendix 1}

The following questionnaire focuses on two types of fashion media, print magazines and online blogs. Please choose the one answer that best reflects your response to each statement. The questions with a corresponding scale range from one to five, with one representing total disagreement and five representing complete agreement. The remaining questions are in standard multiple-choice form.

1 (strongly disagree) $\quad 2$ (disagree) $\quad 3$ (neutral) $\quad 4$ (agree) $\quad 5$ (strongly agree)

\section{Key Terms:}

Fashion magazine: a print fashion magazine such as (but not limited to) Elle Canada, Fashion, or Vogue.

Fashion blog: an online blog with a primary focus on fashion, such as (but not limited to) Man Repeller, The Sartorialist, or Because I'm Addicted.

\section{Section 1: The Fashion Magazine}

1) When I have free time, I am more likely to read a fashion magazine than take part in another leisure activity.

12

3

4

5

2) I read fashion magazines as a pastime.

$\begin{array}{lllll}1 & 2 & 3 & 4 & 5\end{array}$

3) I read fashion magazines to find out what is in style.

$\begin{array}{lllll}1 & 2 & 3 & 4 & 5\end{array}$

4) I read fashion magazines when I want to be distracted.

$\begin{array}{lllll}1 & 2 & 3 & 4 & 5\end{array}$

5) I am more likely to read a fashion magazine on a vacation than during a regular week at home.
1
2
3
4
5

6) I read fashion magazines more frequently on the weekend than during the week.

$\begin{array}{lllll}1 & 2 & 3 & 4 & 5\end{array}$

7) Fashion magazines are convenient in size and portability.

$\begin{array}{llllll}1 & 2 & 3 & 4 & 5\end{array}$ 
8) Fashion magazines usually feature original content.

$\begin{array}{lll}1 & 2 & 3\end{array}$

$4 \quad 5$

9) Fashion magazines have profit driven motives.

$1 \quad 2 \quad 3$

4

5

10) When looking at a fashion magazine, I spend the majority of time...

a) reading the articles

b) looking at the editorials

c) both reading articles and looking at editorials

d) looking at advertisements

11) I prefer to look at fashion magazines....

a) in the evening

b) in the morning

c) throughout the day

\section{Section 2: The Fashion Blog}

12) When I have free time, I am more likely to look at a fashion blog than take part in another leisure activity.

$\begin{array}{lllll}1 & 2 & 3 & 4 & 5\end{array}$

13) Fashion blogs are entertaining.
1
2
3
4
5

14) I look at fashion blogs as a pastime.

1

2

3

4

5

15) I look at fashion blogs to find out what is in style.
1
2
3
4
5

16) I read fashion blogs when I want to be distracted.

1

2

3

4

5

17) I am more likely to look at a fashion blog on a vacation than during a regular week at home
1
2
3
4
5

18) I look at fashion blogs more frequently on the weekend than during the week.

1

2

3

4 
19) I look at fashion blogs when I have gone on the Internet to do something else.

1 2

3

4

5

20) I usually click on links to other blogs, that the blogger has posted.

$\begin{array}{llll}1 & 2 & 3 & 4\end{array}$

5

21) Fashion blogs feature original content.
1
2
3
4
5

22) Anyone can be a good fashion blogger.
1
2
3
4
5

23) Fashion bloggers have profit driven motives.

123

4

5

24) I prefer to look at fashion blogs....
a) in the evening
b) in the morning
c) throughout the day

25) When looking at a fashion blog, I spend the majority of time...
a) reading what the blogger has written
b) looking at the photos
c) reading other viewers comments
d) I spend equal time doing all three

\section{Section 3: Contrast and Compare}

26) Fashion magazine writers are more credible than fashion bloggers.

$$
1
$$

27) Editors of fashion magazines have access to more exclusive products than bloggers do. 1

28) Which below has greater profit driven motives?
a) Fashion magazines
b) Fashion blogs
c) Neither
d) Both fashion magazines and fashion blogs equally 
29) I more often look at , so that I am 'up-to-date' on fashionable trends.
a) a fashion magazine
b) a fashion blog
c) both equally
d) neither

30) I usually see content I have never seen before in....
a) a fashion magazine
b) a fashion blog
c) both equally
d) neither

31) I am most likely to 'mimic' an outfit I have seen in....
a) a fashion magazine
b) a fashion blog
c) both equally
d) neither

32) I am most likely to buy an article of clothing or an accessory I have seen...
a) a fashion magazine
b) a fashion blog
c) both equally
d) neither

33) I spend a greater amount of time, in one sitting, looking at....
a) a fashion magazine
b) a fashion blog
c) both equally
d) neither

34) Fashion magazines and blogs have similar...
a) photos
b) articles
c) content
d) nothing

35) If I read, , that Anna Wintour was fired from Vogue I would believe it.
a) in a fashion magazine
b) on a fashion blog
c) anywhere
d) I would never believe that 
36) I would rather be interviewed for a 'street style' article by....

a) a fashion journalist for a print magazine

b) a fashion blogger

c) equally by a fashion blogger or fashion magazine journalist

d) neither

\section{Appendix 2}

TABLE 1

Fashion Blog Gratifications

\section{Motivational Factors}

To be informed about styles/fashion (for specific information of interest)

(7) 13456810

"I want to see what a lot of people are wearing and how they're wearing it"

"I like to be well dressed and I like to be informed"

"I'm being educated"

"The more I read blogs the more intuitive I am [about styles and fashion]"

"To keep updated and see what other people are doing"

"Just to keep on top of fashions"

"To stay on top of the latest trends"

"To learn about new designers"

\section{Blogs are more personal}

(7) 24567910

"It's nice, it's more personal and it's something you can actually attain for yourself"

"It's a more personal perspective"

"It's more opinioned, you get someone's perspective...it's more critical definitely, people say stuff on blogs that they would never say in a magazine"

"It just seems more approachable"

\section{It is part of a daily routine}

(6) 123567

"It's part of my morning routine"

"I check them everyday"

"There just more of my everyday life"

"It's part of my morning ritual"

\section{To look at fashion images}

(6) 1458910

"I really like the videos and photography"

"I mostly look at them for the images"

"I'm primarily going for the photography element"

"I do value the pictures, it's a more visual way of understanding"

"I like the images he posts and the style of his shots" 
"I love looking at beautiful fashion photography"

\section{Updates are directed to me}

(5) 134810

"They email me their updates - it's delivered right to my inbox, I like that"

"Blogs have other entrances, if they have something on my Facebook feed then I will click on it"

"I put everything on my Google reader"

"I look at things that will pop up on my Facebook"

"Pinterest redirects me to fashion blogs"

\section{For inspiration on how to dress}

(5) 267810

"If I'm stuck in a rut with my clothes"

"It's a good place to get ideas of actually how to get dressed"

Because blogs provide the most up-to-date information (frequency they are undated)

(4) 49310

"You get to see it right away"

"It's faster, more current and more up-to-date"

"I like that you can see trends instantly as they are happening online... and I can imitate it tomorrow"

\section{Because they are easily accessed}

(4) 1356

"I like that they are sort of part of out culture of convenience"

"For convenience sake"

"Just cause they're there"

"I like having it at my fingertips at all times"

\section{Ability to remove and store/save content}

(4) 14710

"I'll pin things on fashion blogs"

"I'll save images and I file them - you can just drag and drop right away"

"If I see an image I like, I'll click and drag it into a file on my computer"

"I can pin something interesting I've found"

\section{To relieve boredom}

(4) 26910

\section{So I don't have to pay for a magazine}

(3) 123

"I can't justify spending a lot of money on fashion magazines"

"There is no point in purchasing the magazine"

"It's free"

\section{For instructional D.I.Y}

(3) 578

"She'll do like a sewing Saturday and she'll post step by step...that's something I'll always go to" 
"I like them because she is not a seasoned sewer at all, her instructions are how I would give instructions"

\section{To escape daily life}

(3) 675

"It's like an escape"

"To balance out the horrible things in the world, to look at things that are pretty and make me feel like the world might be okay"

"It's something that's different and exciting"

\section{To research for school/work}

(2) 45

"For inspiration for work"

Blogs are humorous

(2) 68

"It's really funny"

For access/validation from a community

(2) 37

"It's a lot to do with style, like lifestyle, not just clothes"

"like something as small as when I started rolling my pants up to make them cuffs it was exciting to see that reflected on that blog"

\section{For informal/uncomplicated approach}

(2) 48

"It's not put with other items, it's not overly styled or put on backgrounds - it's just raw, it's just the look"

"Blogs are a lot more creative and they write more casually-I like the informality"

To get information quickly (1) 1

"I like that I can feed my fashion curiosity within one minute"

For links to other information (1) 5

"I like that if I like something I can just click on it and it will take me to the site where I can buy it..."

For minimalistic reasons (1) 1

"They're more disposable"

\section{Environmental awareness (1) 4}

"I wanted to stop reading print magazines and then throwing them out"

To feel efficient (1) 4

"I need to have two or three things happening all at once to feel efficient"

To make fun of others (1) 6

"To make fun of people" 
For information for my own blog (1) 8

\section{Appendix 3}

TABLE 2

Fashion Blog Uses and Gratifications

Categories

F1. ACCESSIBILITY AND CONVENIENCE OF INFORMATION SEEKING to be informed about styles/fashions

entrance (updates are directed to me)

because blogs provide frequent and up-to-date information

easily accessed

to get information quickly

habit (it is part of my daily routine)

F2. BLOG ATTRIBUTES

blogs are more personal

the ability to retrieve and save content

for access to a community

for informal / uncomplicated approach to content

for links to other information

so I don't have to pay for a magazine

\section{F4. SPECIFIC INQUIRY}

for inspiration on how to dress

for instructional d.i.y

for validation from community

for information for my own blog

to research for school/work

\section{F3. ESCAPISM / ENJOYMENT}

to relieve boredom

to look at fashion images

to embrace minimalism

environment awareness

to escape daily life

to make fun of others

to feel efficient 


\section{Appendix 4}

\section{RYERSON UNIVERSITY \\ RESEARCH ETHICS BOARD}

To: Sasha Johnson

Faculty of Communication and Design

Re: REB 2012-265: A comparative analysis of the purpose, value and credibility of print and online fashion media.

Date: November 5, 2012

Dear Sasha Johnson,

The review of your protocol REB File REB 2012-265 is now complete. The project has been approved for a one year period. Please note that before proceeding with your project, compliance with other required University approvals/certifications, institutional requirements, or governmental authorizations may be required.

This approval may be extended after one year upon request. Please be advised that if the project is not renewed, approval will expire and no more research involving humans may take place. If this is a funded project, access to research funds may also be affected.

Please note that REB approval policies require that you adhere strictly to the protocol as last reviewed by the REB and that any modifications must be approved by the Board before they can be implemented. Adverse or unexpected events must be reported to the REB as soon as possible with an indication from the Principal Investigator as to how, in the view of the Principal Investigator, these events affect the continuation of the protocol.

Finally, if research subjects are in the care of a health facility, at a school, or other institution or community organization, it is the responsibility of the Principal Investigator to ensure that the ethical guidelines and approvals of those facilities or institutions are obtained and filed with the REB prior to the initiation of any research.

Please quote your REB file number (REB 2012-265) on future correspondence. Congratulations and best of luck in conducting your research.

Nancy Walton, Ph.D.

Chair, Research Ethics Board 


\section{RYERSONUNIVERSITY}

\section{Ryerson University \\ Consent Agreement}

\section{A Comparative Analysis of the Purpose, Value and Credibility of Print and Online Fashion Media}

You are being asked to participate in a research study. Before you give your consent to be a volunteer, it is important that you read the following information and ask as many questions as necessary to be sure you understand what you will be asked to do.

Investigators: The research study you are being asked to participate in is being conducted by Sasha Johnson, a student in the Masters of Arts in Fashion program from the Department of Communication and Design at Ryerson University. This study is being conducted as partial fulfilment of requirements to obtain a Masters of Arts degree. This study will be conducted under the supervision of Joseph Medaglia, Assistant Professor at Ryerson University.

Purpose of the Study: Fashion magazines in print form and online fashion blogs will be examined, in order to draw conclusions about the similarities and differences of perceived uses and gratifications as determined by user experiences. This research will address issues regarding the purpose, credibility, and value of content associated with each medium. Eligible participants will be women living in Canada between 18 and 30 years of age and have a personal interest in fashion magazines and/or fashion blogs.

Description of the Study: The research study requires that participants fill out an online questionnaire consisting of 36 multiple-choice questions. The questionnaire can be filled out online and will take between 15 to 30 minutes to complete.

Risks or Discomforts: There is no more risk associated with the completion of the study than experienced in everyday life. Questions deal with personal opinions of leisure activities and because of this personal nature you may be prompted to consider aspects about how you spend your leisure time. If at any point throughout the questionnaire you feel uncomfortable you may discontinue participation, either temporarily or permanently.

Benefits of the Study: This research will provide additional information on women's opinions of fashion magazines as compared to fashion blogs. You may not experience any direct benefit from participating in this study. The primary benefit of this research will be that it will add to the body of literature in the area of fashion and communication research.

Confidentiality: As a participant your identity will remain anonymous. If you are interested in participating in a future follow-up interview, you may leave your name and email address at the end of the questionnaire. Your identity will remain confidential. Confidential information will be stored electronically on both a password-protected document and passwords protect USB drive.

Voluntary Nature of Participation: Participation in this study is voluntary. Your choice of whether or not to participate will not influence your future relations with Ryerson University. If you decide to participate, you are free to withdraw your consent and to stop your participation at any time without penalty or loss of benefits to which you are allowed.

At any particular point in the study, you may refuse to answer any particular question or stop 
participation altogether. You may withdraw from the study by exiting the browser; this may be done at any time. Any questionnaire that has not been fully completed will be deleted and will not be included in the study.

Questions about the Study: If you have any questions about the research now, please ask. If you have questions later about the research, you may contact.

\author{
Sasha Johnson \\ Masters Candidate \\ School of Fashion \\ Faculty of Communication \& Design \\ Ryerson University \\ Toronto, Canada \\ sasha.johnson@ryerson.ca
}

\title{
Joseph Medaglia
}

Assistant Professor

School of Fashion

Faculty of Communication \& Design

Ryerson University

Toronto, Canada

$4169795000 \times 7068$

jmedaglia@ryerson.ca

If you have questions regarding your rights as a human subject and participant in this study, you may contact the Ryerson University Research Ethics Board for information.

Research Ethics Board

c/o Office of the Vice President, Research and Innovation

Ryerson University

350 Victoria Street

Toronto, ON M5B 2K3

416-979-5042

\section{Agreement:}

By clicking 'accept' below it indicates that you have read the information in this agreement and have had a chance to ask any questions you have about the study. Your advancement to the next page indicates that you agree to be in the study and have been told that you can change your mind and withdraw your consent to participate at any time. You have been given a copy of this agreement.

You have been told that by clicking 'accept' to this consent agreement you are not giving up any of your legal rights. 


\section{Appendix 5}

REB 2012-265

Project Title: A comparative analysis of the purpose, value and credibility of print and online fashion media.

Dear Sasha Johnson,

Thank you very much for the submission of amendments for the above project. The Research Ethics Board has completed the review of your resubmission and the proposed amendments have been approved. This does not change the approval status nor the original approval date of the project.

Congratulations and best of luck with the project.

Please quote your REB file number (REB 2012-265) on future correspondence.

If you have any questions regarding your submission or the review process, please do not hesitate to get in touch with the Research Ethics Board (contact information below).

No research involving humans shall begin without the prior approval of the Research Ethics Board.

Record respecting or associated with a research ethics application submitted to Ryerson University.

Yours sincerely,

Toni Fletcher

Research Ethics Coordinator on behalf of

Nancy Walton, Ph.D.

Chair, Research Ethics Board

Associate Professor

Ryerson University POD470B

350 Victoria St., Toronto, ON

(416)979-5000 ext. 6300

nwalton@ryerson.ca

rebchair@ryerson.ca

http://www.ryerson.ca/research 


\section{RYERSONUNIVERSITY}

\section{Ryerson University \\ Consent Agreement}

\section{A Comparative Analysis of the Purpose, Value and Credibility of Print and Online Fashion Media}

You are being asked to participate in a research study. Before you give your consent to be a volunteer, it is important that you read the following information and ask as many questions as necessary to be sure you understand what you will be asked to do.

Investigators: The research study you are being asked to participate in is being conducted by Sasha Johnson, a student in the Masters of Arts in Fashion program from the Department of Communication and Design at Ryerson University. This study is being conducted as partial fulfilment of requirements to obtain a Masters of Arts degree. This study will be conducted under the supervision of Joseph Medaglia, Assistant Professor at Ryerson University.

Purpose of the Study: Fashion magazines in print form and online fashion blogs will be examined, in order to draw conclusions about the similarities and differences of perceived uses and gratifications as determined by user experiences. This research will address issues regarding the purpose, credibility, and value of content associated with each medium. Eligible participants will be women living in Canada between 18 and 30 years of age and have a personal interest in fashion magazines and/or fashion blogs.

Description of the Study: The research study requires that participants take part in an individual interview. The interview will take approximately 30 to 45 minutes to complete. Questions will be regarding your fashion blog and fashion magazine use.

Risks or Discomforts: There is no more risk associated with the completion of the study than experienced in everyday life. Questions deal with personal opinions of leisure activities and because of this personal nature you may be prompted to consider aspects about how you spend your leisure time. If at any point throughout the questionnaire you feel uncomfortable you may discontinue participation, either temporarily or permanently.

Benefits of the Study: This research will provide additional information on women's opinions of fashion magazines as compared to fashion blogs. You may not experience any direct benefit from participating in this study. The primary benefit of this research will be that it will add to the body of literature in the area of fashion and communication research.

Confidentiality: As a participant your identity will remain confidential and will not be revealed. Confidential information will be stored electronically on both a password-protected document and passwords protect USB drive.

Voluntary Nature of Participation: Participation in this study is voluntary. Your choice of whether or not to participate will not influence your future relations with Ryerson University. If you decide to participate, you are free to withdraw your consent and to stop your participation at any time without penalty or loss of benefits to which you are allowed.

At any particular point in the study, you may refuse to answer any particular question or stop participation altogether. You may withdraw from the study and end the interview; this may be done 
at any time. Any interview that has not been fully completed will be deleted and will not be included in the study.

Questions about the Study: If you have any questions about the research now, please ask. If you have questions later about the research, you may contact.

\author{
Sasha Johnson \\ Masters Candidate \\ School of Fashion \\ Faculty of Communication \& Design \\ Ryerson University \\ Toronto, Canada \\ sasha.johnson@ryerson.ca

\section{Joseph Medaglia} \\ Assistant Professor \\ School of Fashion \\ Faculty of Communication \& Design \\ Ryerson University \\ Toronto, Canada \\ $4169795000 \times 7068$ \\ jmedaglia@ryerson.ca
}

If you have questions regarding your rights as a human subject and participant in this study, you may contact the Ryerson University Research Ethics Board for information.

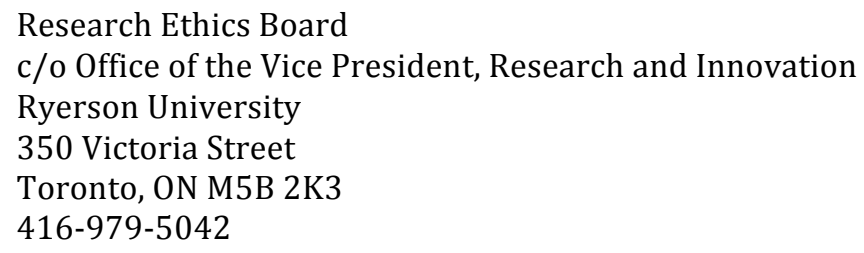

\title{
Agreement:
}

By signing below it indicates that you have read the information in this agreement and have had a chance to ask any questions you have about the study. By signing below you agree to be in the study and have been told that you can change your mind and withdraw your consent to participate at any time. You have been given a copy of this agreement.

You have been told that by signing this consent agreement you are not giving up any of your legal rights.

Participant Signature 


\section{Appendix 6}

\section{Question 7}

When I have free time, I am more likely to read a fashion magazine than take part in another type of leisure activity.
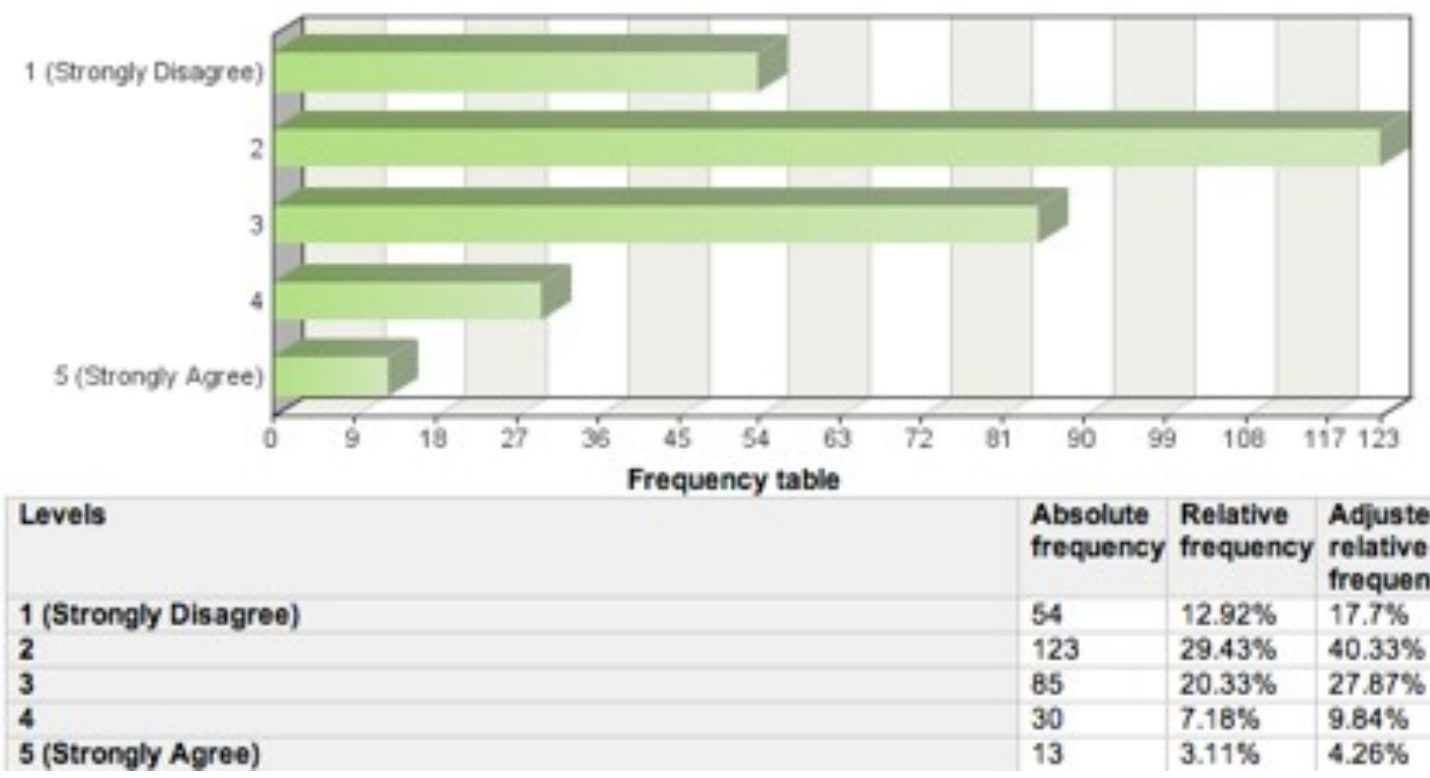

\begin{tabular}{|l|l|l|}
\hline $\begin{array}{l}\text { Absolute } \\
\text { frequency }\end{array}$ & $\begin{array}{l}\text { Relative } \\
\text { frequency }\end{array}$ & $\begin{array}{l}\text { Adjusted } \\
\text { relative } \\
\text { frequency }\end{array}$ \\
\hline 54 & $12.92 \%$ & $17.7 \%$ \\
\hline 123 & $29.43 \%$ & $40.33 \%$ \\
\hline 85 & $20.33 \%$ & $27.87 \%$ \\
\hline 30 & $7.18 \%$ & $9.84 \%$ \\
\hline 13 & $3.11 \%$ & $4.26 \%$ \\
\hline
\end{tabular}

\section{Question 8}

I read fashion magazines as a pastime.

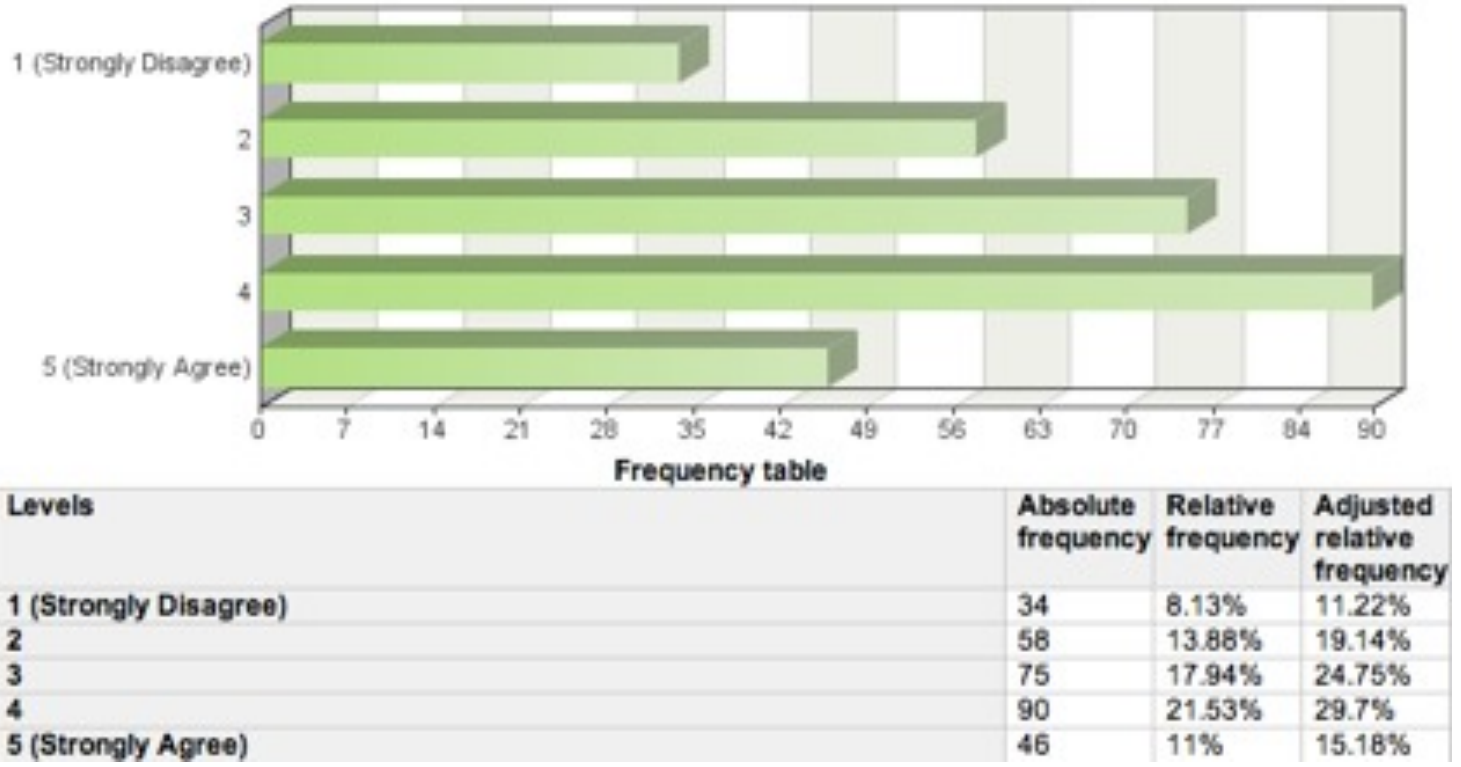




\section{Question 9}

I read fashion magazines to find out what is in style.

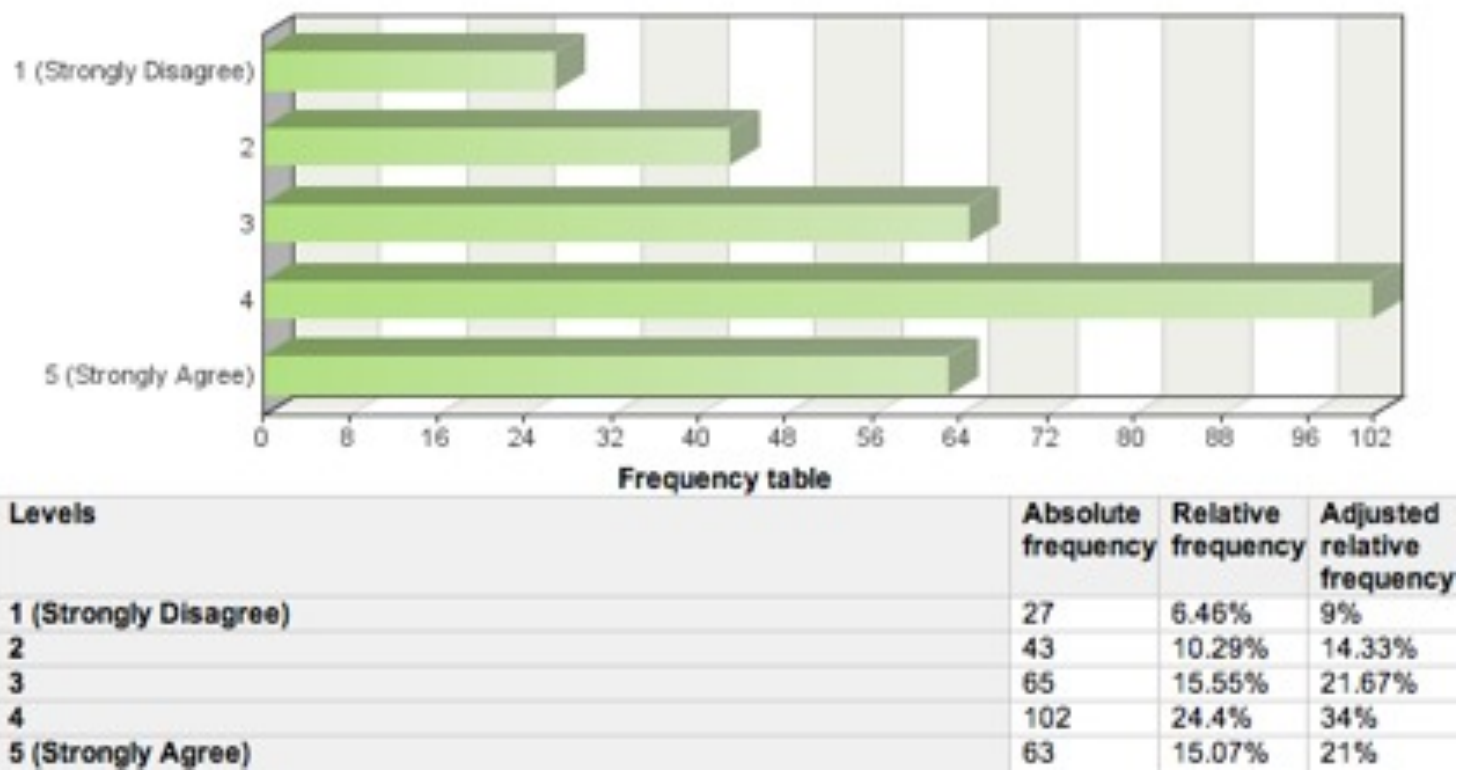

\section{Question 10}

I am more likely to read a fashion magazine on a vacation than during a regular week at home.

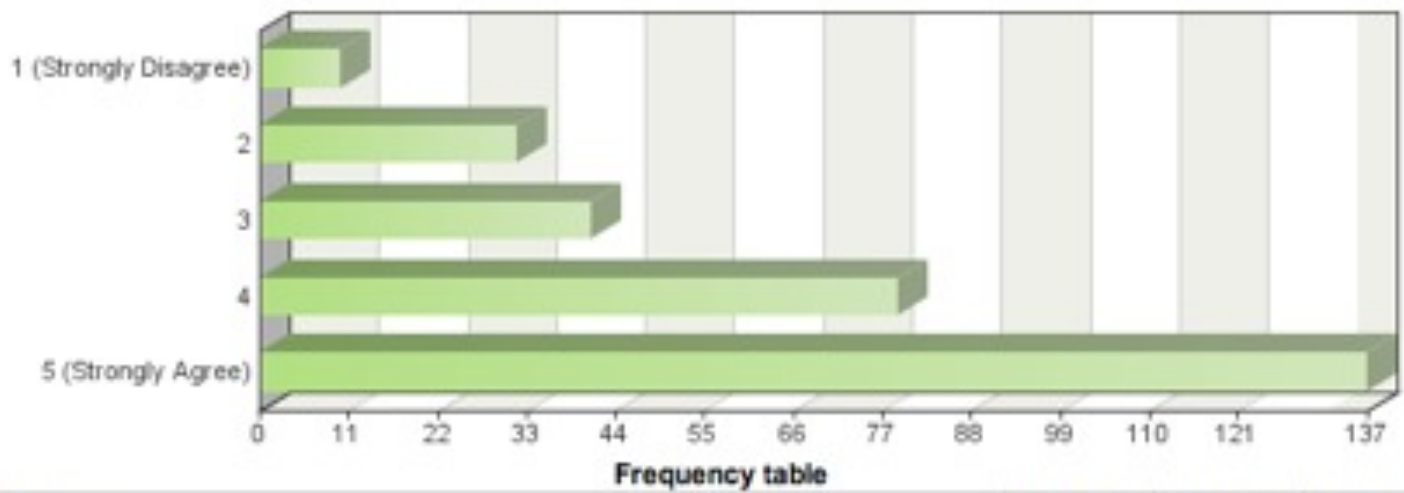

Levels

1 (Strongly Disagree)

2

3

4

5 (Strongly Agree)
Absolute Relative Adjusted frequency frequency relative

\begin{tabular}{|l|l|l|}
\hline 10 & $2.39 \%$ & $3.34 \%$ \\
\hline 32 & $7.66 \%$ & $10.7 \%$ \\
\hline 41 & $9.81 \%$ & $13.71 \%$ \\
\hline 79 & $18.9 \%$ & $26.42 \%$ \\
\hline 137 & $32.78 \%$ & $45.82 \%$ \\
\hline
\end{tabular}




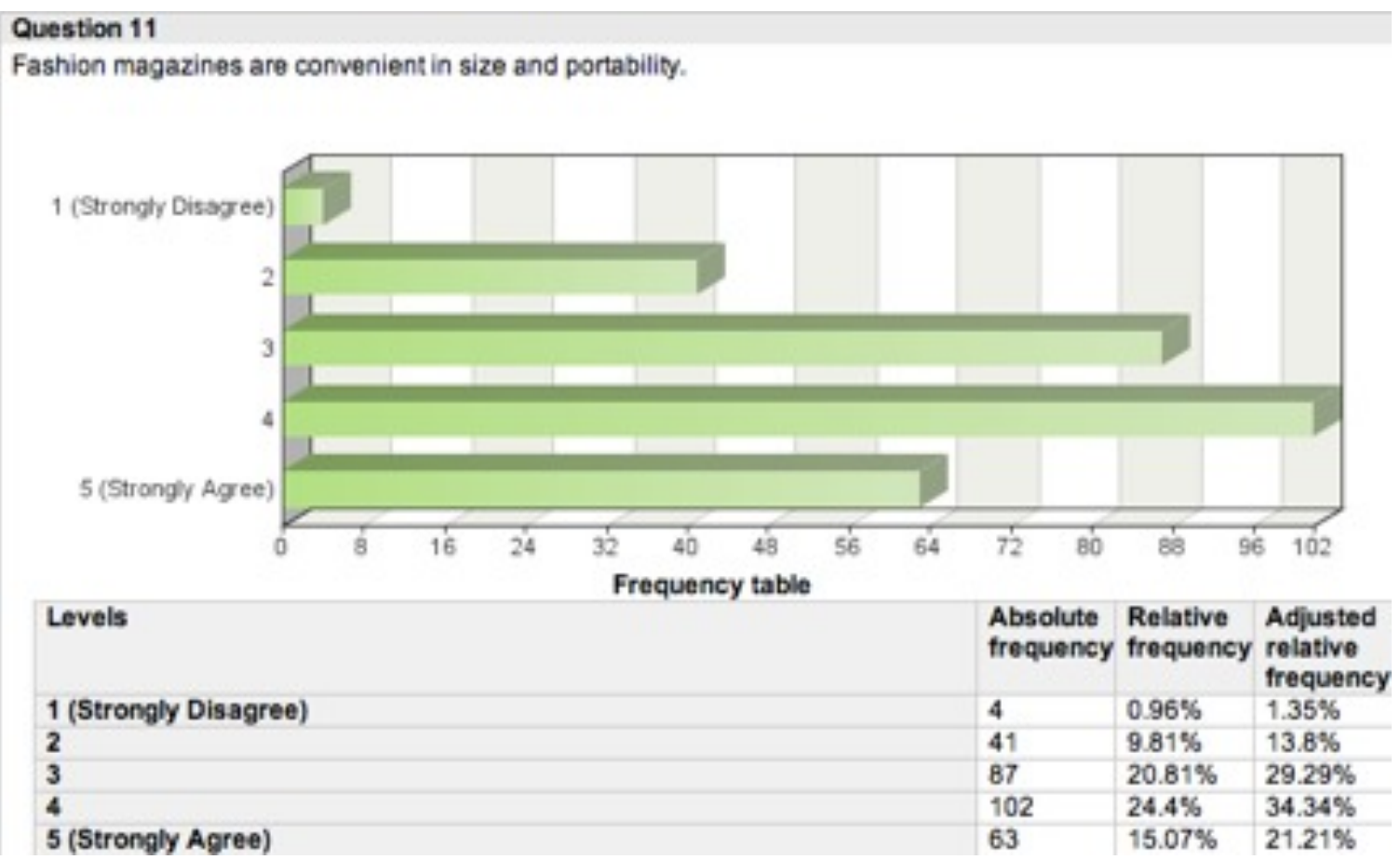

\section{Question 12}

Fashion magazines feature original content.

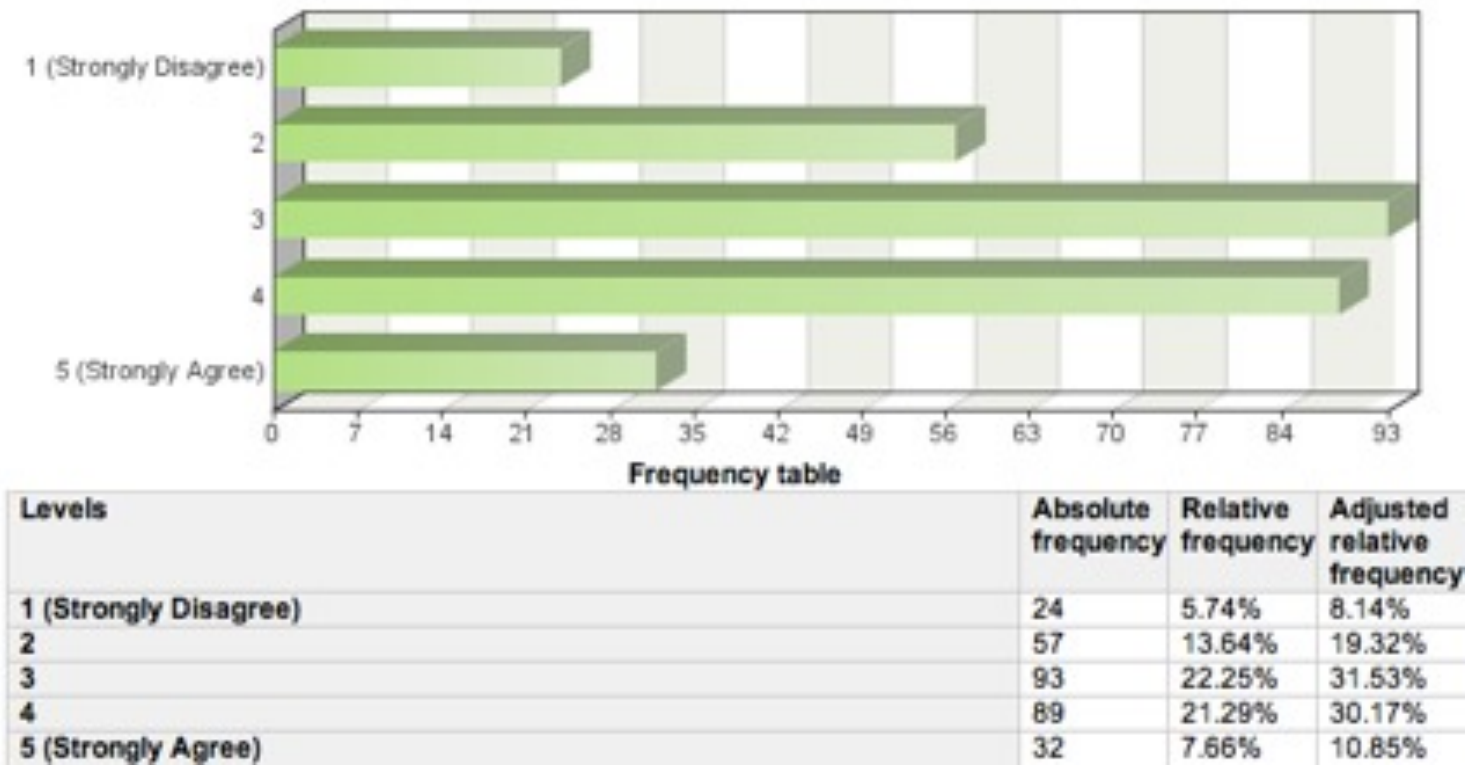




\section{Question 13}

Fashion magazines have profit driven motives.

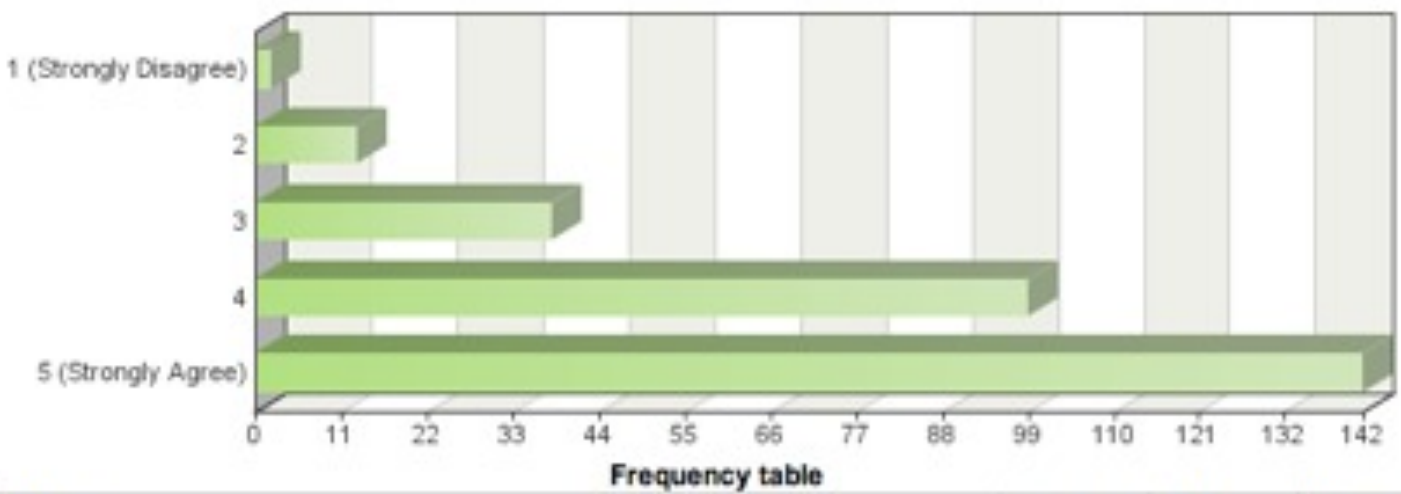

\begin{tabular}{|l|l|l|l|}
\hline Levels & $\begin{array}{l}\text { Absolute Relative } \\
\text { frequency } \\
\text { frequency }\end{array}$ & $\begin{array}{l}\text { Adjusted } \\
\text { relative } \\
\text { frequency }\end{array}$ \\
\hline $\mathbf{1}$ (Strongly Disagree) & 2 & $0.48 \%$ & $0.68 \%$ \\
\hline $\mathbf{2}$ & 13 & $3.11 \%$ & $4.42 \%$ \\
\hline $\mathbf{3}$ & 38 & $9.09 \%$ & $12.93 \%$ \\
\hline $\mathbf{4}$ & & $36 \%$ & $33.67 \%$ \\
\hline
\end{tabular}

\section{Question 14}

I prefer to look at fashion magazines....

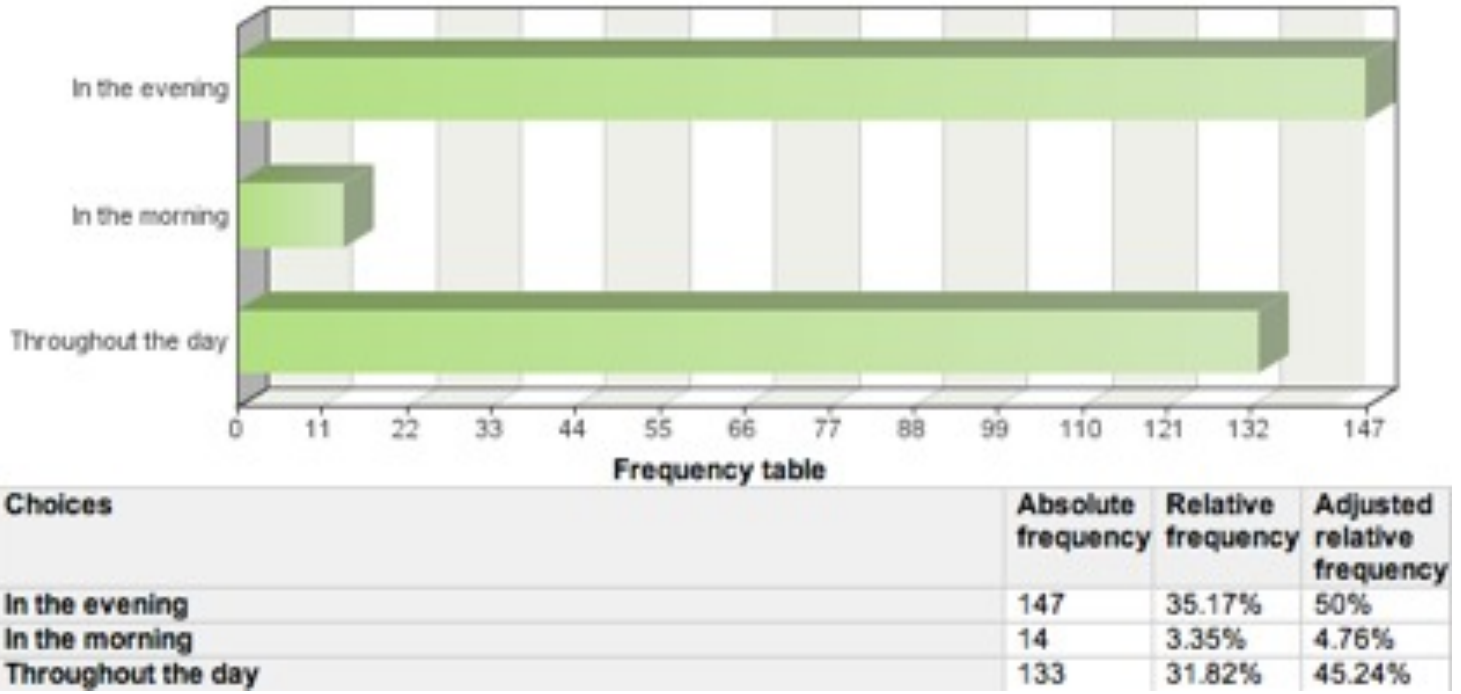




\section{Question 15}

When I have free tme, I am more likely to look at a fashion blog than take part in another type of leisure activity.

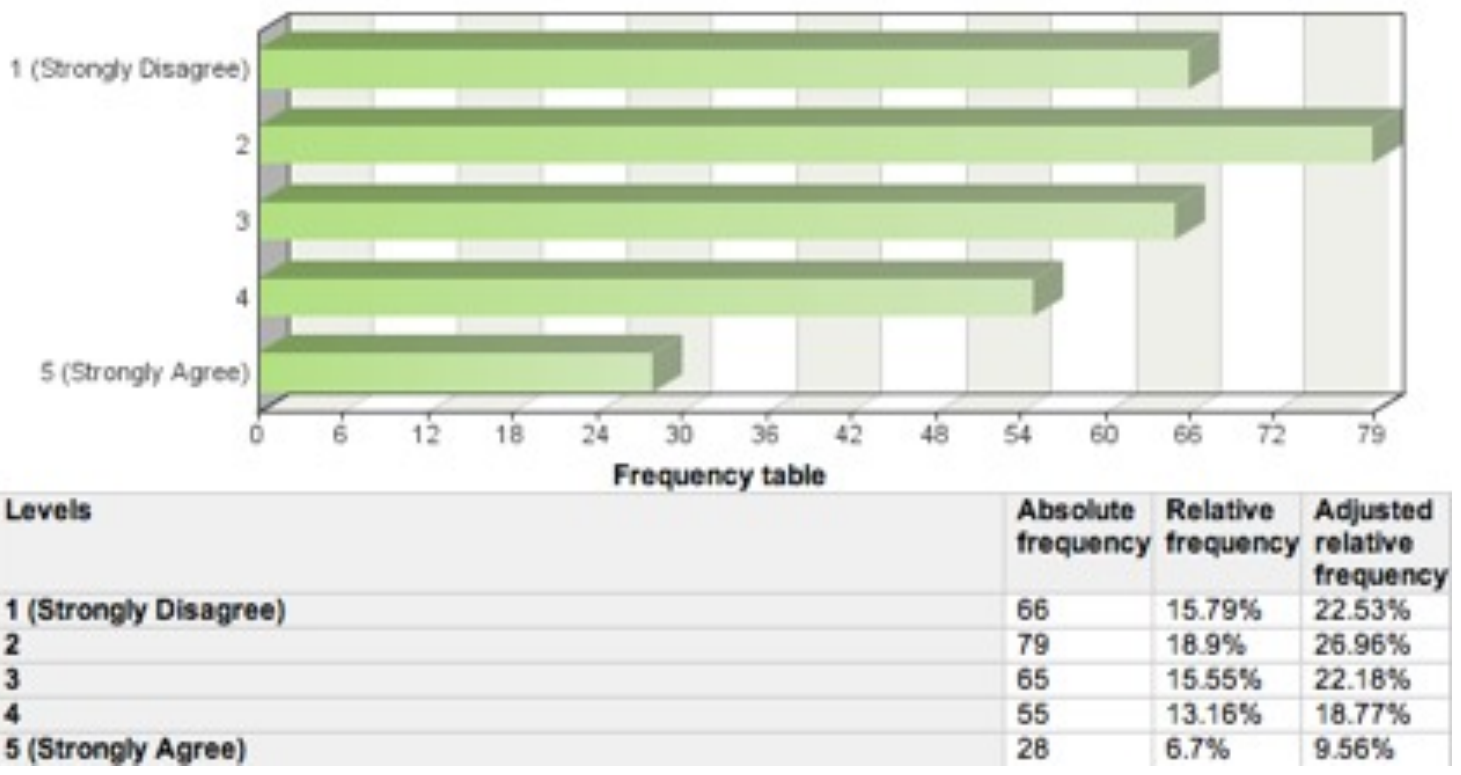

\section{Question 16}

Fashion blogs are entertaining.

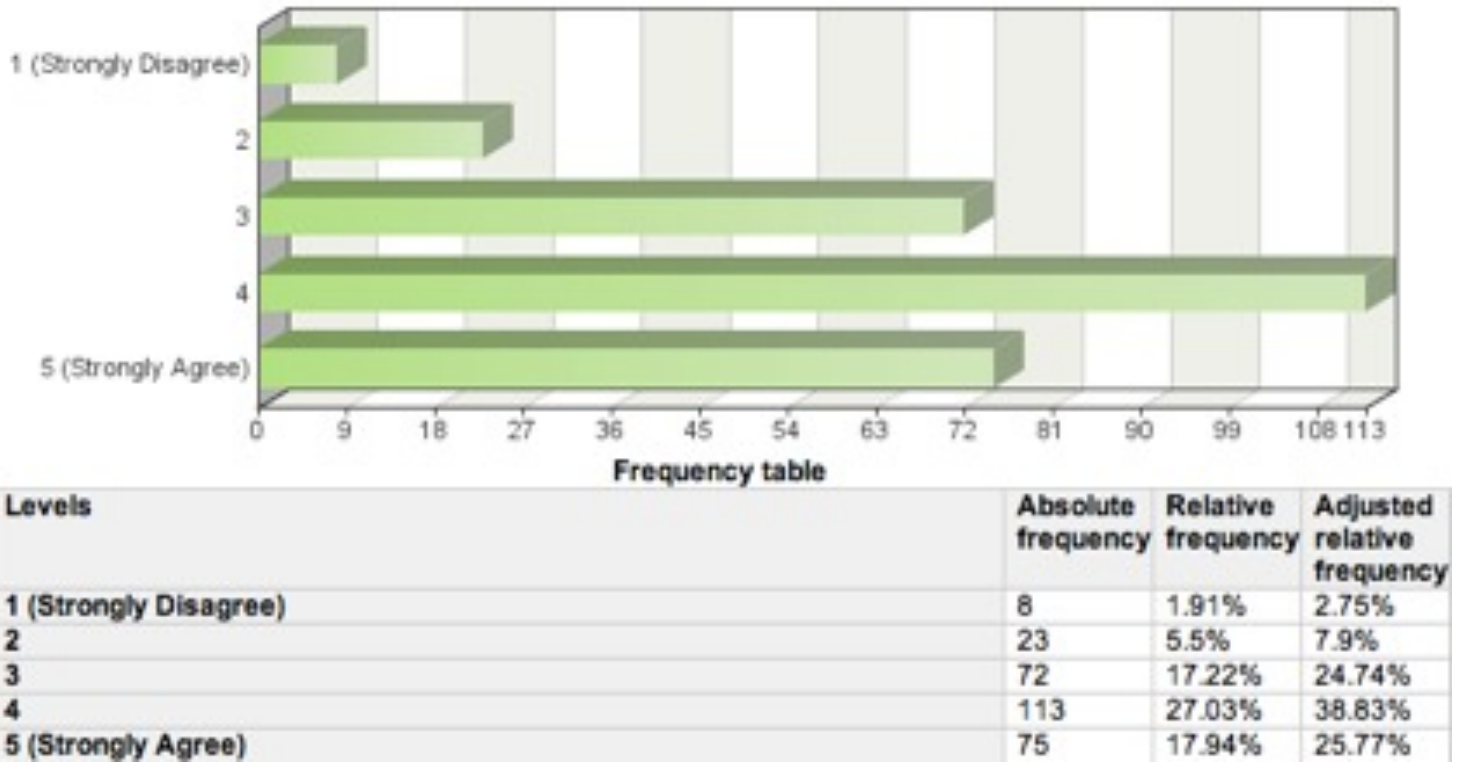




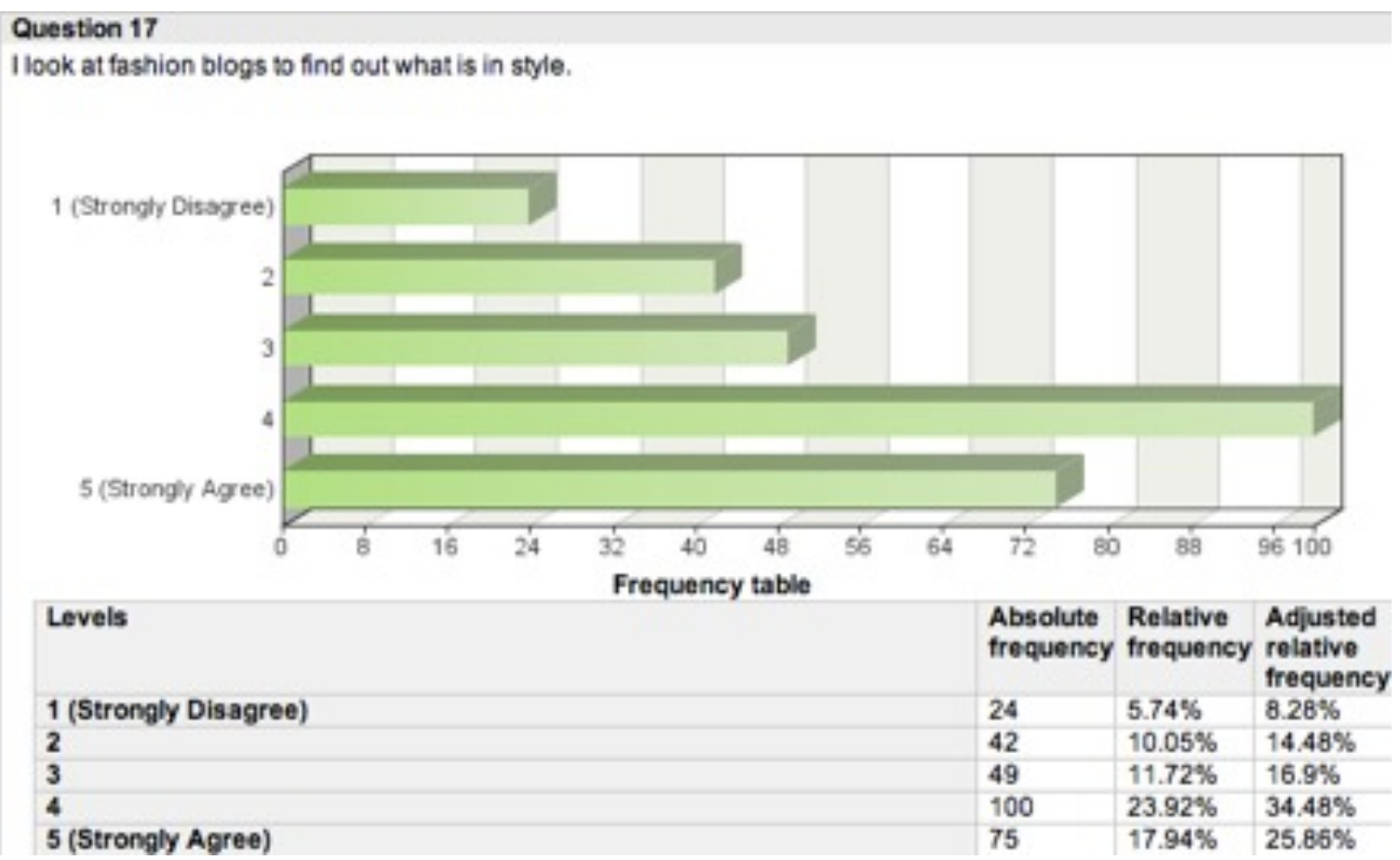

\section{Question 18}

I am more likely to look at a fashion blog on a vacation than during a regular week at home.

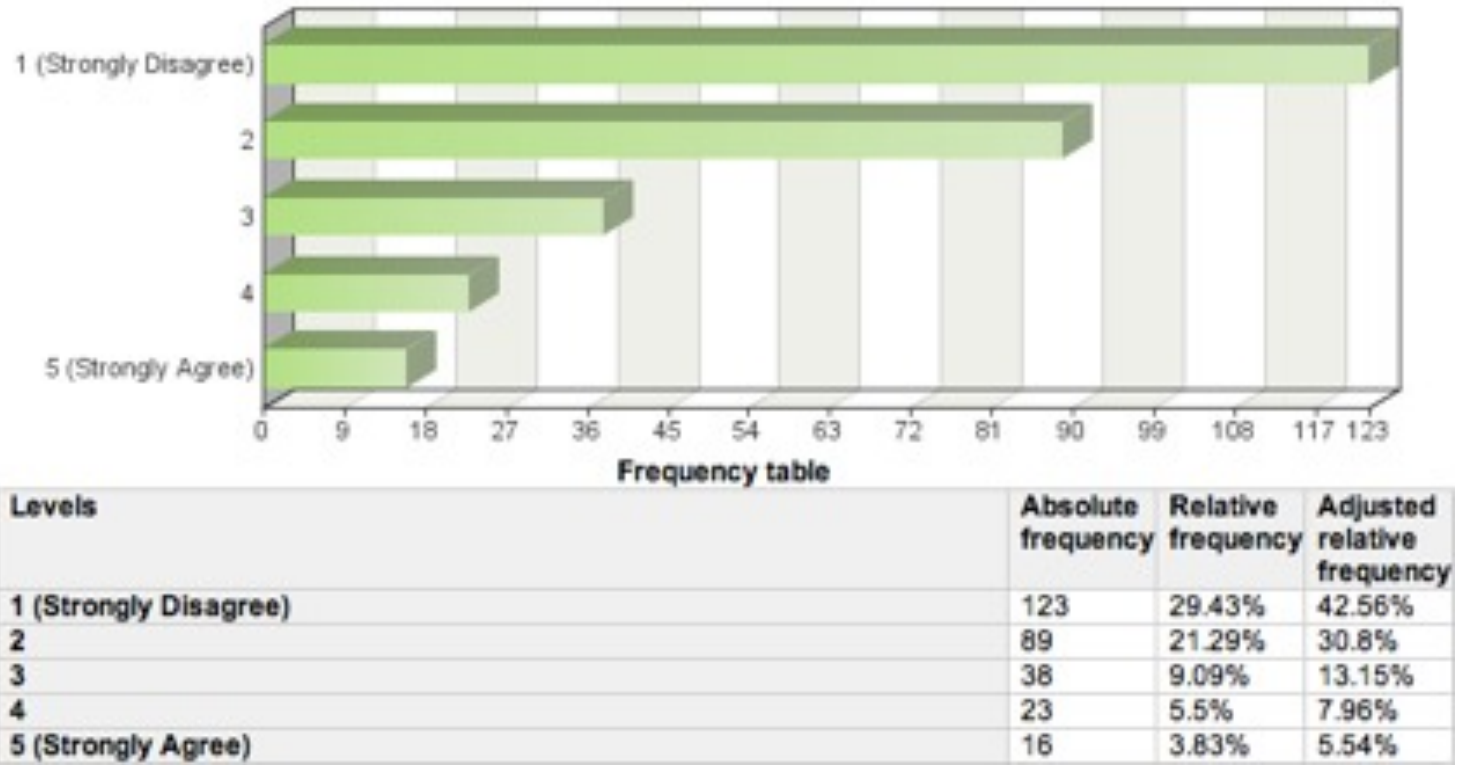




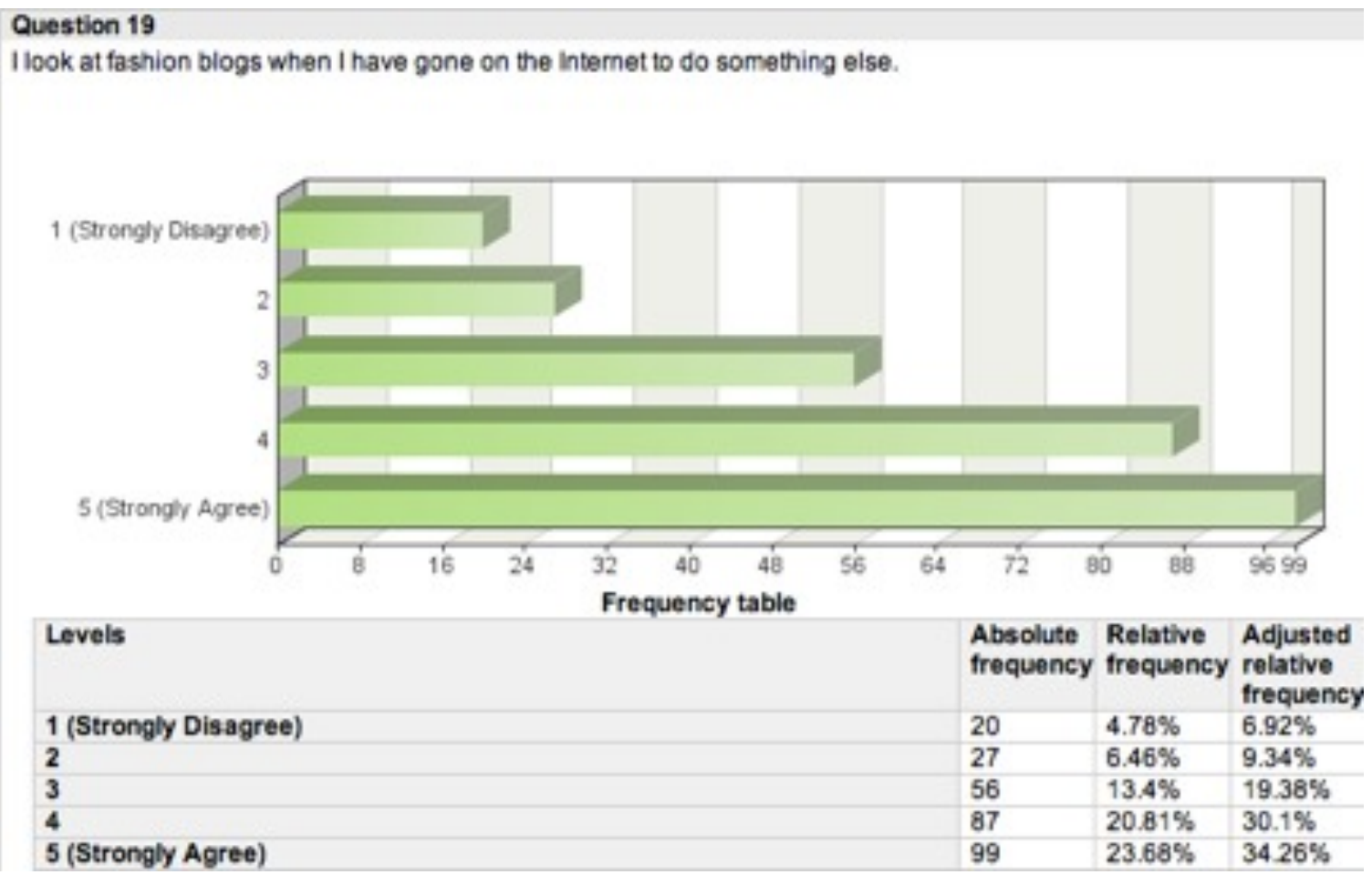

\section{Question 20}

I usually click on links to other websites that the blogger has posted.

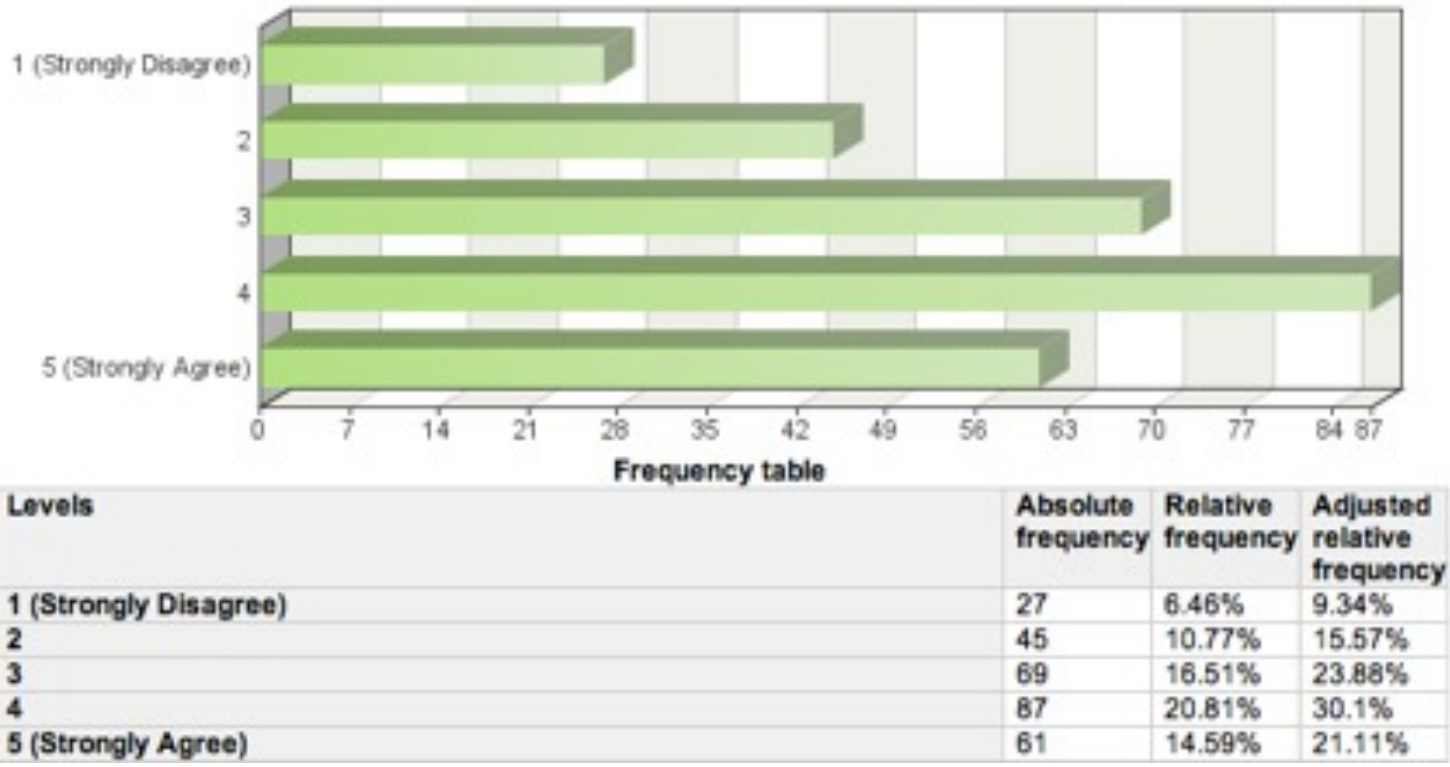




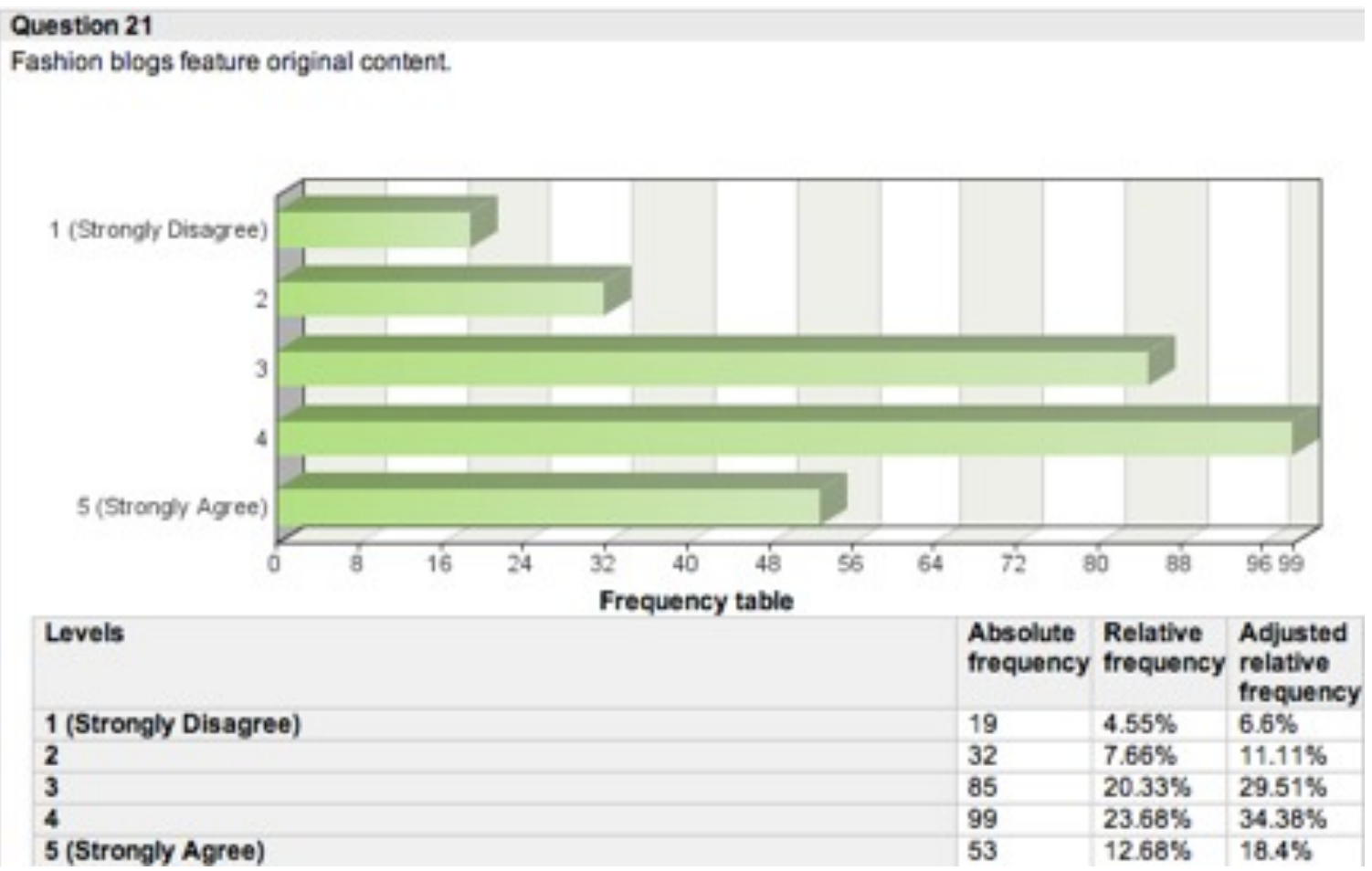

\section{Question 22}

Anyone can be a good fashion blogger.

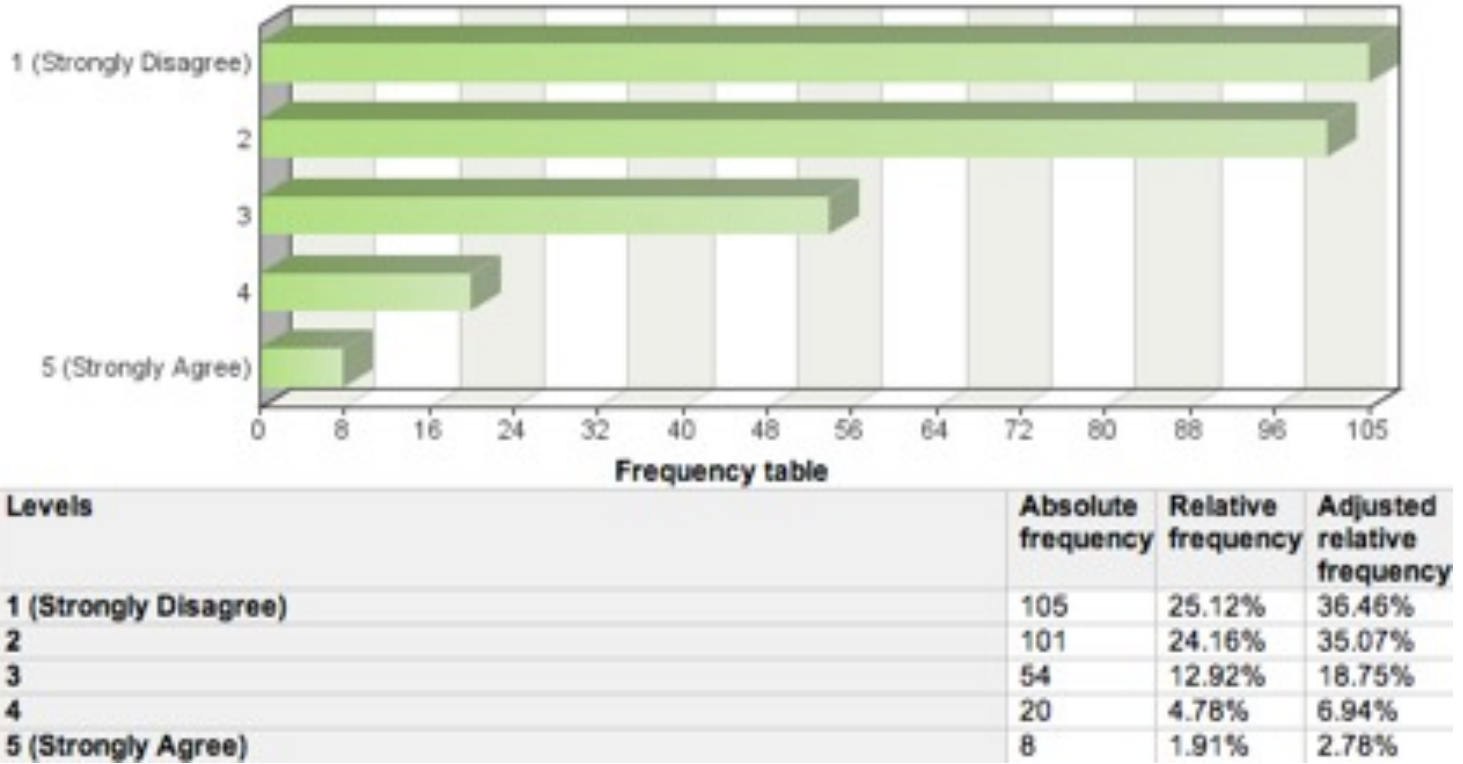




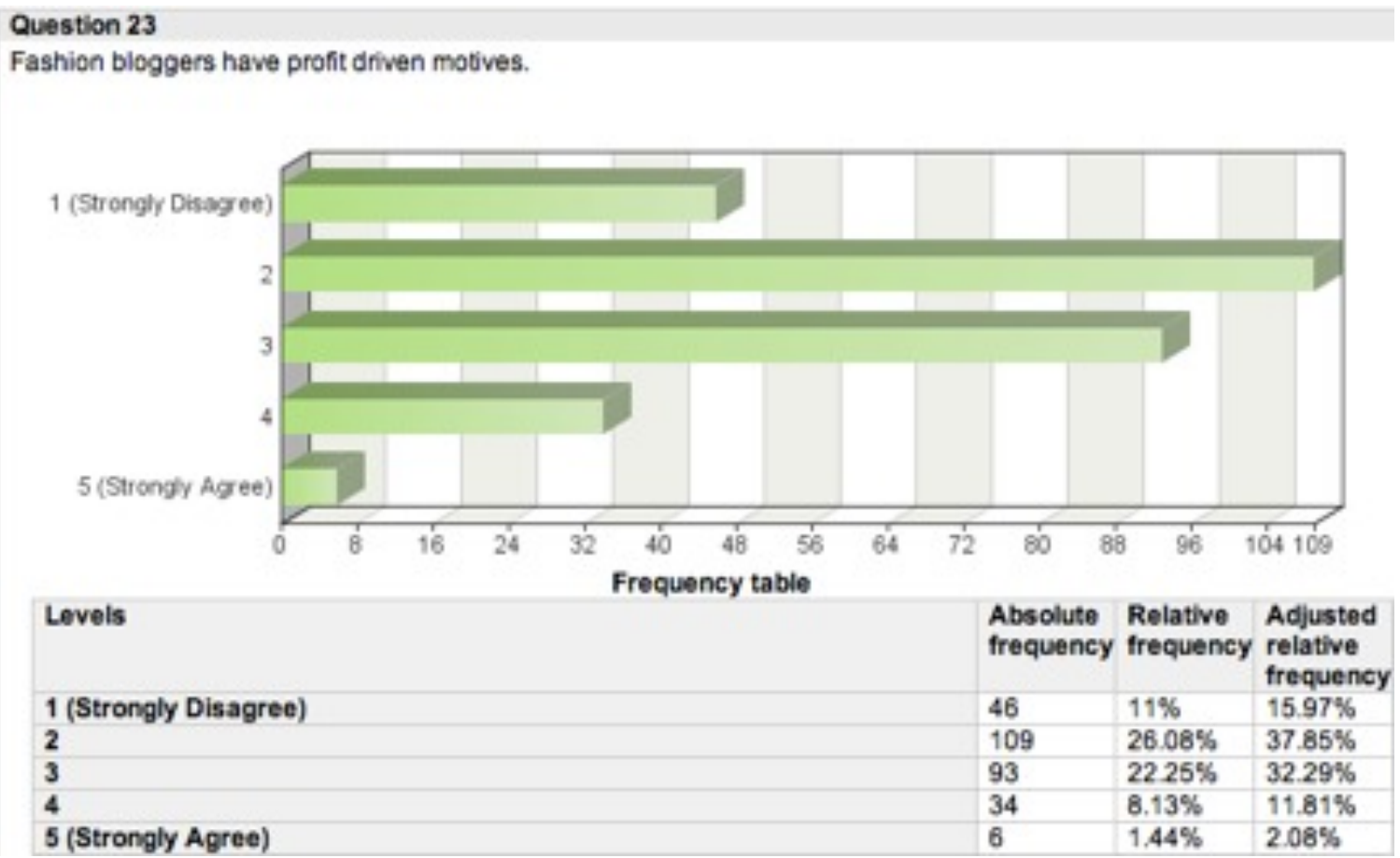

\section{Question 24}

Bloggers have been accepted into the fashion industry.

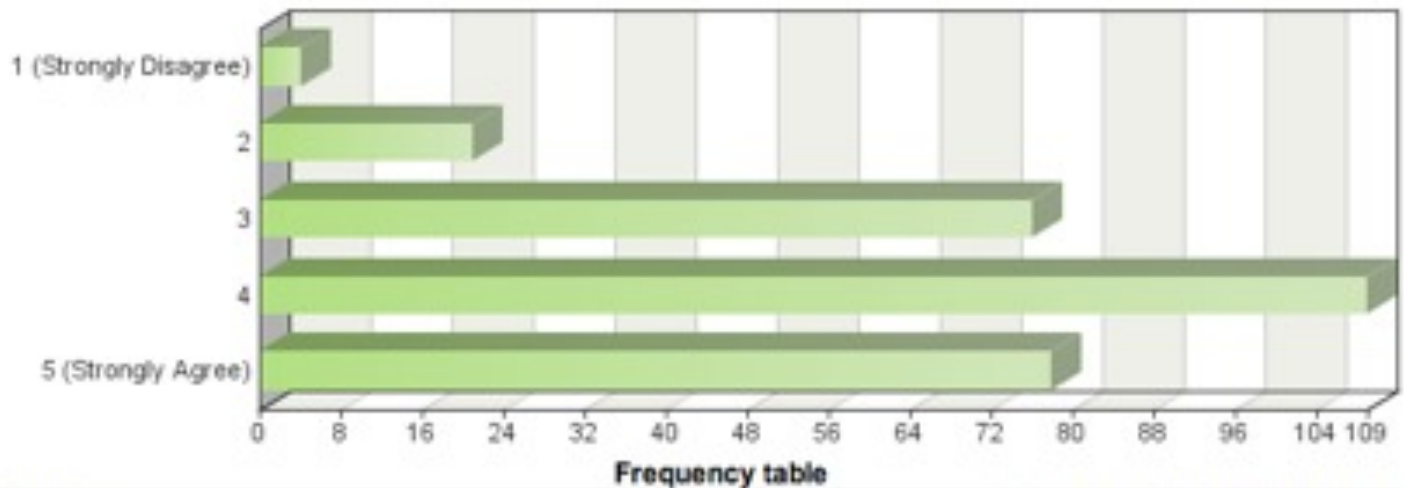

\section{Levels}

1 (Strongly Disagree)

2

3

4

5 (Strongly Agree)
Absolute Relative Adjusted frequency frequency relative

\begin{tabular}{|l|l|l|}
\hline 4 & $0.96 \%$ & $1.39 \%$ \\
\hline 21 & $5.02 \%$ & $7.29 \%$ \\
\hline 76 & $18.18 \%$ & $26.39 \%$ \\
\hline 109 & $26.08 \%$ & $37.85 \%$ \\
\hline 78 & $18.66 \%$ & $27.08 \%$ \\
\hline
\end{tabular}




\section{Question 25}

Bloggers help make the fashion industry more transparent and inclusive.

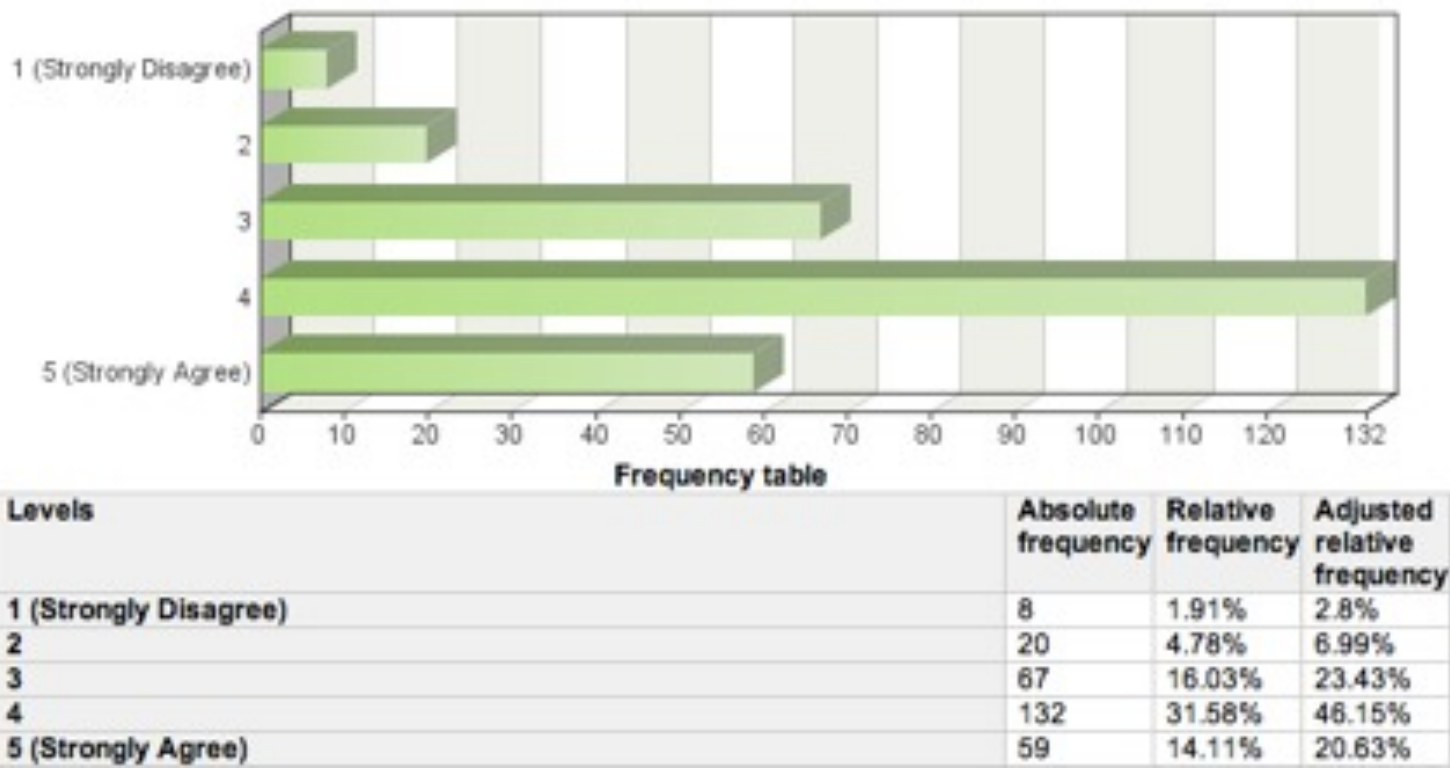

\section{Question 26}

I use links provided by bloggers to shop online.

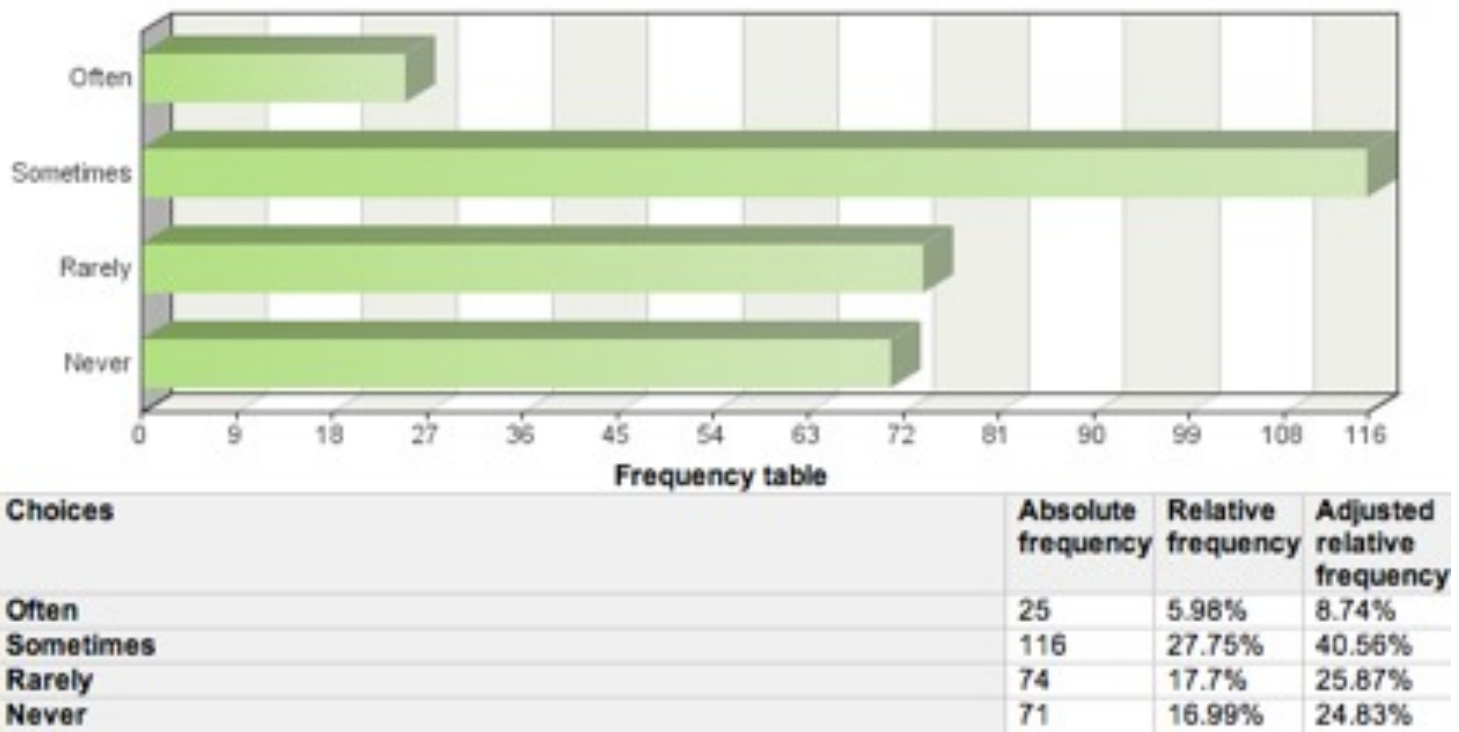




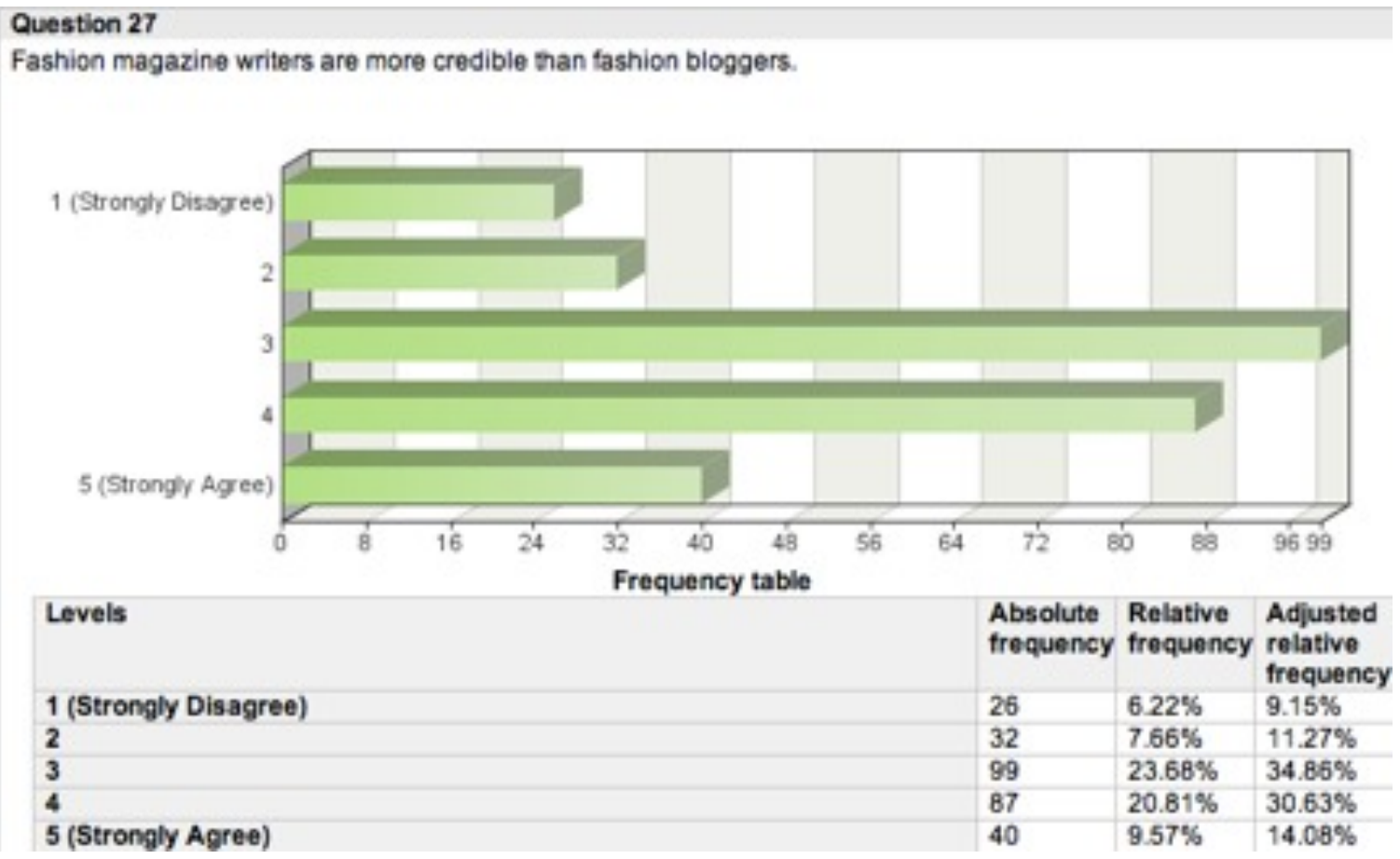

\section{Question 28}

Editors of fashion magazines have access to more exclusive products than bloggers do.

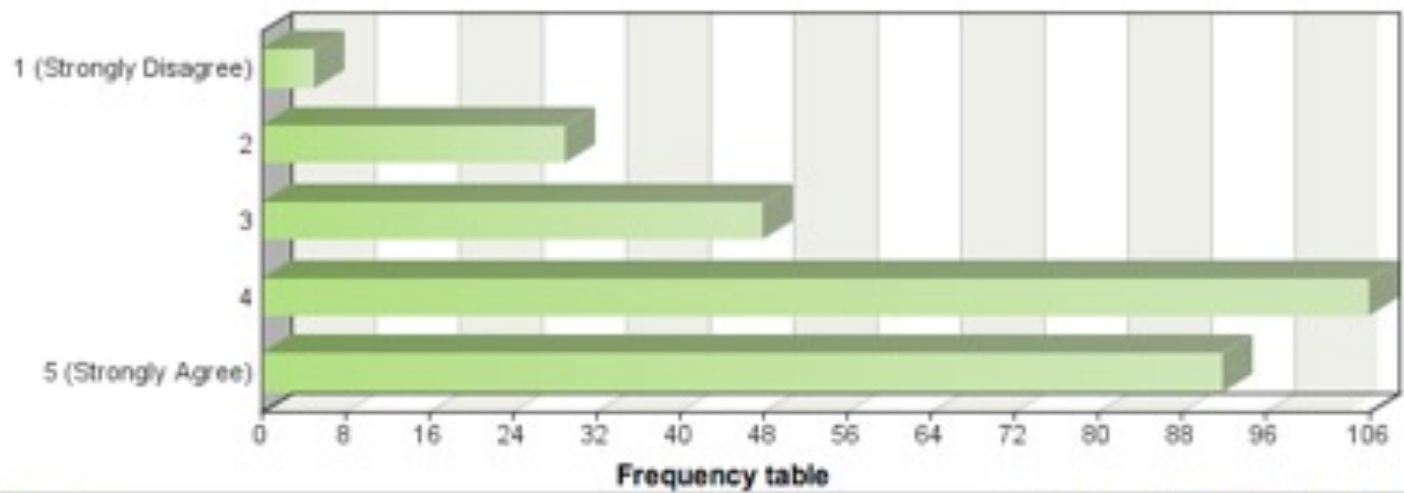

Levels

1 (Strongly Disagree)

2

3

4

5 (Strongly Agree)
Absolute Relative Adjusted frequency frequency relative

\begin{tabular}{|l|l|l|}
\hline 5 & $1.2 \%$ & $1.79 \%$ \\
\hline 29 & $6.94 \%$ & $10.36 \%$ \\
\hline 48 & $11.48 \%$ & $17.14 \%$ \\
\hline 106 & $25.36 \%$ & $37.86 \%$ \\
\hline 92 & $22.01 \%$ & $32.86 \%$ \\
\hline
\end{tabular}




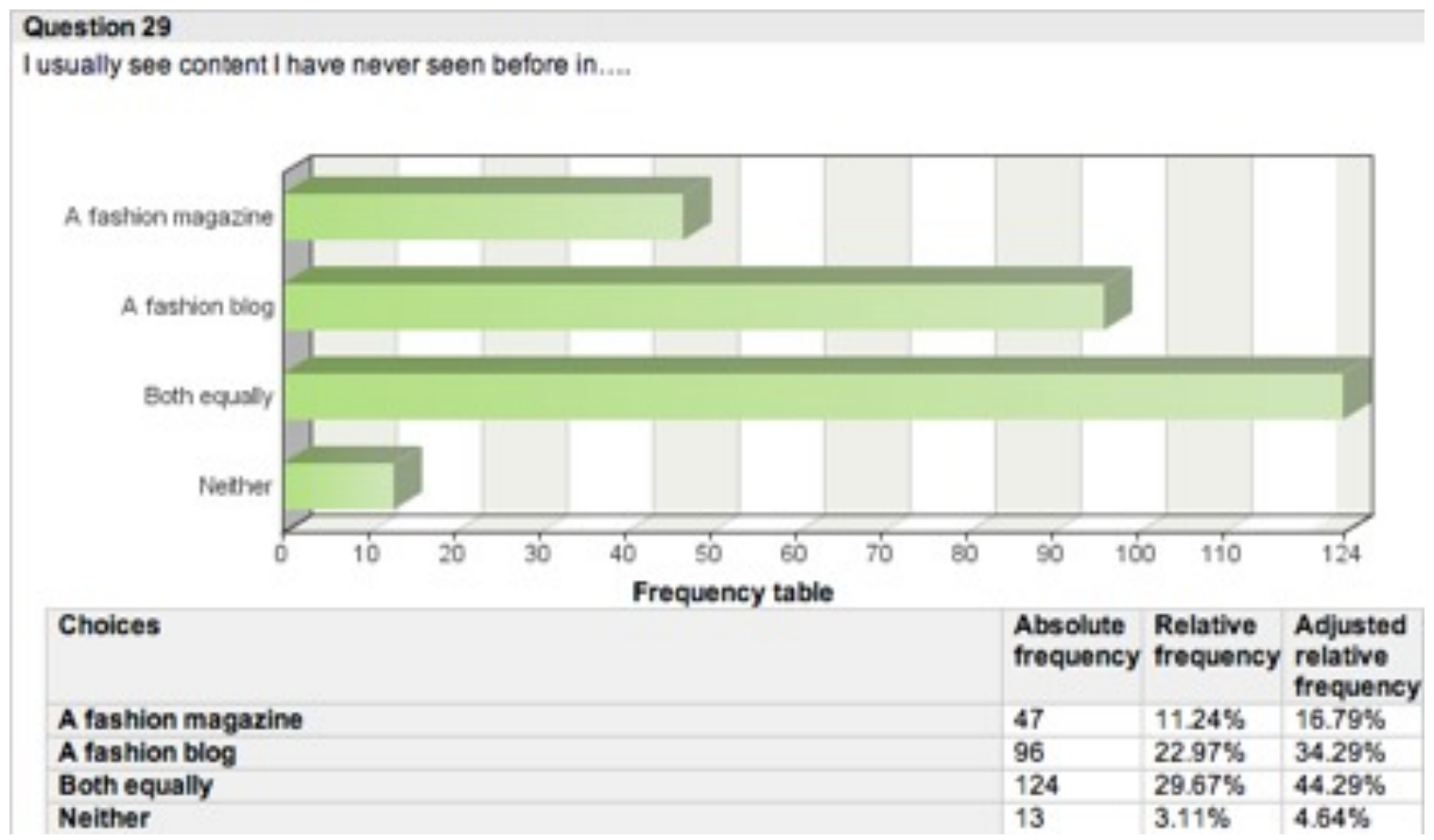

\section{Question 30}

I am most likely to 'mimic' an outlt I have seen in....

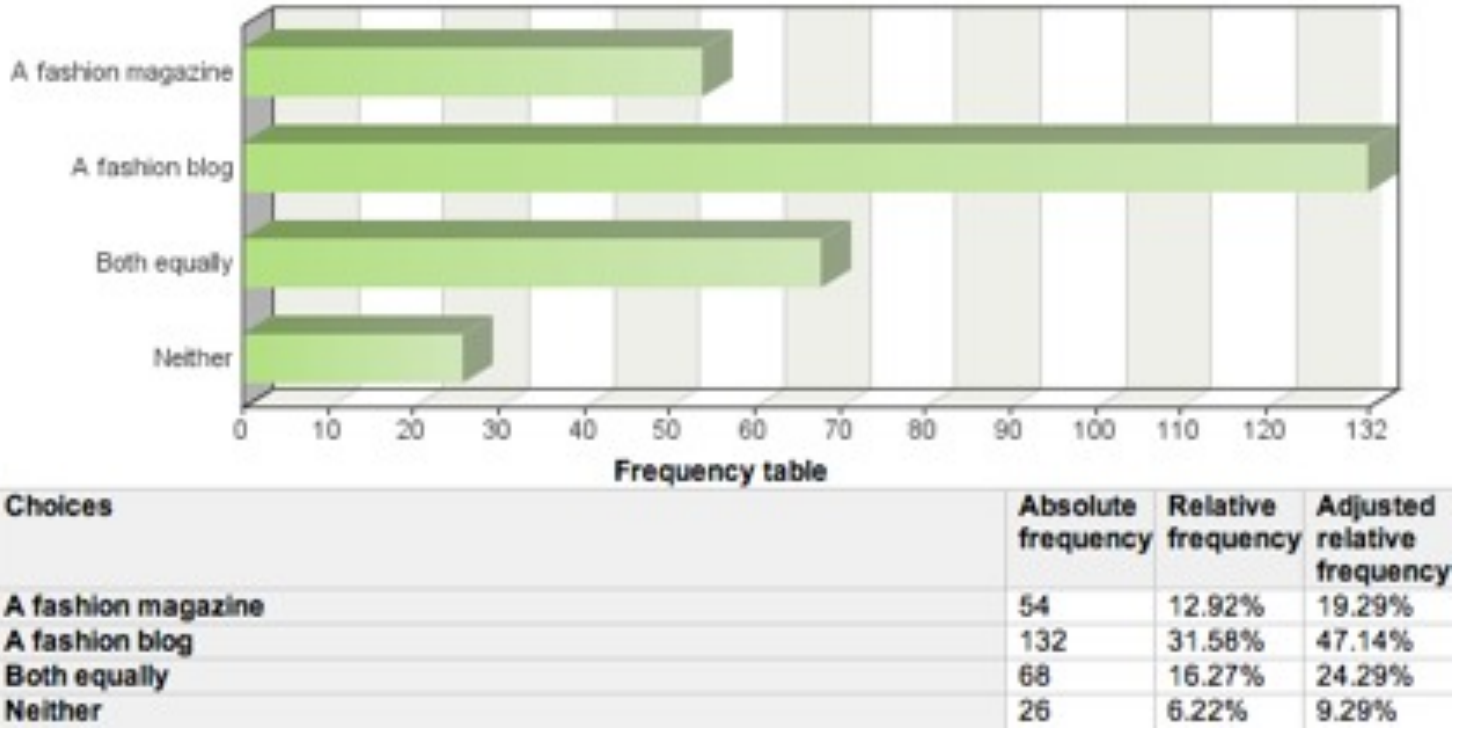




\section{Question 31}

I am most likely to buy an article of clothing or an accessory I have seen in...

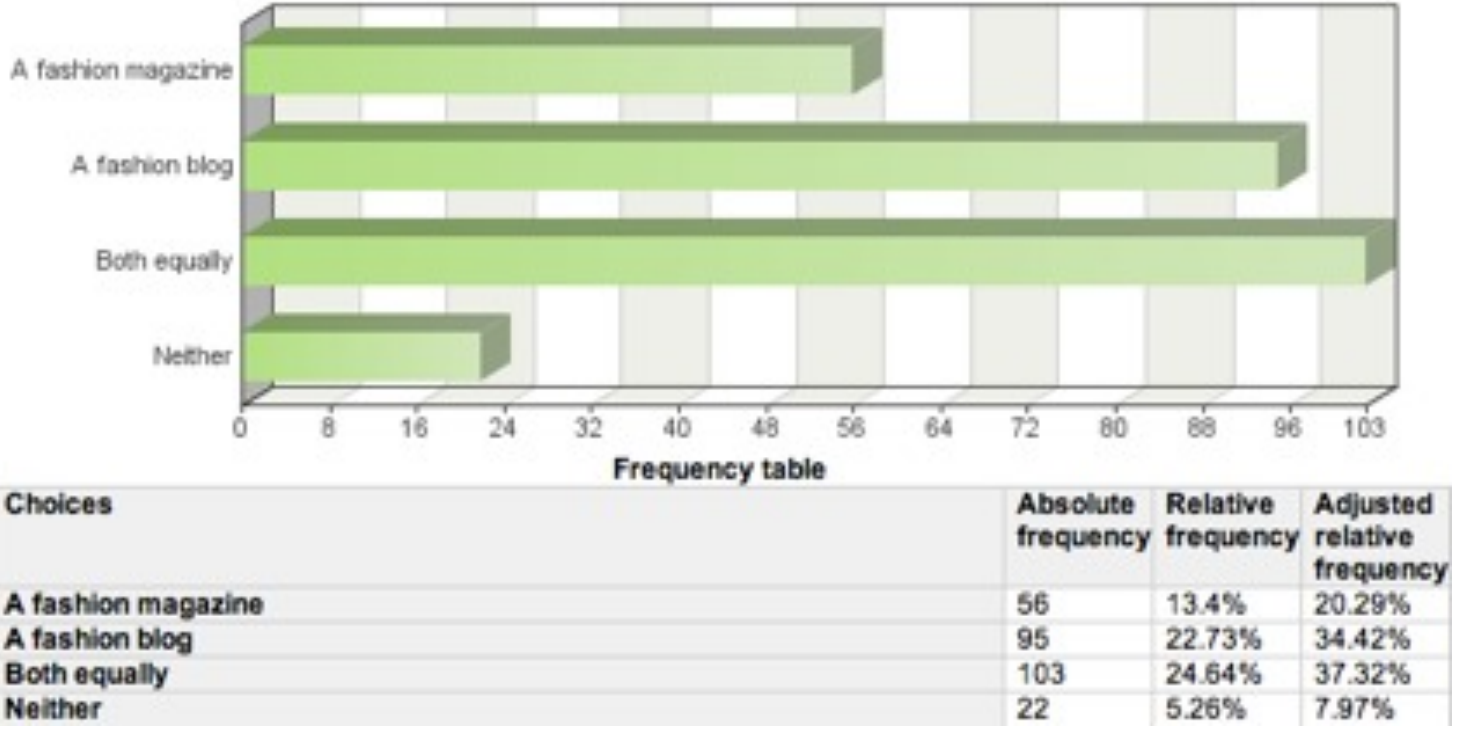

\section{Question 32}

I spend a greater amount of time, in one sining, looking at...

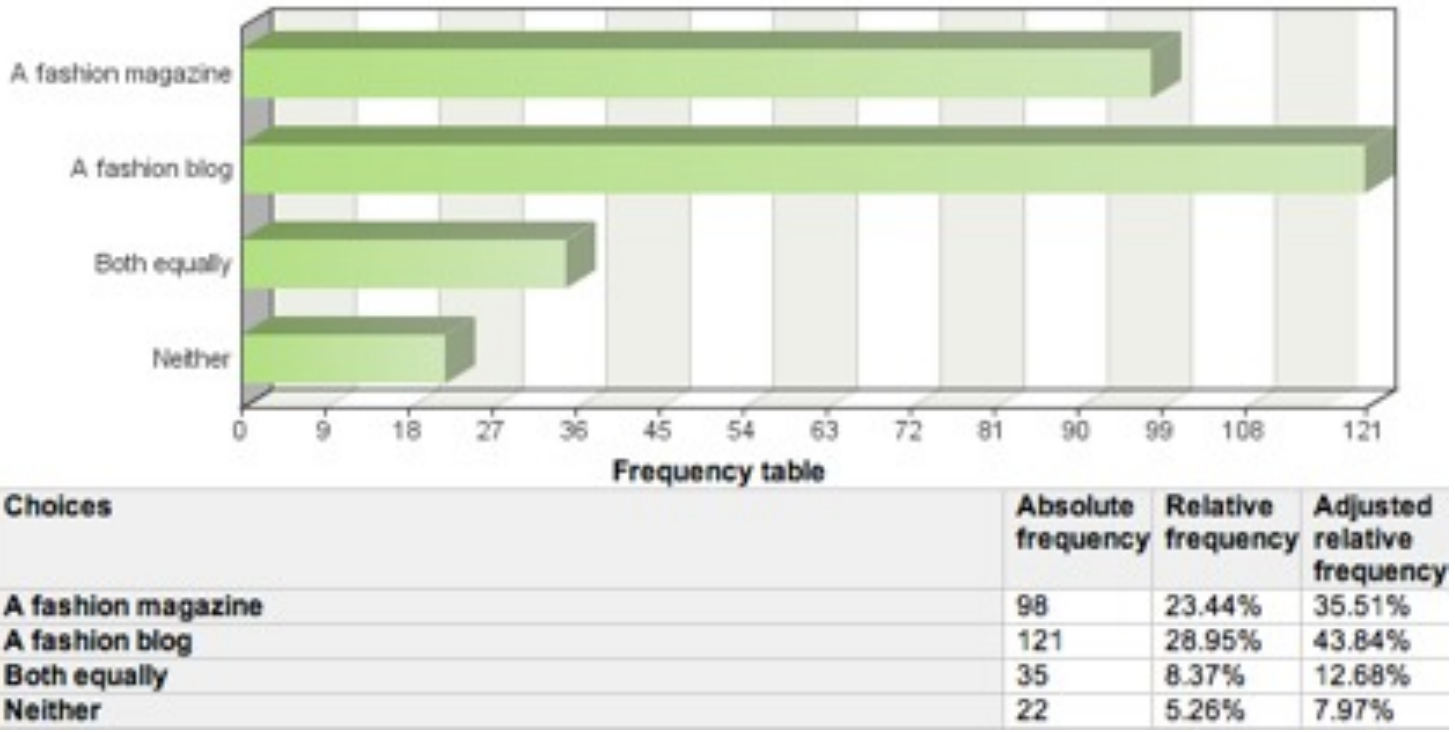




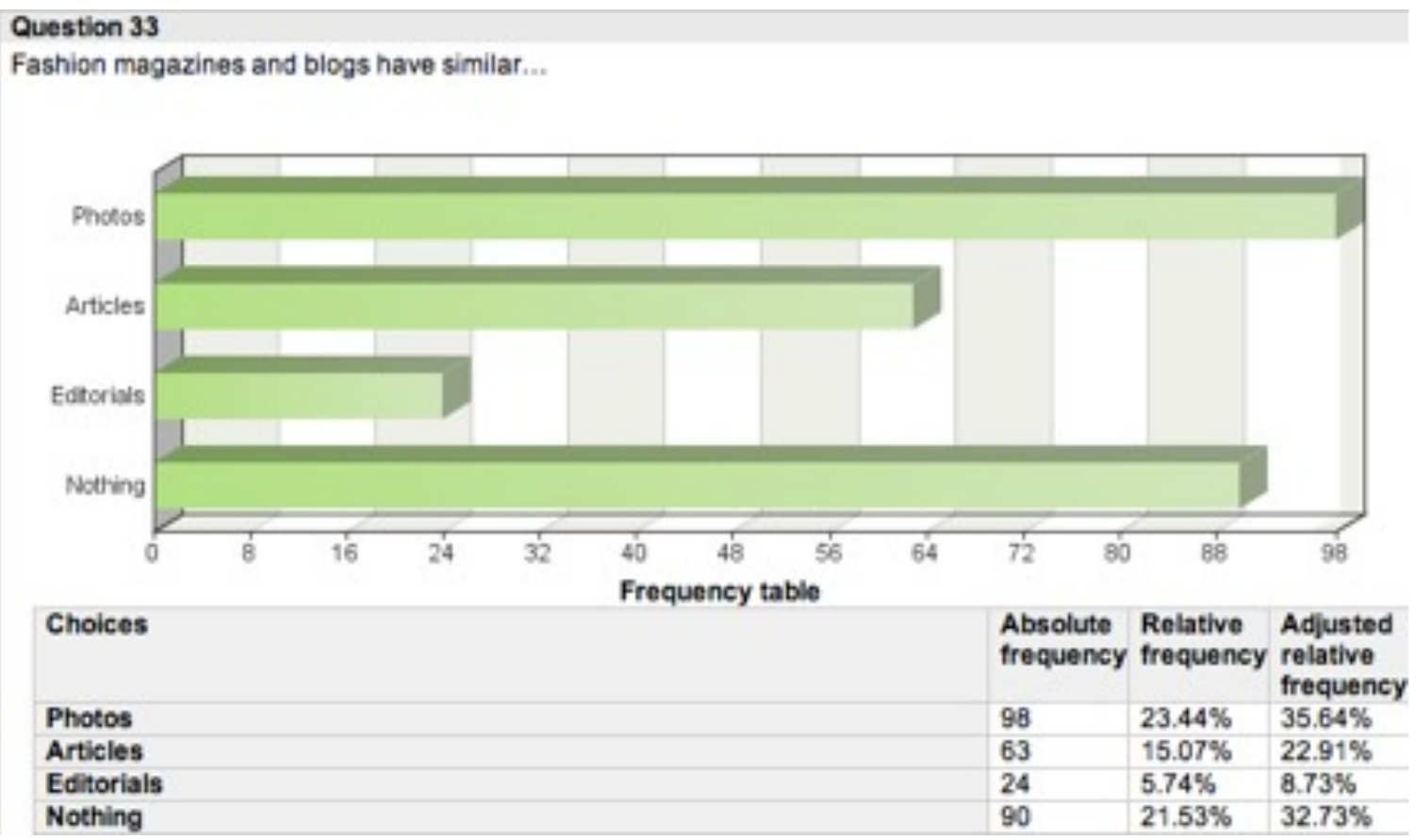

\section{Question 34}

I would rather be interviewed for a 'street style' article by....

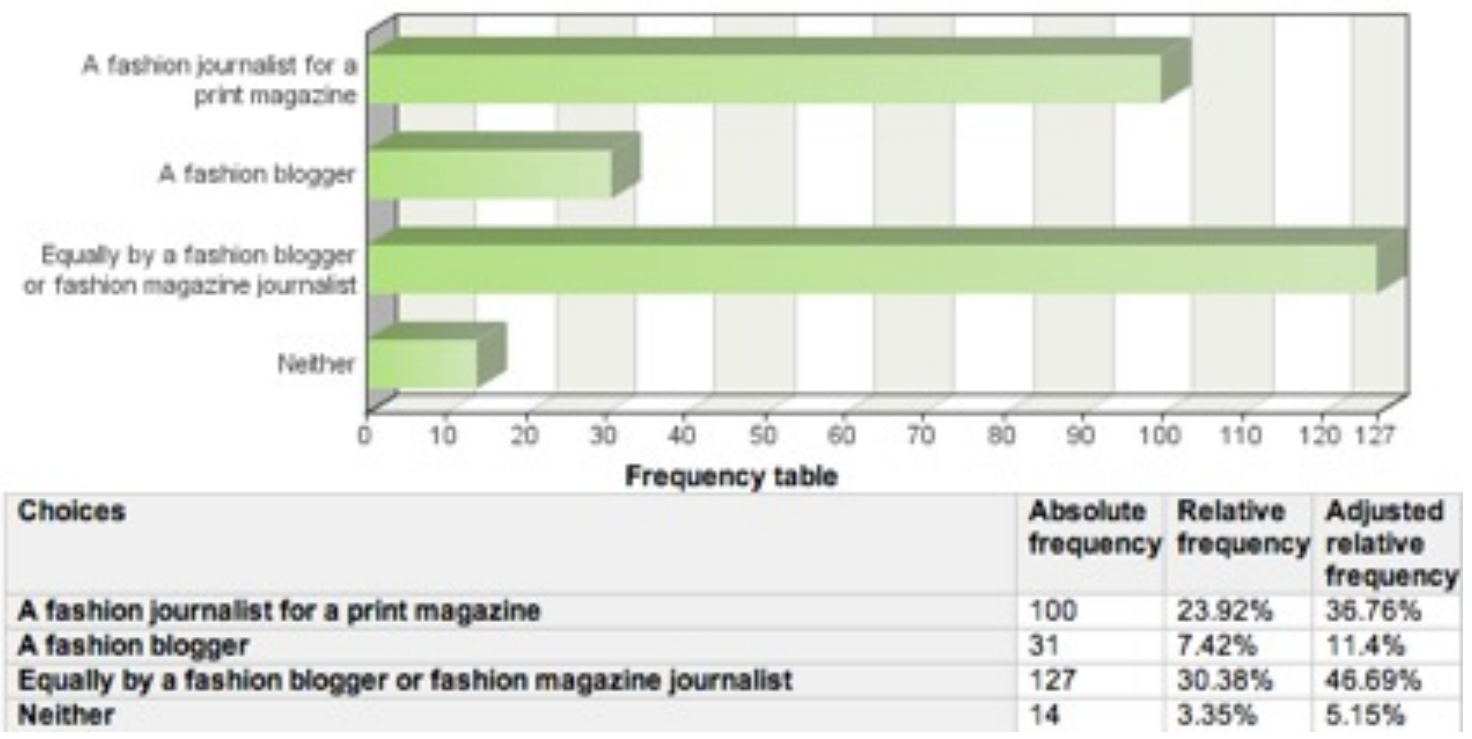




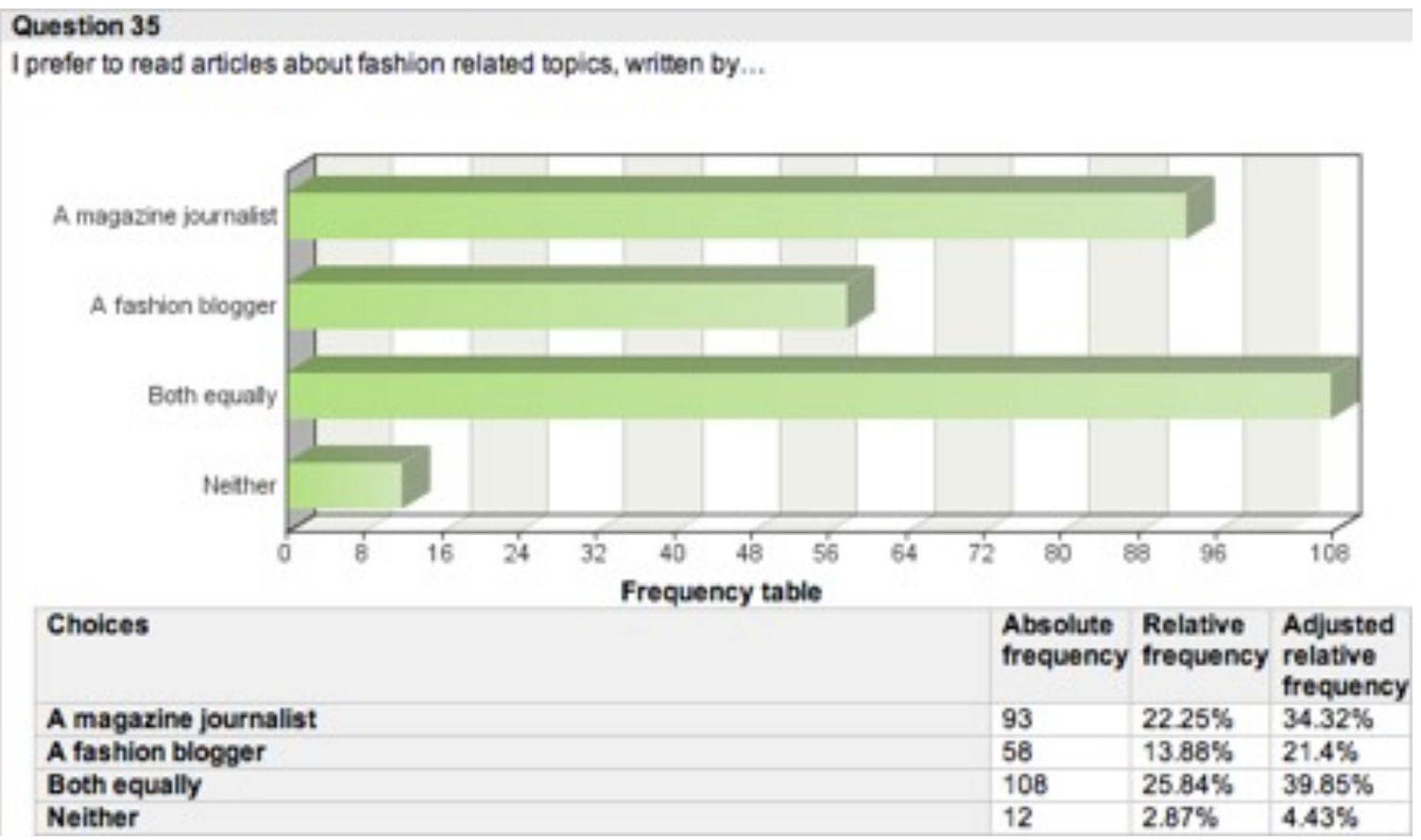

\section{Question 36}

rely more heavily on advertisements.

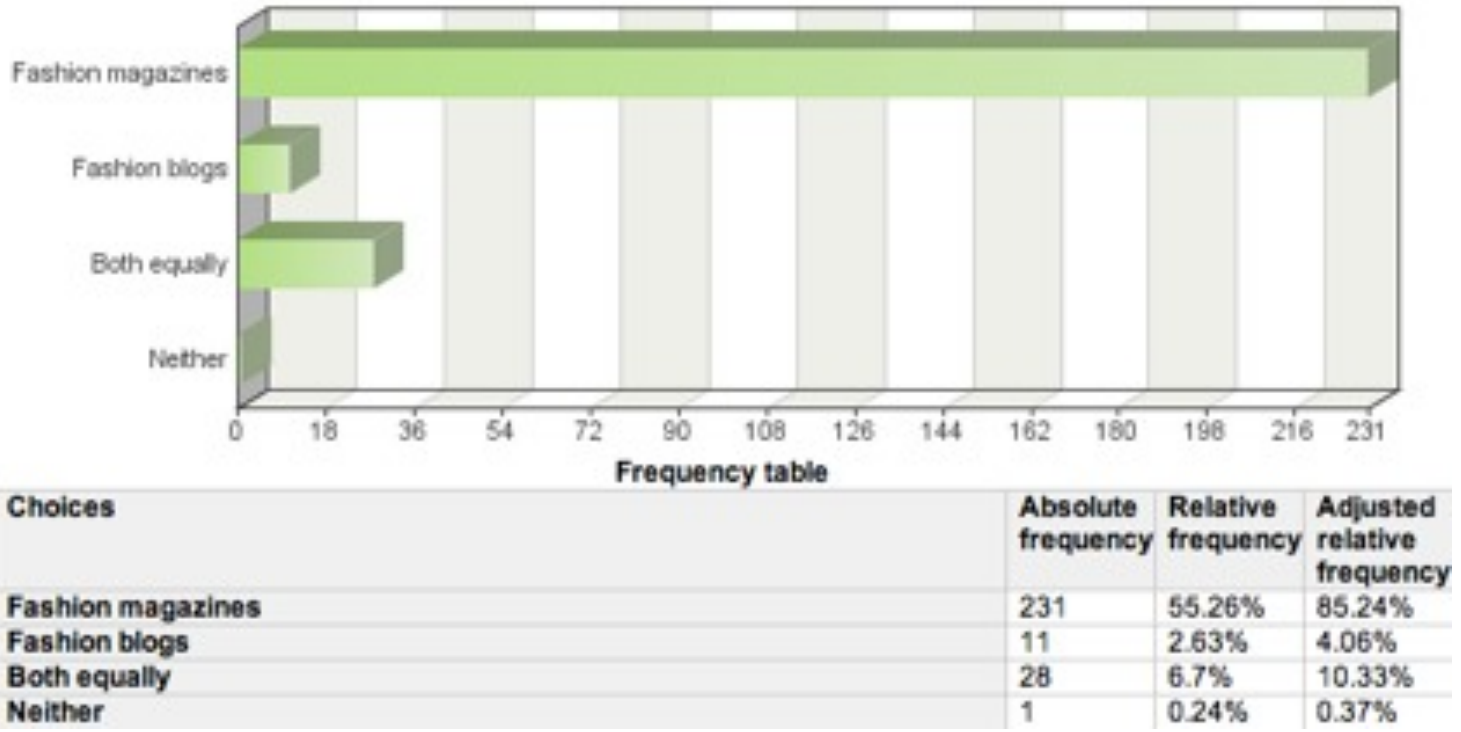


rely more heavily on industry collaborations.

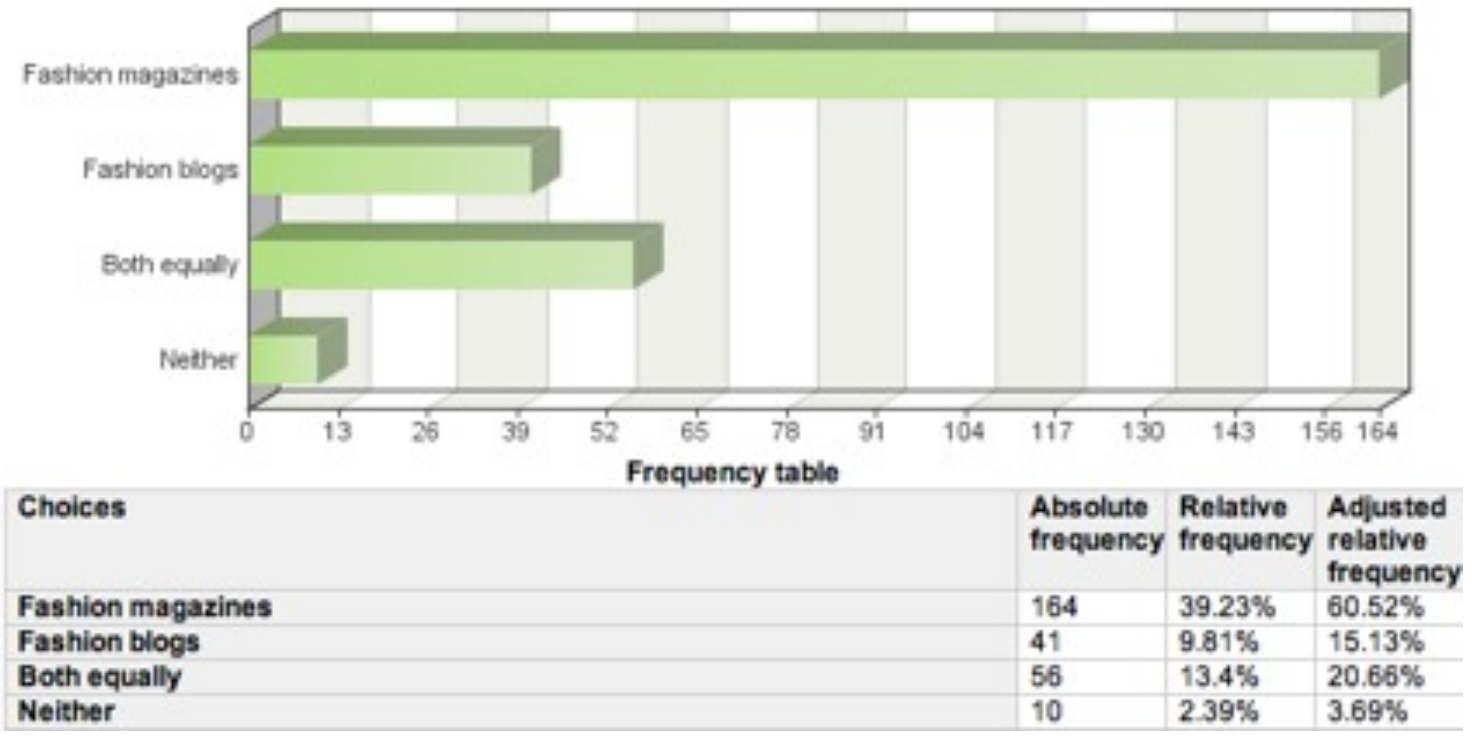




\section{Works Cited}

Armstrong, C. L., \& McAdams, M. (2011). Blogging the Time Away? Young Adults' Motivations for Blog Use. Atlantic Journal of Communication, 19, 113-128.

Bailey, L. R., \& Seock, Y. K. (2010). The relationship of fashion leadership, fashion magazine content and loyalty tendency. Journal of Fashion Marketing and Management, 14(1), 39-57.

Bantz, C. R. (1982). Exploring Uses and Gratifications: A Comparison of Reported Uses of Television and Reported Uses of Favorite Program Type. Communication Research, 9(3), 352-379.

Blumler, J. G. (1979). The Role of Theory in Uses and Gratifications Studies.Communication Research, 6(9), 9-36.

Bolter, J. D., \& Grusin, R. (2000). Remediation Understanding New Media. London, England: The MIT Press.

Bryant, J., \& Oliver, M. B. (2009). Media effects: Advances in theory and research. (3rd ed., pp. 1-640). New York, NY: Routledge Taylor \& Francis Group.

Chen, G. M. (2011). Tweet this: A uses and gratifications perspective on how active Twitter use gratifies need to connect with others. Computers in Human Behavior, 27, 755-762.

Chittenden, T. (2010). Digital dressing up: Modeling female teen identity in the discursive spaces of the fashion blogosphere. Journal of Youth Studies, 13(4), 505-520.

Chung, D. S. (2008).Blogging Activity Among Cancer Patients and Their Companions: Uses, Gratifications, and Predictors of Outcomes. Journal of the American Society for Information Science and Technology, 59(2), 297-306.

Chung, D. S., Eunseong, K., Trammell K. D., \& Porter, L.V. (2007). Uses and Perceptions of Blogs: A Report on Professional Journalists and Journalism Educators. Journalism \& Mass Communication Educator, 62(3), 305-322.

Clifford, S. (2009, September 27). Cuts meet a culture of spending at Condé Nast. The New York Times. Retrieved from http://www.nytimes.com/2009/09/28/business/media/28conde.html?

Colliander, J., \& Micael, D. (2011). Following the fashionable friend: The power of social media weighing publicity effectiveness of blogs versus online magazines. Journal of Advertising Research, 313-320.

Condé Nast. (2012) Vogue media kit [Data file]. Retrieved from http://www.condenast.com/brands/vogue/media-kit

Demers, D. (2000). Communication Theory in the 21st Century: Differentiation and Convergence. Mass Communication \& Society, 3(1),1-2.

Diddi, A, \& LaRose, R. (2006). Getting Hooked on News: Uses and Gratifications and the Formation of News Habits Among College Students in an Internet Environment. Journal of Broadcasting \& 
Electronic Media, 50(2), 193-210.

Dimmick, J., Kline, S., \& Stafford, L. (2000). The Gratification Niches of Personal E-mail and the Telephone: Competition, Displacement and Complementarity. Communication Research, 27(2), 227-248.

Dunne, Á., Lawlor, M., \& Rowley, J. (2010). Young people's use of online social networking sites- a uses and gratifications perspective. Journal of Research in Interactive Marketing, (4(1), 46-58.

Eades, V. (2011). Fashion blogs: Too trendy for libraries or useful resources?. Art Libraries Journal, $36(2), 12-16$.

Eighmey, J., \& McCord, L. (1998). Adding Value in the Information Age: Uses and Gratifications of Sites on the World Wide Web. Journal of Business Research, 41,187-194.

Elliott, P. (1974). Uses and gratifications research: A critique and a sociological alternative. In J. G. Blumler \& E. Katz (Eds.), The uses of mass communications: Current perspectives on gratifications research (pp. 249-268). Beverly Hills, CA: Sage.

Elle Canada. (2012). Media information 2012 [Data file].

Ferguson, D. A., \& Perse, E. M. (2000). The World Wide Web as a Functional Alternative to Television. Journal of Broadcasting \& Electronic Media, 44(2),155-174.

Flanagin, A. J., \& Metzger, M. (2001). Internet Use in the Contemporary Media Environment. Human Communication Research, 27(1),153-181.

Flanagin, A. J. (2005).IM Online: Instant Messaging Use Among College Students. Communication Research Reports, 22(3), 175-197.

Flew, T. (2005). New media. (2nd ed., pp. 1-280). Victoria, Australia: Oxford University Press.

Gay, J. (2001, June 18). Madison avenue shopkeepers weep for CNN style diva elsa klensch. New York Observer. Retrieved from http://observer.com/2001/06/madison-avenue-shopkeepersweep- for-cnn-style-diva-elsa-klensch/

Gil de Zuniga, H. (2011). Blogging as a journalistic practice: A model linking perception, motivation, and behavior. Journalism, 12(5), 586-606.

Hermes, J. (1995). Reading women's magazines. (pp. 1-226). Cambridge, MA: Blackwell Publishers Ltd.

Hollenbaugh, E. E. (2011). Motives for Maintaining Personal Journal Blogs. Cyberpsychology, Behavior and Social Networking, 14(1), 13-19.

Jere, M. G., \& Davis, S. V. (2011). An application of uses and gratifications theory to compare consumer motivations for magazine and internet usage among south african women's magazine readers. Southern African Business Review, 15(1), 1-27. 
Johnson, T., \& Kaye, B. (2010). Choosing Is Believing? How Web Gratifications and Reliance Affect internet Credibility Among Politically Interested Users. Atlantic Journal of Communication, 18, $1-18$.

Jung, T., Youn, H., \& McClung, S. (2007). Motivations and Self-Presentation Strategies on Korean-Based 'Cyworld' Weblog Format Personal Homepages. CyberPsychology \& Behavior, 10(1), 24-31.

J.L.Nevinson. (1967). Origin and early history of the fashion plate. Washington, D.C.: Smithsonian.

Katz, E., Blumler, J., \& Gurevitch, M. (1974). Utilization of mass communication by the individual. In J. Blumler \& E. Katz (Eds.), The uses of mass communication: Current perspectives on gratifications research (pp. 19-34). Beverly Hills, CA: Sage.

Kawamura, Y. (2005). Fashion-ology: An introduction to fashion studies. Dress, body, culture. Oxford: Berg.

Kang, M., \& Atkin, D.J. (1999). Exploring the role of media uses and gratifications in multimedia cable adoption. Telematics and Informatics, 16, 59-74.

Katz, E., Haas, H. \& Michael Gurevitch. (1973). On the Use of the Mass Media for Important Things. American Sociological Review, 38(2), 164-181.

Kaye, B.K., \& Johnson, T.J. (2004). A Web for all reasons: uses and gratifications of Internet components for political information. Telematics and Informatics, 2, 197-223.

Kaye, B.K. (2010). Going to the Blogs: Toward the Development of a Uses and Gratifications Measurement Scale for Blogs. Atlantic Journal of Communication, 18, 194-210.

Kaye, B. K. (2005). It's a Blog, Blog, Blog, Blog World. Atlantic Journal of Communication, 3(2), 73-95.

Kline, F. G., \& Tichenor, P. J. (1972). Current perspectives in mass communications research. (pp. 1-319). Beverly Hills, California: Sage Publication, Inc.

Krause-Wahl, A. (2009). Between Studio and Catwalk-Artists in Fashion Magazines. Fashion Theory: The Journal of Dress, Body \& Culture, 13(1), 7-27.

LaRose, R, D. Mastro, D. \& Eastin, M.S. (2001). Understanding Internet Usage. Social-Cognitive Approach to Uses and Gratifications, 19(4), 395-413.

Le Masurier, M. (2012). Independent magazines and the rejuvenation of print. International Journal of Cultural Studies, 15(4), 383-398.

Lee, D. H., Im, S., \& Taylor, C. R. (2008). Voluntary self-disclosure of information on the internet: A multimethod study of the motivations and consequences of disclosing information on blogs. Psychology \& Marketing, 25(7), 692-710.

Lin, C. A. (2001). Audience Attributes, Media Supplementation, and Likely Online Service Adoption. Mass Communication \& Society, 4(1),19-38. 
Lin, C. A. (1996). Looking Back: The Contribution of Blumler and Katz's Uses of Mass Communication to Communication Research. Journal of Broadcasting \& Electronic Media, 40, 574-581.

Magazines Canada. (2012). Consumer magazine fact book [Data file].

Magazines Canada. (2012). Digital magazine fact book [Data file].

Magazines Canada. (2011). Put magazines to work for you [Data file].

Menkes, S. (2013, February 10). The circus of fashion. T Magazine. Retrieved from http:// tmagazine.blogs.nytimes.com/2013/02/10/the-circus-of-fashion/

Moeran, B. A. (2004). Japanese discourse of fashion and taste. Fashion Theory, 8(1), 35-62.

Moeran, B. (2010). The portrayal of beauty in women's fashion magazine. Fashion Theory, 14(4), 491-510.

Morris, M., \& Ogan, C. (1996). The internet as mass media. Journal of Communication, 46(1).

Murray, J. B. (2002). The politics of consumption: A re-inquiry on Thompson and Haytko's (1997) 'speaking of fashion'. Journal of Consumer Research, 29(3), 427-440.

Nardi, B. A., Schiano, D. J., Gumbrecht, M., \& Swartz, L. (2004). Why we blog. Communications of the $A C M, 47(12), 41-46$.

Nevinson, J. L. (1967). Origin and early history of the fashion plate. Washington, D.C: Smithsonian Press. Retrieved from http://www.gutenberg.org/files/34472/34472-h/34472-h.htm

Papacharissi, Z. (2002). The self online: The utility of personal home pages. Journal of Broadcasting \& Electronic Media, 46(3), 346-368.

Papacharissi, Z., \& Rubin, A. M. (2000). Predictors of internet use. Journal of Broadcasting \& Electronic Media, 44(2), 175-196.

Parker, B. J., \& Plank, R. E. (2000). A uses and gratifications perspective on the internet as a new information source. American Business Review, 18(2), 43-49.

Pham, M. H. T. (2011). Blog ambition: Fashion, feelings, and the political economy of the digital raced body. Camera Obscura, 26(1), 1-37.

Quan-Haase, A., \& Young, A. L. (2010). Uses and gratifications of social media: A comparison of Facebook and instant messaging. Bulletin of Science, Technology \& Society, 30(5), 350-361.

Rickman, T. A., \& Cosenza, R. M. (2007). The changing digital dynamics of multichannel marketing. Journal of Fashion Marketing and Management, 11(4), 604-621.

Rocamora, A. (2009). Fashioning the city. (pp. 1-237). London, England: I.B. Tauris \& Co Ltd.

Rocamora, A. (2011). Personal fashion blogs: Screens and mirrors in digital self-portraits. Fashion Theory, 15(4), 407-424. 
Rocamora, A. (2012). Hypertextuality and remediation in the fashion media. Journalism Practice, 6(1), 92-106.

Rogers, E. M. (1995). Diffusion of Innovations. New York: The Free Press.

Rubin, A. M. (1993). Audience activity and media use. Communication Monographs, 60, 98-105.

Rubin, A. M. (1981). An examination of television viewing motivations. Communication Research, 8(2), 141-165.

Rubin, A. M. (1984). Ritualized and instrumental television viewing. Journal of Communication, 67-77.

Rubin, A. M., \& Bantz, C. R. (1987). Utility of videocassette recorders. American Behavioral Scientist, $30(5), 471-485$.

Rubin, A. M., \& Perse, E. M. (1987). Audience activity and television news gratifications. Communication Research, 14(1), 58-84.

Rubin, A. M., \& Rubin, R. B. (1985). Interface of personal and mediated communication: A research agenda. Critical Studies in Mass Communication, 2(1), 36-53.

Rubin, A. M. (1994). Media uses and effects: A uses and gratifications perspective. In J. Bryant \& D. Zillmann (Eds.), Media effects: Advances in theory and research (pp. 417-436). Hillsdale, NJ: Lawrence Erlbaum Associates, Inc.

Ruggiero, T. E. (2000). Uses and gratifications theory in the 21 st century. Mass Communications \& Society, 3(1), 3-37.

Schmidt, J. (2007). Blogging practices: An analytical framework. Journal of Computer-Mediated Communication, 12, 1409-1427.

Shao, G. (2009). Understanding the appeal of user-generated media: A uses and gratifications perspective. Internet Research, 19(1), 7-25.

Schultz, B., \& Sheffer, M. L. (2007). Sports journalists who blog cling to traditional values. Newspaper Research Journal, 28(4), 62-76.

S H Steinberg, John Trevitt. (2006). Five hundred years of printing. London: British Library.

Stafford, T. F., \& Gonier, D. (2005). What americans like about being online. Communications of the $A C M, 47(11), 107-112$.

Stafford, T. F., \& Stafford, M. R. (2004). Determining uses and gratifications for the internet. Decision Sciences, 35(2), 259-288.

Swanson, D. L. (1977). The uses and misuses of uses and gratifications. Human Communication Research, 3, 214-221.

Swanson, D. L. (1987). Gratification seeking, media exposure, and audience interpretations. Journal of Broadcasting \& Electronic Media, 31, 237-254. 
Trammell, K. D., Tarkowski, A., Hofmokl, J., \& Sapp, A. M. (2006). Rzeczpospolita blogow [republic of blog]: Examining polish bloggers through content analysis. Journal of Computer-Mediated Communication, 11, 702-722.

Tremayne, M. (2007). Blogging, citizenship and the future of media. (pp. 1-287). New York, NY: Routledge.

Vitalari, N. P., Venkatesh, A., \& Grohnaug, K. (1985). Computing in the home: Shifts in the time allocation patterns of households. Communications of the ACM, 28(5), 512-522.

Williams, A. P., Trammell, K. D., Postelnicu, M., Landreville, K. D., \& Martin, J. D. (2005). Blogging and hyperlinking: Use of the web to enhance viability during the 2004 us campaign. Journalism Studies, 6(2), 177-186.

Wilson, E. (2009, December 24). Bloggers crash fashion's front row. The New York Times. Retrieved from http://www.nytimes.com/2009/12/27/fashion/27BLOGGERS.html? _r=4\&adxnnl=1\&hpw=\&adxnnlx=1261911805-qUV5SxAN7dEQSsqH5ktlVw\&

Windahl, S. (1981). Uses and gratifications at the crossroads. Mass Communication Review Yearbook, 2, 174-185.

Winship, J. (1987). Inside women's magazines. (pp. 1-179). London: Pandora Press.

Ytre-Arne, B. (2011). 'I want to hold it in my hands': Readers' experiences of the phenomenological differences between women's magazines online and in print. Media, Culture \& Society, 33(3), 467-477. 